\title{
Review of the First Charged-Particle Transport Coefficient Comparison Workshop
}

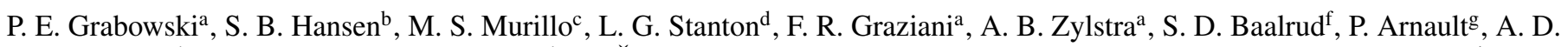
Baczewski $^{\mathrm{b}}$, L. X. Benedict ${ }^{\mathrm{a}}$, C. Blancard ${ }^{\mathrm{h}}$, O. Čertík ${ }^{\mathrm{e}}$, J. Clérouin ${ }^{\mathrm{g}}$, L. A. Collins ${ }^{\mathrm{e}}$, S. Copeland $^{\mathrm{a}}$, A. A. Correa ${ }^{\mathrm{a}}$, J. Dai ${ }^{\mathrm{i}}, \mathrm{J}$

Daligault $^{\mathrm{e}}$, M. P. Desjarlais ${ }^{\mathrm{b}}$, M. W. C. Dharma-wardana ${ }^{\mathrm{j}}$, G. Faussurier $^{\mathrm{h}}$, J. Haack ${ }^{\mathrm{e}}$, , $^{\mathrm{a}}$ T. Haxhimali ${ }^{\mathrm{a}}$, A. Hayes-Sterbenz ${ }^{\mathrm{e}}$, Y. Hou $^{\mathrm{i}}$, S. X. Hu ${ }^{\mathrm{k}}$, D. Jensen ${ }^{\mathrm{b}}$, G. Jungman ${ }^{\mathrm{e}}$, G. Kagan ${ }^{1}$, D. Kang ${ }^{\mathrm{i}}$, J. D. Kress ${ }^{\mathrm{e}}$, Q. Ma ${ }^{\mathrm{i}}$, M. Marciante ${ }^{\mathrm{e}}$, E. Meyer ${ }^{\mathrm{e}}$, R. E. Rudd ${ }^{\mathrm{a}}$, D. Saumon $^{\mathrm{e}}$, L. Shulenburger ${ }^{\mathrm{b}}$, R. L. Singleton Jr. ${ }^{\mathrm{e}}$, T. Sjostrom ${ }^{\mathrm{e}}$, L. J. Stanek ${ }^{\mathrm{c}}$, C. E. Starrett ${ }^{\mathrm{e}}$, C. Ticknor ${ }^{\mathrm{e}}$, S. Valaitis $^{\mathrm{e}}$, J. Venzke $^{\mathrm{e}}$, A. White $e^{e}$

\author{
${ }^{a}$ Lawrence Livermore National Laboratory, Livermore, CA 94550, USA \\ ${ }^{b}$ Sandia National Laboratory, Albuquerque, NM 87185, USA \\ ${ }^{c}$ Department of Computational Mathematics, Science and Engineering, Michigan State University, East Lansing, Michigan 48824, USA \\ ${ }^{d}$ Department of Mathematics and Statistics, San José State University, San José, California 95192, USA \\ ${ }^{e}$ Los Alamos National Laboratory, Los Alamos, NM 87545, USA \\ ${ }^{f}$ Department of Physics and Astronomy, University of Iowa, Iowa City, IA 52242, USA \\ ${ }^{g}$ Département de Physique Théorique et Appliquée, CEA, DAM, DIF Île-de-France BP12, 91680 Bruyéres-le-Châtel Cedex, France \\ ${ }^{h} C E A, D A M, D I F$, F-91297 Arpajon, France \\ ${ }^{i}$ Department of Physics, National University of Defense Technology, Changsha, Hunan 410073, People's Republic of China \\ ${ }^{j}$ National Research Council of Canada, Ottawa, Ontario, Canada, K1A OR6. \\ ${ }^{k}$ Laboratory for Laser Energetics, University of Rochester, 250 East River Road, Rochester, New York 14623, USA \\ ${ }^{l}$ Imperial College, London, SW7 2AZ, United Kingdom
}

\section{Abstract}

We present the results of the first Charged-Particle Transport Coefficient Code Comparison Workshop, which was held in Albuquerque, NM October 4-6, 2016. In this first workshop, scientists from eight institutions and four countries gathered to compare calculations of transport coefficients including thermal and electrical conduction, electron-ion coupling, inter-ion diffusion, ion viscosity, and charged particle stopping powers. Here, we give general background on Coulomb coupling and computational expense, review where some transport coefficients appear in hydrodynamic equations, and present the submitted data. Large variations are found when either the relevant Coulomb coupling parameter is large or computational expense causes difficulties. Understanding the general accuracy and uncertainty associated with such transport coefficients is important for quantifying errors in hydrodynamic simulations of inertial confinement fusion and high-energy density experiments.

Keywords:

charged particle transport, code comparison, conductivity, stopping power, diffusion, viscosity

\section{Introduction}

Charged-particle transport is a key part of high-energydensity plasma science. Transport coefficients feed into both radiation-hydrodynamic simulations and diagnostic data interpretation, but neither uncertainties in these coefficients nor the features of generally reliable transport models are well established. They are particularly important when inter-particle correlations of the plasma are weak enough that there are important deviations from the ideal fluid (Euler) limit, but strong enough so that the simplest kinetic treatments (e.g. the Vlasov equation) are no longer valid. Reliance on theoretical predictions is driven by the challenges of experimentally isolating various transport processes, together with the paucity of experimental data of any kind at well-characterized extreme conditions. These coefficients have particular impact on the field of inertial confinement fusion, feeding into the development of

Email address: grabowski5@llnl.gov (P. E. Grabowski) instabilities and the overall energy balance of burning fusion plasma. Crucial processes include thermal and electrical conduction, electron-ion coupling, inter-ion diffusion, ion viscosity, and charged particle stopping.

The first charged-particle transport coefficient workshop (CPTCW-16) was established to examine theoretical uncertainties in our predictive ability. Workshops of this sort have become a tradition in dense plasma physics. Recently, there has been the 2016 kinetics workshop [1] and 2017 equation-of-state (EOS) workshop [2], which have built on the successes of the long-running non-local thermodynamic equilibrium (non-LTE) opacity code comparison workshops $[3,4,5,6,7,8,9,10,11]$ and similar WorkOp LTE opacity workshop [12, 13, 14]. A set of test cases spanning a range of ionization, coupling, and degeneracy regimes was selected with the aim of establishing the present state of agreement among various theoretical approaches. In addition to this goal, the workshop aimed to quantify uncertainties in calculated transport coefficients, address the strengths and limitations of different approaches, provide 


\begin{tabular}{c|l|l} 
element & density $\left(\mathrm{g} / \mathrm{cm}^{3}\right)$ & temperature $(\mathrm{eV})$ \\
\hline $\mathrm{C}$ & $0.1,1,10,100$ & $0.2,2,20,200,2000$ \\
$\mathrm{H}$ & $0.1,1,10,100$ & $0.2,2,20,200,2000$ \\
$\mathrm{CH}$ & $0.1,1,10,100$ & $0.2,2,20,200,2000$
\end{tabular}

Table 1: Summary of workshop cases.

a forum for discussions, and identify research priorities for inertial confinement fusion (ICF) and high energy-density (HED) science.

\section{Test Cases}

Three plasma compositions were chosen across wide temperature and density variations, including pure hydrogen, pure carbon, and an equimolar carbon-hydrogen mixture. These are summarized in Table 1. Plasmas across these conditions are relevant to fuel and ablator materials important to ICF. In particular, the low-density, high-temperature hydrogen case approaches the conditions of recent Omega experiments measuring stopping powers $[15,16]$ and the low-density, moderatetemperature carbon case is at conditions relevant to recent Omega experiments on heated beryllium [17, 18], with additional relevance to thermal conductivity experiments in plastic and beryllium [19, 20].

More than thirty researchers attended the workshop, representing eight institutions; participation is summarized in Table 2. There were averages of $5.5,6.3,8.6,8.6$, and 2.9 contributions for the 60 different cases, for electrical conductivity, thermal conductivity, viscosity, diffusion, and stopping power, respectively. Models expressed as analytic formulae, which can be used inline in hydrodynamic codes, to those employing a range of potentials in molecular dynamics were represented. While several approaches presented data for all cases, most contributions only provided ionic transport (diffusion, viscosity) or electronic transport (thermal and electrical conductivities) or stopping powers. The results reported here represent output from the contributed codes at the time of the workshop; any subsequently published updates to those codes are noted in the table of contributors but not represented in the present paper.

\section{Dimensionless Parameters and Test Case Coverage in Plasma Parameter Space}

HED plasmas span many orders of magnitude in density and temperature, including regimes for which different approximations are valid. In this section we will discuss dimensionless parameters that capture this diversity and show where our test cases fall.

We can characterize the importance of interactions with the Coulomb coupling parameter

$$
\Gamma_{j k}=\left|\frac{q_{j} q_{k}}{a_{j k} T_{j k, e f f}}\right|,
$$

which gives the relative magnitude of the potential energy of neighboring particles to their kinetic energy. Here, $j$ and $k$ are indices for particle types. For ions, $q_{i}=\bar{Z}_{i} e$, while for electrons, $q_{e}=e$, where $e$ is the magnitude of the electron charge and $\bar{Z}_{i}$ is the mean ionization the ion, which for convenience we set to More's Thomas-Fermi fit [57] (such a choice is not unique [58]). The typical separation between neighbors is approximated by

$$
a_{j k}=\left[\frac{6}{4 \pi\left(n_{j}+n_{k}\right)}\right]^{1 / 3},
$$

where for ions, $n_{i}=\rho_{i} / m_{i}$ and for electrons, $n_{e}=\sum_{i} Z_{i} \rho_{i} / m_{i}$ with the sum over the ions, $Z_{i}$ is the bare ion charge, $\rho_{i}$ is the mass density of ion $i$ and $m_{i}$ is its mass. A non-unique effective temperature, $T_{j k, e f f}$, is a measure of the relative kinetic energy of collisions between particles of types $j$ and $k$. We set

$$
T_{j k, e f f}=\sqrt{T^{2}+\frac{2}{25}\left(T_{j, F}^{2}+T_{k, F}^{2}\right)},
$$

where

$$
k_{B} T_{j, F}=\frac{\hbar^{2}}{2 m_{j}}\left(3 \pi^{2} n_{j}\right)^{2 / 3},
$$

$k_{B}$ is Boltzmann's constant, $m_{j}$ is the mass of particles of type $j$, and $n_{j}$ is their number density. This effective temperature is a simple interpolation between the zero and infinite temperature limits.

These coupling parameters fall into three categories: ion-ion, electron-ion, and electron-electron, depending on the particle types, $j$ and $k$. Different transport coefficients are more sensitive to some of these Coulomb coupling parameters than others and so become harder to calculate in different regimes. As ion viscosity and ion diffusion are mediated mainly by ion-ion collisions, the ion-ion Coulomb coupling parameter is most important. Of course, electron screening also plays a role. The main hindrance to electrical conductivity is electron-ion scattering, and so the electron-ion Coulomb coupling parameter matters for this property. Stopping power of fast ions is dominated by projectile-electron collisions, which are similar to the target ion-electron collisions except for having a different energy scale: the relative kinetic energy of the ion and the electrons $\left(K_{r e l}=\mu\left\langle v_{r e l}^{2}\right\rangle / 2\right.$, where $\mu$ is the reduced mass of the projectile and target particles and $\left\langle v_{r e l}^{2}\right\rangle$ is the ensemble mean of the square of their relative velocities), suggesting one replace $T_{j k, \text { eff }}$ with $K_{r e l}$ in the coupling parameter expression. So the ion-electron coupling parameter shown in Figs. 1 and 2 should be considered upper bounds for stopping power and mostly relevant to low energy (at and below the Bragg Peak) ions. Thermal conductivity is sensitive to both the electron-electron and electronion parameters.

For small $\Gamma$ 's $(\ll 1)$, it is valid to introduce screening and collision physics through cutoffs in collision integrals, which leads to a Coulomb logarithm. As $\Gamma_{j k}$ approaches unity, such treatments break down and one should use more sophisticated methods, the limits of which are explored in this article. The relevant values of $\Gamma_{j k}$ for our study are shown in Figs. 1 and 2 for pure hydrogen and carbon plasmas, respectively. We do not show the $\mathrm{CH}$ mixture case, but it is qualitatively similar to the other two. We see that all three (ion-ion, ion-electron, and 


\begin{tabular}{|c|c|c|}
\hline Contributors & Institution & Description \\
\hline Baalrud & U Iowa & Effective Potential Theory (EPT) with Average Atom potentials [21, 22] \\
\hline $\begin{array}{l}\text { Baczewski, Jensen, } \\
\text { Shulenburger }\end{array}$ & SNL & Ehrenfest-TDDFT (VASP-TDDFT ) (stopping powers) [23, 24] \\
\hline Clérouin, Arnault & CEA & $\begin{array}{l}\text { Global One-Component Plasma (PIJ) [25], } \\
\text { orbital-free Thomas Fermi }[26,27]\end{array}$ \\
\hline Copeland & LLNL & various analytic models $[28,29,30]$ \\
\hline $\begin{array}{l}\text { Copeland, Stanton, } \\
\text { Murillo, Stanek }\end{array}$ & $\begin{array}{l}\text { LLNL, SJSU } \\
\quad \text { MSU }\end{array}$ & Effective Yukawa T-Matrix [31] \\
\hline Daligault & LANL & classical molecular dynamics (MD) with Average Atom potentials \\
\hline Desjarlais & SNL & SNL-modified quantum MD with Kubo-Greenwood (VASP-SNL) [32] \\
\hline Dharma-wardana & NRC Canada & Neutral Pseudo-Atom $[33,34,35]$ \\
\hline Faussurier, Blancard & CEA & Two-component electron-ion Average-Atom (SCAALP) $[36,37]$ \\
\hline Grabowski, Starrett, Saumon & LLNL, LANL & Pseudo-Atom MD density with strong scattering corrections [17] \\
\hline Hansen & SNL & $\begin{array}{l}\text { Average Atom and Neutral Pseudo-Atom } \\
\text { with Ziman conductivity ( MuZe and BeMuZe) }\end{array}$ \\
\hline Haxhimali, Rudd & LLNL & Hybrid Kinetic Molecular Dynamics (KMD) [38] \\
\hline Hayes, Singleton, Jungman & LANL & degenerate Brown-Preston-Singleton (BPS) (Stopping) [39] \\
\hline Hou & NUDT & average atom hypernetted chain [40] \\
\hline $\mathrm{Hu}$ & LLE & $\begin{array}{l}\text { Spitzer-Lee-More and quantum MD } \\
\text { with Kubo-Greenwood (VASP) [41, 42, 43, 44] }\end{array}$ \\
\hline Kang, Dai & NUDT & $\begin{array}{l}\text { Path Integral Molecular Dynamics (PIMD), } \\
\text { Quantum MD (Quantum Espresso) }[45,46]\end{array}$ \\
\hline Ma, Dai & NUDT & electron Force Field (eFF) [47] \\
\hline Marciante & LANL & Thomas-Fermi-Yukawa MD \\
\hline Meyer, Collins & LANL & $\begin{array}{l}\text { quantum MD with Kubo-Greenwood (VASP) }[41,42,43,44] \\
\text { Quantum MD (Quantum Espresso), }\end{array}$ \\
\hline Sjostrom & LANL & $\begin{array}{l}\text { Kohn-Sham MD with nonlocal corrections [48], } \\
\text { Thomas-Fermi MD }\end{array}$ \\
\hline Starrett, Saumon & LANL & Pseudo-Atom MD [49, 50, 51]; updated [52] \\
\hline $\begin{array}{l}\text { Ticknor, Čertík, White } \\
\text { Collins, Venzke, Valaitis }\end{array}$ & LANL & Orbital-free molecular MD with Thomas-Fermi-Dirac functional $[53,54,55,56]$ \\
\hline
\end{tabular}

Table 2: Summary of contributors and models.

electron-electron) coupling parameters are small in the hightemperature low-density limit. We note that for carbon and any other multi-electron atom, there is a large plateau of moderate ion-ion coupling due to the roughly equal and opposite effects of temperature and ionization [59, 60]. In the low-temperature high-density limit, the ions are very strongly coupled and crystalize, causing long-range correlations well beyond the screening length and caging effects. However, because the electrons are degenerate in this limit and so have kinetic energies of order the Fermi energy, they become weakly coupled at large densities. This means that conductivity and stopping power models which take into account degeneracy can be accurate. Electrons are only strongly coupled in the nondegenerate low-temperature low-density limit, which is outside the field of high energy density physics.

Aside from the modeling challenges of nonideal plasma effects, there are also computational ones. A complete calculation should be converged with respect to system size while also resolving all important length scales. For example, a quantum molecular dynamics simulation should be large enough that ions are screened from their periodic images while also includ- ing enough basis functions to resolve the thermal de Broglie wavelength as well as the atomic structure around each ion. We take as a rough measure of this complexity the ratio between the volume of a sphere of radius equal to the screening length to one with radius which is the maximum of the classical distance of closest approach and the thermal de Broglie wavelength:

$$
C_{j}=\frac{b_{j, \max }^{3}}{b_{j, \min }^{3}}
$$

The maximum impact parameter is given by a representative screening length. Since electrons are usually much faster than the ions, they tend to only be screened by themselves, while ions are screened by both other ions and electrons. This distinction does not apply to static properties involving a long-time average $(\omega=0)$. However, for use in dynamic contexts shorter than ion-motion time scales, we approximate the maximum impact parameter by

$$
b_{j, \text { max }}= \begin{cases}\lambda_{T F} & \text { if } j=\text { electron } \\ \left(\lambda_{T F}^{-2}+\lambda_{D H, j}^{-2}\right)^{-1 / 2} & \text { if } j=\text { ion }\end{cases}
$$




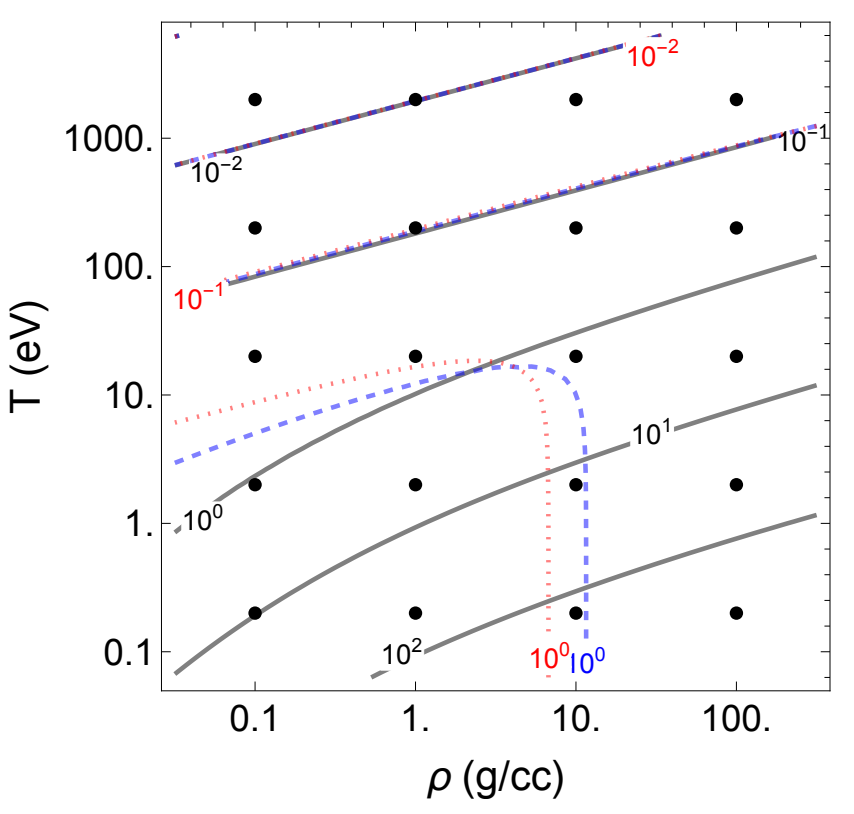

Figure 1: Ion-Ion (solid black), ion-electron (dashed blue), and electronelectron (dotted red) Coulomb coupling parameters for pure hydrogen. See text for definitions. Large Coulomb coupling parameters indicate where analytic expressions break down. The workshop cases are at the positions of the black dots. The ion-ion coupling parameter is large at high densities and low temperatures, whereas the electron-ion and electron-electron coupling parameters are never much above unity in the high energy density regime due to the Pauli exclusion principle.

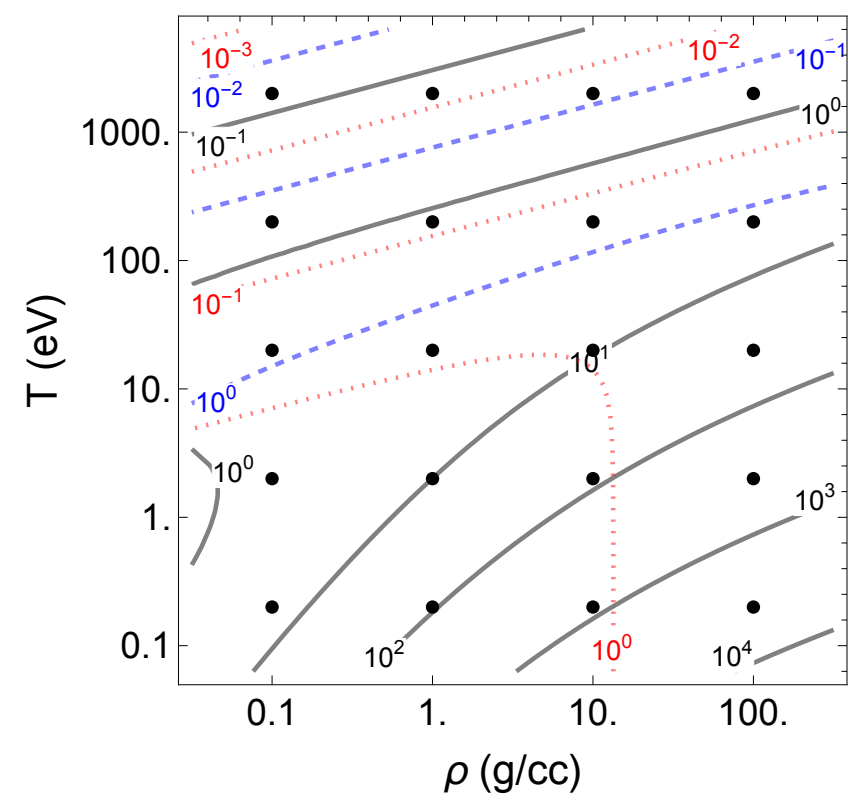

Figure 2: Same as Fig. 1 but for pure carbon. Note the broad range of parameters for which the ion-ion coupling is close to unity, due to roughly equal and opposite effects of temperature and mean ionization. where

$$
\lambda_{T F}^{-2}=4 \pi e^{2} \frac{\partial n_{e}}{\partial \mu}
$$

is the Thomas-Fermi screening length and

$$
\lambda_{D H, j}^{-2}=4 \pi q_{j}^{2} \frac{n_{j}}{T}
$$

is the Debye-Hückel screening length for species $j$. The minimum impact parameter is given by the maximum of the thermal de Broglie wavelength and the classical distance of closest approach:

$$
b_{j, \min }=\max \left[\sqrt{\frac{2 \pi \hbar^{2}}{m_{j} T_{j j, e f f}}}, \frac{q_{j}^{2}}{T_{j j, e f f}}\right] .
$$

These types of length scales are usually the starting point for simple Coulomb logarithms (e.g. Landau-Spitzer [61, 62, 63] or Gericke-Murillo-Schlanges [64]). We plot the numerical complexity, $C_{j}$ for electrons and ions in pure hydrogen and carbon plasmas in Figs. 3 and 4, respectively. This number gets very large in the high-temperature low-density limit for both electrons and ions. Of course, many things simplify at high temperatures; so simpler models become more valid and many details are washed out. This measure should only apply if one tries to do a brute force calculation, resolving all states and length scales.

Since the $\Gamma$ 's and $C$ 's are large in different limits, it is very difficult to have a model which can span the entire range of parameter space and hence, we almost never have a "best" model to compare against for every condition, which would require heroic efforts of theory and computation. Proper interpretation of the results of this code comparison requires keeping these complexity measures in mind.

\section{Theoretical Origins of Transport Coefficients}

Transport processes in hydrodynamic equations are typically described using linearized flux models, in which the leading order coefficient associated with each process is known as a "transport coefficient". While the underlying symmetries of a given system will determine the general form of hydrodynamic equations, the actual transport coefficients (along with any equation of state information) must be determined by the micro-physics at the particle scale. For this reason, there are several approaches to calculating transport coefficients, each of which requires connecting micro-physics processes to a particular hydrodynamic model.

We illustrate the most popular strategies of calculating transport coefficients in Figure (5), where we have categorized the methods into two main branches. The first branch, as discussed in Section (4.1), begins with a hydrodynamic model determined by symmetries and conservation laws, and micro-physics calculations are used to determine the transport coefficients. Meanwhile, the second branch, as discussed in Section (4.4), uses a kinetic equation to derive a hydrodynamic model, and connects transport coefficients to micro-physics quantities in the process.

We emphasize that this discussion is not intended to be a comprehensive review. Rather, this article aims to summarize 


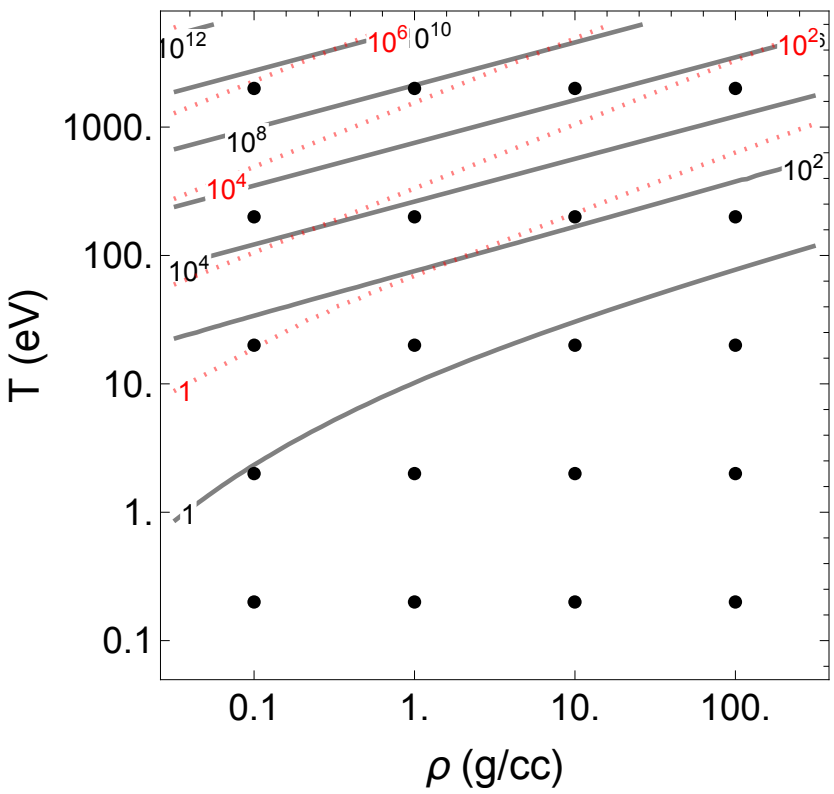

Figure 3: The ratio of $b_{\max }^{3} / b_{\min }^{3}$ (see text for definitions) for ion-ion (solid black) and electron-electron (dotted red) interactions for hydrogen. This ratio is a measure of the computational complexity of first-principles methods. The workshop cases are at the positions of the black dots. The ratio becomes large and it becomes more difficult to apply first principles methods in the same regime where simple physics approximations become valid.

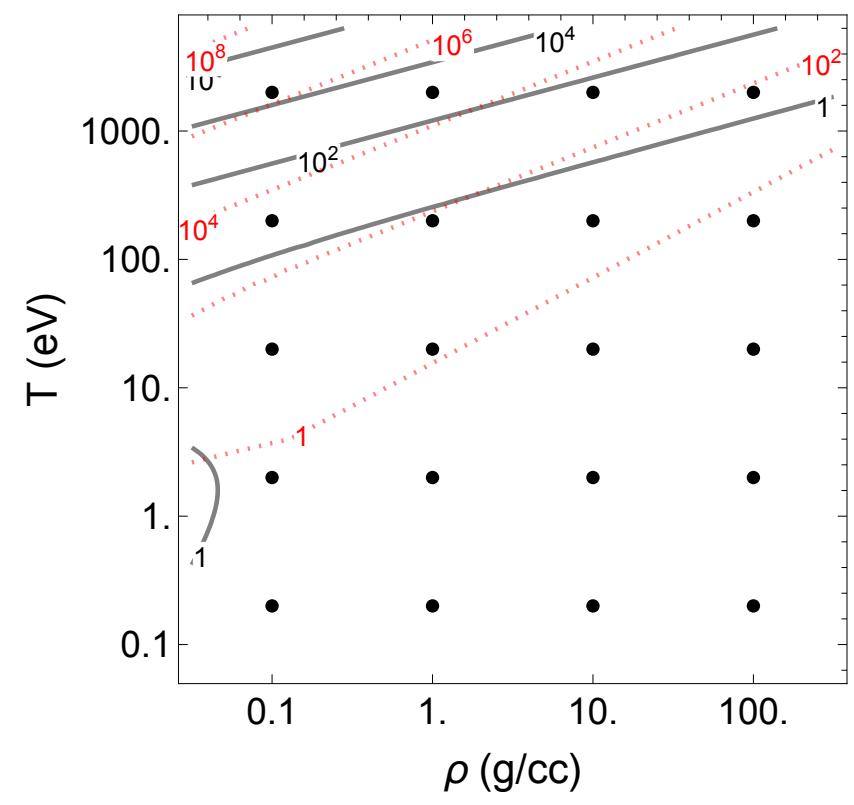

Figure 4: Same as Fig. 3, but for carbon.

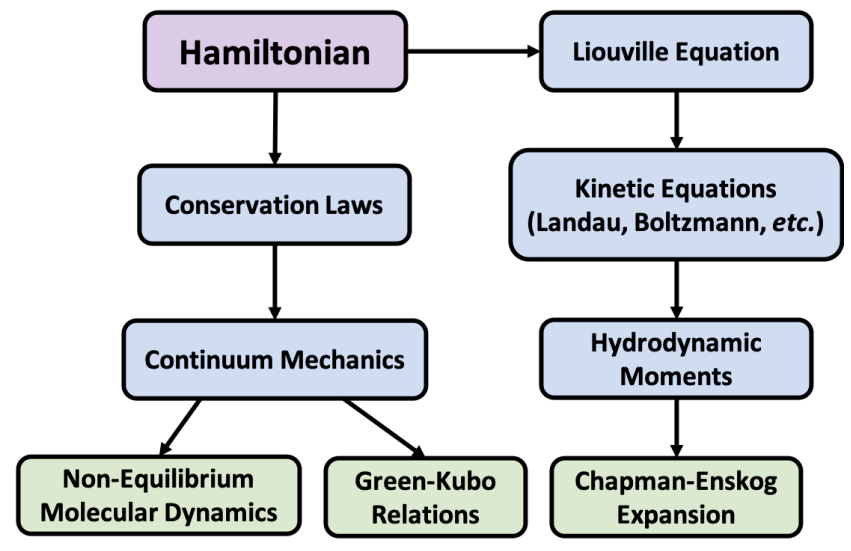

Figure 5: Diagram of calculation methods for transport coefficients. In the left branch, transport coefficients are calculated directly from correlations or currents of many-body simulations, while in the right branch, a kinetic equation is used to generate the continuum model and thus the corresponding transport coefficients.

the approaches taken by self-selected contributors to the workshop. For the interested reader, we here provide some important general references on the following relevant topics: fluid dynamics [65, 66, 67], kinetic theory [68, 69], dense plasma theory [70, 71, 72], density functional theory [73, 74], quantum Monte Carlo [75], response functions [76], molecular dynamics [77], average atom models [58], atoms in plasma environments [78, 79], wave packet molecular dynamics [80, 81], ion transport [31], diffusion [82, 83, 84, 85], viscosity [86, 87, 88], electrical and thermal conductivity [89, 90, 91, 92, 93, 94], and stopping power $[95,96,97,98,99,100,101,102,103,104$, $105]$.

\subsection{Origin of Transport Coefficients from Conservation Laws}

The most fundamental approach to calculating transport coefficients is to compare directly with the equations of hydrodynamics that have been determined by the symmetries and conservation laws of the system of interest. In its most generic form, the conservation of particle number, linear momentum and energy for a continuum field with no external sources can be expressed respectively by the equations

$$
\begin{aligned}
& \frac{\partial n}{\partial t}+\nabla \cdot(n \mathbf{v})=0 \\
& m n\left(\frac{\partial \mathbf{u}}{\partial t}+\mathbf{u} \cdot \nabla \mathbf{v}\right)-\nabla \cdot \boldsymbol{\sigma}=0 \\
& n\left(\frac{\partial e}{\partial t}+\mathbf{u} \cdot \nabla e\right)-\boldsymbol{\sigma}:(\nabla \mathbf{u})+\nabla \cdot \mathbf{q}=0 .
\end{aligned}
$$

Here, $m$ is the particle mass, $n(\mathbf{r}, t)$ is the number density, $\mathbf{u}(\mathbf{r}, t)$ is the velocity field, $e(\mathbf{r}, t)$ is the energy density, $\sigma(\mathbf{r}, t)$ is the Cauchy stress tensor, and $\mathbf{q}(\mathbf{r}, t)$ is the heat flux. Furthermore, angular momentum is conserved by enforcing the symmetry $\sigma=\sigma^{T}$. Relevant approximations and closure relations are required to reduce this system of equations to the more familiar hydrodynamic models (Euler, Navier-Stokes, etc.).

For example, if we consider a binary system, we can introduce the number densities $n_{1,2}(\mathbf{r}, t)$ and velocity fields $\mathbf{u}_{1,2}(\mathbf{r}, t)$ 
for the individual species, each of which will satisfy a continuity equation associated with conservation of particle number

$$
\frac{\partial n_{i}}{\partial t}+\nabla \cdot\left(n_{i} \mathbf{u}_{i}\right)=0, \quad i=\{1,2\} .
$$

In hydrodynamic models, diffusion is usually measured relative to the bulk motion of the fluid. For a binary fluid we can define the bulk center of mass velocity $\mathbf{u}=x_{1} \mathbf{u}_{1}+x_{2} \mathbf{u}_{2}$, where $x_{i}=$ $m_{i} n_{i} / \rho$ and $\rho=\left(m_{1} n_{1}+m_{2} n_{2}\right)$. The continuity equations are transformed into a frame moving at bulk velocity $\mathbf{u}$ to obtain

$$
\rho \frac{\partial x_{i}}{\partial t}+\rho \mathbf{u} \cdot \nabla x_{i}=-\nabla \cdot \mathbf{j}_{i}
$$

where $\mathbf{j}_{i}$ is the relative (to $\mathbf{u}$ ) mass flux density of the $i^{\text {th }}$ species. For small gradients in the concentration field, the temperature field $T(\mathbf{r}, t),{ }^{1}$ and the total pressure pressure field $P(\mathbf{r}, t)$, the Taylor expansion of the flux density can be truncated to linear order as

$$
\mathbf{j}_{i} \approx-\rho D\left(\nabla x_{i}+\frac{k_{T}}{T} \nabla T+\frac{k_{P}}{P} \nabla P\right),
$$

where we have defined $D$ as the diffusion coefficient, $k_{T} D$ as the thermal diffusion coefficient, and $k_{P} D$ as the barodiffusion coefficient [66]. Of course, gradients in these fields will appear in the remaining hydrodynamic equations as well, in which each term will have its own coefficient that must be calculated from the micro-physics. We have illustrated this approach in the left branch of the diagram in Figure (5).

One such method along this branch is non-equilibrium molecular dynamics (NEMD), where molecular dynamics simulations are used to measure the response of a system to gradients in the appropriate state variables (density, temperature, etc.). This is possible because of the simple linear relationship in (15). NEMD calculations can be particularly challenging due to not only the computational complexity of the simulations, but isolating a gradient in a particular observable without inducing gradients in other quantities is often impossible as well; that is, one wishes to remain deeply in the linear regime to avoid generating the other gradients, and this creates signal-to-noise issues.

\subsection{Green-Kubo Relations}

For linear transport coefficients one can also employ equilibrium MD. In this approach, one derives transport coefficients from equilibrium time correlation functions to generate the celebrated Green-Kubo (GK) relations for the transport coefficients. In this subsection we will sketch how the GK relationships arise. We illustrate this approach using inter-diffusion again as an example, which is the key process for atomic-scale mixing.

If we assume gradients in the temperature and pressure fields to be negligible, the flux density (15) of the $i^{\text {th }}$ species reduces

\footnotetext{
${ }^{1}$ Here and throughout this review, we will assume there is only a single temperature for the sake of simplicity.
}

to the well-known form of Fick's Law defined in terms of the relative density, $\mathbf{j}_{i}=-\rho D \nabla x_{i}$. Upon linearization, the continuity equation in Equation (14) can thus be written as

$$
\frac{\partial x_{i}}{\partial t}+\mathbf{u} \cdot \nabla x_{i}=D \nabla^{2} x_{i}
$$

Note that the Fick's law for interdiffusion is written in terms of the total fluid mass density $\rho$ and the fractional density $x_{i}$ of species $i$. The resulting equation is then solved as an initial value problem in Laplace-Fourier space, which allows the equation to be written in terms of a time correlation function. So far, there is no connection to the microscopic dynamics, as all manipulations are consistent with macroscopic/hydrodynamic definitions. Next, the ensemble average of the resulting timecorrelation function is written in terms of its microscopic definition, connecting the transport coefficient $D$ to the phase-space trajectory of the microscopic many-body system, yielding the GK formula for inter-diffusion [106]

$$
D=\frac{x_{1} x_{2}}{S_{c c}(0)} \int_{0}^{\infty} d t V_{D}(t)
$$

Here, the autocorrelation function is defined as

$$
\begin{aligned}
V_{D}(t) & \equiv \frac{1}{3 N x_{1} x_{2}}\left\langle\mathbf{v}_{d}(t) \cdot \mathbf{v}_{d}(0)\right\rangle, \\
v_{d}(t) & \equiv x_{2} \sum_{i=1}^{N_{1}} \mathbf{v}_{i}(t)-x_{1} \sum_{j=1}^{N_{2}} \mathbf{v}_{j}(t),
\end{aligned}
$$

where the first sum is over species 1 , the second sum is over species 2 , and $(\cdot)$ denotes a dot product between the two vectors. Furthermore, we have introduced the concentration structure factor, which is defined in terms of the partial static structure factors as

$$
S_{c c}(k)=x_{1} x_{2}\left[x_{2} S_{11}(k)+x_{1} S_{22}(k)-2 \sqrt{x_{1} x_{2}} S_{12}(k)\right] .
$$

Importantly, note how the resulting GK relation is intimately connected with specific choices and definitions at the hydrodynamic level. That is, each correlation function corresponds to a specific type of current with a precise definition, which should match what is meant in the hydrodynamic equations. In a similar fashion, one can employ the momentum equation of the Navier-Stokes equation to find a correlation function associated with viscosity that can be connected to microscopic dynamics; this strategy can be used for all of the other coefficients, and is readily adapted to quantum systems [107, 108].

While the GK relations present an elegant connection between transport processes and the underlying statistical mechanics of the system, they still leave the correlation functions themselves to be determined. However, for the past few decades, there are a variety of computational methods, such as equilibrium molecular dynamics simulations, that can inform these correlation functions through detailed calculation of the trajectories.

\subsection{Kubo-Greenwood and Ziman approaches}

The usual GK formulation can be connected with the Boltzmann equation (under certain assumptions, see Ref. [109]) 
and this expresses the static conductivity in terms of scattering cross sections and one-body distributions instead of the current-current correlation function. In practice the evaluation of the current-current correlation function can also be simplified by using the Fermi-Golden rule and the assumption of a momentum relaxation time $(\tau)$ to calculate a conductivity. The frequency-dependent Kubo-Greenwood approaches uses KohnSham eigenstates as the initial and final states of the scattering process to obtain a dynamic conductivity $\sigma(\omega)$, but the extraction of a static conductivity involves obtaining a $\tau$ by fitting to a Drude model, with the following formula for the static conductivity:

$$
\sigma=\frac{n e^{2} \tau}{m_{e}}
$$

in a standard notation. That is, in spite of the complexity of the theories, they all finally depend on the above equation with all its assumptions to extract the static conductivity.

Equation 21 is also used in the Ziman formula. However, the Ziman formula does NOT use the static current-current correlation function, but relies on evaluating the static force-force correlation function. It gives the inverse of the conductivity (i.e., resistivity). In most applications, the result is equivalent to the use of a Fermi golden rule with the initial and final states being plane waves, while the scattering potential is a linearly screened weak pseudopotential. The evaluation of the inverse of the conductivity $R=1 / \sigma$ rather than $\sigma$ is claimed to sum a larger class of scattering graphs, and the Ziman formula had been the preferred method for computations in liquid metals (e.g., see Ref. [110]). In fact Pozzo et al's computationally very heavy tour de force evaluation of the static conductivity of liquid sodium using the Kubo-Greenwood formula, can be compared with easy calculations from the Ziman formula [111].

The Ziman formula is the favorite route in models based on the neutral-pseudo-atom (NPA) model [112], or various types of average atom (AA) models. The NPA provides a freeelectron pile up $\Delta n(r)$ around the nucleus based on a KohnSham calculation, and this is used to construct an electron-ion pseudopotential $U_{e i}$ and an ion-ion pair potential $V_{i i}$. The latter is used in the hypernetted chain equation (with bridge corrections where needed) to generate an ion-ion structure factor $S_{i i}(k)$. The structure factor and the pseudopotential $U_{e i}(k)$ are used in the Ziman formula. This ensures that the Kohn-Sham calculation, the pseudopotential, pair-potential and the structure factor are, in principle, self-consistent with each other.

\subsection{Kinetic model based approaches}

As an alternative to calculating transport coefficients directly from equilibrium or non-equilibrium many-body simulations, kinetic equations (e.g., Boltzmann, Landau/FokkerPlanck, BGK) can be used to generate a hydrodynamic model through a hierarchy of hydrodynamic moments. While the hydrodynamic model will be limited by the often restrictive approximations of the governing kinetic equation, this approach has the advantage of analytic simplicity over the methods listed in Section (4.1), which usually require a numerical many-body calculation. We have illustrated this alternative approach in the right branch of the diagram in Figure (5).

We now demonstrate this approach using a very simple model. Suppose our kinetic equation has the BGK form [68]

$$
\frac{\partial f}{\partial t}+\mathbf{v} \cdot \nabla f=\frac{f_{0}-f}{\tau}
$$

where $f=f(\mathbf{r}, \mathbf{v}, t)$ is the one-body distribution function, and $f_{0}=f_{0}(n, \mathbf{u}, T)$ is an equilibrium distribution function (e.g., a drifting Maxwellian) in terms of the density, mean velocity and temperature that has the same lowest-order moments as $f(\mathbf{r}, \mathbf{v}, t)$, and $\tau$ is a collision time. The lowest-order moment yields the continuity equation for the density $n(\mathbf{r}, t)$, whereas the first-order moment yields the momentum equation for the fluid velocity $\mathbf{u}(\mathbf{r}, t)$

$$
\begin{aligned}
& \frac{\partial n \mathbf{u}}{\partial t}+\nabla \cdot\langle\mathbf{v v}\rangle=0 \\
& \frac{\partial n \mathbf{u}}{\partial t}+\nabla \cdot \mathbf{u u}+\nabla \cdot\langle\mathbf{c c}\rangle=0
\end{aligned}
$$

In the second line the mean velocity has been separated to isolate the central moment in terms of the relative velocity $\mathbf{c}=\mathbf{v}-\mathbf{u}$. This equation is not closed as a result of the term $\langle\mathbf{c c}\rangle=\int d^{3} v f$ cc. If the collision time is very small, which corresponds to a very short mean-free path, the kinetic equation yields the approximate solution $f \approx f_{0}$; using $f_{0}$ in $\langle\mathbf{c c}\rangle$ yields the usual pressure term in terms of the temperature, which leads to the Euler form of hydrodynamics. For weaker collisions, an improved solution of the kinetic equation is needed, of which the lowest-order solution is

$$
f \approx f_{0}-\tau\left(\mathbf{v} \cdot \nabla f_{0}\right)
$$

This is a simple form of the Chapman-Enskog (CE) expansion [65].

The second term, when used to evaluate $\langle\mathbf{c c}\rangle$, yields transport terms that are proportional to the collision time $\tau$. Note that the transport terms will contain terms proportional to $\nabla n, \nabla \mathbf{u}$ and $\nabla T$ because of the dependencies in $f_{0}$. Moreover, note that we can identify the various transport processes by inspection and the transport coefficient naturally arises as the coefficient of those terms. In this case, all of the transport coefficients would self-consistently be connected through $\tau$; other kinetic equations, such as Landau/Fokker-Planck or Boltzmann, would have similar properties.

\subsection{Open Questions}

While the results presented below pertain to the linear transport regime, we wish to mention some extensions worth future study. As we have seen, linearization is used at nearly every step, either in writing the fluxes, or, equivalently, in keeping the lowest order terms in the CE expansion and in obtaining the GK relations. Non-linear contributions yield both higherorder terms in the gradients, but also generate cross terms. The cross terms couple the various transport processes to create new forms of transport; for example, the Biermann battery [113] results from a $\nabla n \times \nabla T$ cross term. Moreover, it is possible in 
some cases for the non-linear terms to create a situation where the steady state flux relationships of the form $\mathbf{j} \sim-C \nabla U$ no longer hold. In addition, as we will see below, most of the transport coefficients have their largest values, and therefore are more important to the hydrodynamic evolution, at higher temperatures (weaker coupling). At high enough temperature, the mean-free path of the particles will exceed the gradient scale length (e.g., the scale of the density gradient in diffusion); this is the non-local transport regime [114, 115] for which transport coefficients cease to have their usual utility; non-locality in transport is particularly important in thermal conduction [116].

We have also limited ourselves to the canonical ensemble of fixed volume with one temperature for all species. However, the advent of fast lasers and the ability to create two-temperature plasmas that can be probed using femto-second pulses has led to the possibility of studying dynamic conductivities dependent on two temperatures, that is with ion and electron temperatures such that $T_{i} \neq T_{e}$. Furthermore, laser techniques allow the study of isochoric conductivities, whereas most techniques used up to the 1980s (e.g., for liquid metals) were for isobaric conductivities. This distinction has not been well understood by the community, and it is not unusual to see papers where isochoric conductivities are compared with isobaric conductivities [117].

\section{Models}

Many choices go into each model. Their biggest difference is whether the electrons are treated dynamically or statically. A fully dynamic treatment allows an explicit calculation of time-dependent electron-ion and electron-electron correlations, which can be used in GK formulas [118, 119] or the quantity of interest (e.g. the energy of the projectile in stopping power) can be directly tracked. Example time-dependent methods which were contributed to our workshop are Time-Dependent Density Functional Theory (TDDFT) [23, 120] and electron Force Field (eFF) $[121,122]$. Alternatively, a great simplification of electron dynamics can be made by modeling their effect with the Langevin equation [123].

All the other models rely on the Born-Oppenheimer approximation, in which the electrons are assumed to instantaneously screen the much slower ions. The ion motions from molecular dynamics yield the viscosity and diffusion, while electron dynamics must be inferred through some approximations to the electron-ion and electron-electron collision operators of kinetic theory. Approximations to the electron screening differ most in how they treat ion-ion correlations. For example, the average atom assumes the ion-ion radial distribution function is a step function at the ion-sphere radius. The correlations can later be inferred by mapping the average atom to the one component plasma with an effective ion charge, such as in PIJ [25], or altering the ion charge and introducing a screening length as in KMD [38, 31]. Using the quantum hypernetted chain approximation $[124,125,126]$ one can obtain spherically symmetric potentials that can exhibit liquid-like behavior as in EPT [21], but angular correlations are neglected unless one does a three-dimensional quantum mechanical density functional theory (DFT) [73] calculation. Such DFT calculations come in several different flavors, all of which are based upon semiclassical approximations about uniform electron density of the electron free energy. In order of increasing expected accuracy and increasing computational cost, these are Thomas-Fermi [127, 128], Sjostrom-Daligault (SDMD) [129], and Kohn-Sham [130]. The derived potentials can be used in two different ways: effective binary interactions can be used within Boltzmann collision operators as in EPT [21] or the binary or many-body interactions can be used in molecular dynamics simulations [50].

Whenever a model includes a sufficient representation of the electrons' state, quantities dependent on electron-ion or electron-electron collisions (e.g. electrical and thermal conductivities and stopping power) can be calculated. We employed four types of approximations: Ziman-type expressions [131, 132], which are used in various single-center plasma models [133, 134, 135, 136, 137, 138, 139], the Kubo-Greenwood approximation [140], which approximates the electron wave function with the Kohn-Sham wave function and can be employed in either single-center models [141, 142, 143, 144] or threedimensional multi-atom calculations [145, 146, 147, 148, 149], local density approximations [150, 98], which use homogeneous electron gas formulas as a starting point for the inhomogeneous problem (almost all stopping power models used this approximation when bound electrons are important), and directly simulating dynamics $[23,24,151]$.

\section{Results}

In this section, we present five different quantities (electrical and thermal conductivity, viscosity, diffusion, and stopping power) for three types of materials (hydrogen, carbon, and an equimolar mixture of the two) across twenty different conditions (four different densities, five different temperatures, and in the case of stopping power, seven different energies). There were up to 15 submissions for each of the included 520 cases (we had no submissions for stopping in the $\mathrm{CH}$ mixture). Since one of our main goals is to facilitate sensitivity analyses, we focus on mean and spread measures. However, for the researcher interested in making detailed comparisons, we include some discussion below and have included all the submitted data as a supplementary data file, except from those who requested anonymity.

It is useful to give a measure of the spread in the reported values for each quantity. A conservative measure would be the ratio of maximum to minimum values, but this tends to overemphasize outliers. We would also prefer a method that uses information from all of the data rather than the two extrema. A more natural quantity to assess is the standard deviation, $\sigma\left(\left\{d_{i}\right\}\right)$, where $\left\{d_{i}\right\}$ represents our data set for a particular quantity at some condition. However, data which is spread over decades may give a value of $\sigma$ which is very skewed by one data point. Therefore, we define a spread measure

$$
\tilde{\sigma}=\exp \left[\sigma\left(\left\{\ln d_{i}\right\}\right)\right]-1
$$


Note, this measure does not depend on the units or scale of the data. Small values of $\tilde{\sigma}$ (much less that one) mean that there is little variation while very large values indicate lack of consensus. These values correspond roughly to the fractional variation within the data.

\subsection{Electronic Transport}

The means and standard deviations of all submissions of electrical and thermal conductivity are plotted in Fig. 6. Individual submissions are listed in the appendix. For all materials, we find fair agreement among the four independent average-atom models for both electrical and thermal conductivities. These models also agree fairly well with the MD models at moderate densities. The outliers tend to be the parameterized analytic models, while values actually used in hydrodynamic simulations tend to fall within the range of more sophisticated models. For carbon, the widely used Lee-More approximation agrees with QMD at $1 \mathrm{~g} / \mathrm{cc}$ but is a factor of 10 too small at $10 \mathrm{~g} / \mathrm{cc}$. Large disagreements at low temperatures and densities are due primarily to differences in calculated ionization, while large disagreements at high densities are attributable to differing treatments of ionic structure and electron degeneracy. For hydrogen in the high-density regime relevant to ICF stagnation, factors of three to ten among models persist even at high temperatures. These spreads can be seen in Figs. 8 to 10 .

The Lorenz number is shown in Fig. 7. For both carbon and hydrogen, most codes recover Weideman-Franz scaling [152] at high densities and low temperatures. There is less agreement among calculated thermal to electrical conductivity ratios in the classical limit, where the treatment of electronic collisions in both electrical and thermal conductivities varies among the models.

\subsection{Ionic Transport}

Ion viscosity and ion diffusion coefficients are presented in the lower two rows of Fig. 6. In the pure element cases, the self-diffusion coefficient is shown, while for the mixture, it is the interdiffusion coefficient. Because ions are much more massive than electrons, they carry most of the momentum in the plasma. Consequently, viscosity is associated with ions. The electric field associated with electrons may influence ion-ion interactions [87], but the electrons themselves do not provide a significant direct contribution.

A striking feature of the shear viscosity coefficient at warm dense matter conditions is that a minimum can be reached as temperature varies. This is associated with the underlying physical mechanisms responsible for viscosity, which are directly illustrated in the Green-Kubo relation [153]. At weak coupling (low density or high temperature), shear viscosity is determined by the kinetic energy of particles. In this regime, traditional Landau-Spitzer $[61,62,63]$ theory predicts that the shear viscosity increases with temperature as $\eta \propto T^{5 / 2}$. Essentially all of the submissions appear to capture this limit. At sufficiently low temperature, the kinetic energy of particles does not contribute significantly, and the shear viscosity is instead determined by the Coulomb potential energy of ions. Much understanding of this transition is based on the one-component plasma model, where it occurs at $\Gamma \simeq 17[154,155,156]$. In low temperature dense plasmas, shear viscosity decreases with increasing temperature, as it does in ordinary liquids. This is a challenging regime for theory because the many-body potential energy is difficult to model. It is also a challenging regime for firstprinciples simulations because ion transport occurs much more slowly than electron transport, which often requires unattainably long simulations to achieve reliable results.

As expected, the spread in data at high density low temperature conditions is especially severe, often spanning several orders of magnitude. At these conditions there is little agreement among any of the submissions, illustrating that this is one of the least understood transport processes considered in this workshop. Ion viscosity in this regime is relevant to modeling the fuel-shell interface in ICF (e.g. Ref. [157]) This highlights one of the most important areas where improved theory and simulations are needed. It may contribute to a high degree of uncertainty for some aspects of hydrodynamic simulations when these conditions are encountered. However, it is important to recall that small values of transport coefficients imply correspondingly small contributions to the hydrodynamic equations: the stronger the collisions, the smaller the transport coefficients, and the smaller the terms in the hydrodynamics model, unless there are extremely large gradients.

The submitted ion diffusion coefficients tend to be in closer agreement than ion viscosity coefficients, but with still substantial disagreement in the strongly coupled regime. Analytic models tend to be outliers. Again, the agreement is best at high temperature and low density conditions (weak coupling), where all submissions appear to asymptote to the $D \propto T^{5 / 2}$ regime of Landau-Spitzer theory. Similar trends are observed for the self-diffusion processes in the single component systems as for interdiffusion in the $\mathrm{CH}$ mixture. With the exception of one analytic model, all submissions predict that $D$ monotonically decreases with decreasing temperature, consistent with expectations from the one-component plasma [158, 159]. The better agreement for diffusion, compared to viscosity, may be that the correlation function for diffusion is entirely determined by the kinetic energy of particles. Thus, there is not a fundamental transition in the physical mechanism responsible for diffusion as there is with viscosity.

Diffusion processes are important in ICF plasmas particularly with regard to deuterium and tritium fuel mixing, or demixing, near a hot spot, but also in the mixing of shell materials near the edge of the fuel. The data suggest that reliable models exist in the weakly coupled plasma regimes, such as may be expected in the former example of fusion fuel mixing in a hot plasma. However, there may be much less reliable models in the latter example concerning mixing of shell materials in the cooler outer regions of the plasma. Continued progress in such simulations will rely on further improvements to the diffusion models particularly in these more dense or cool regions.

\subsection{Stopping Power}

Accurate values for the stopping powers are needed for ICF target design [160] because alpha particle heating maintains the 
$\mathrm{H}$

C

$\mathrm{CH}$

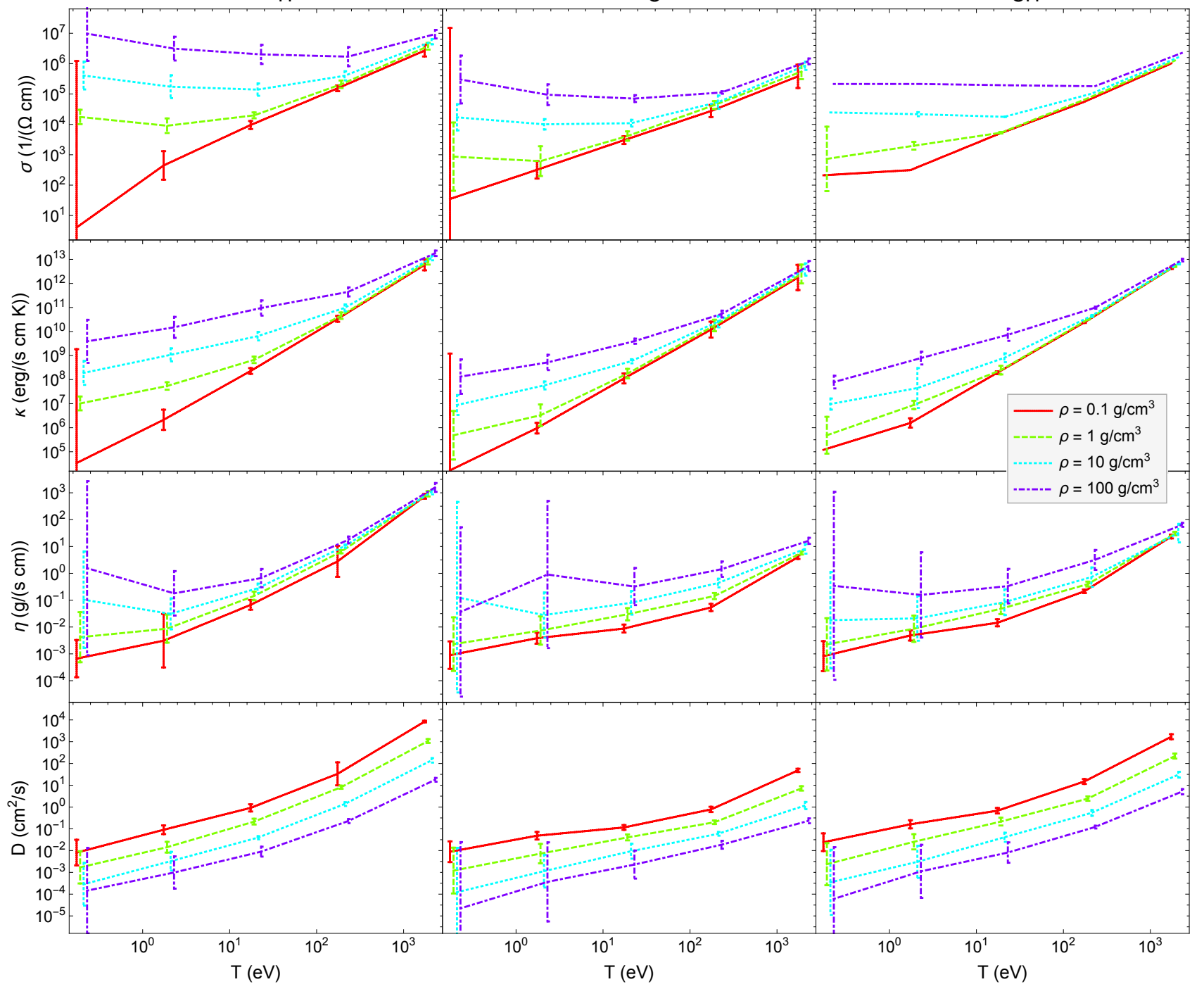

Figure 6: Electrical (first row) and thermal (second row) conductivity, ion viscosity (third row), and the diffusion coefficient (fourth row) for pure hydrogen (first column), pure carbon (second column), and an equimolar carbon-hydrogen mixture. For the pure cases the diffusion coefficient is the self diffusion while for the mixture, it is the interdiffusion. Plotted are the mean (position) and standard deviations (error bars) in logarithmic space of all submissions as a function of temperature. The different density cases plotted are $\rho=0.1 \mathrm{~g} / \mathrm{cm}^{3}$ (red, solid), $\rho=1 \mathrm{~g} / \mathrm{cm}^{3}$ (green, dashed), $\rho=10 \mathrm{~g} / \mathrm{cm}^{3}$ (cyan, dotted), and $\rho=100 \mathrm{~g} / \mathrm{cm}^{3}$ (purple, dot-dashed). The spreads tend to be larger at low temperatures or high densities For clarity, the different densities curves are slightly offset from one another in temperature from the actual values of $0.2,2,20,200$, and $2000 \mathrm{eV}$. 
$\mathrm{H}$
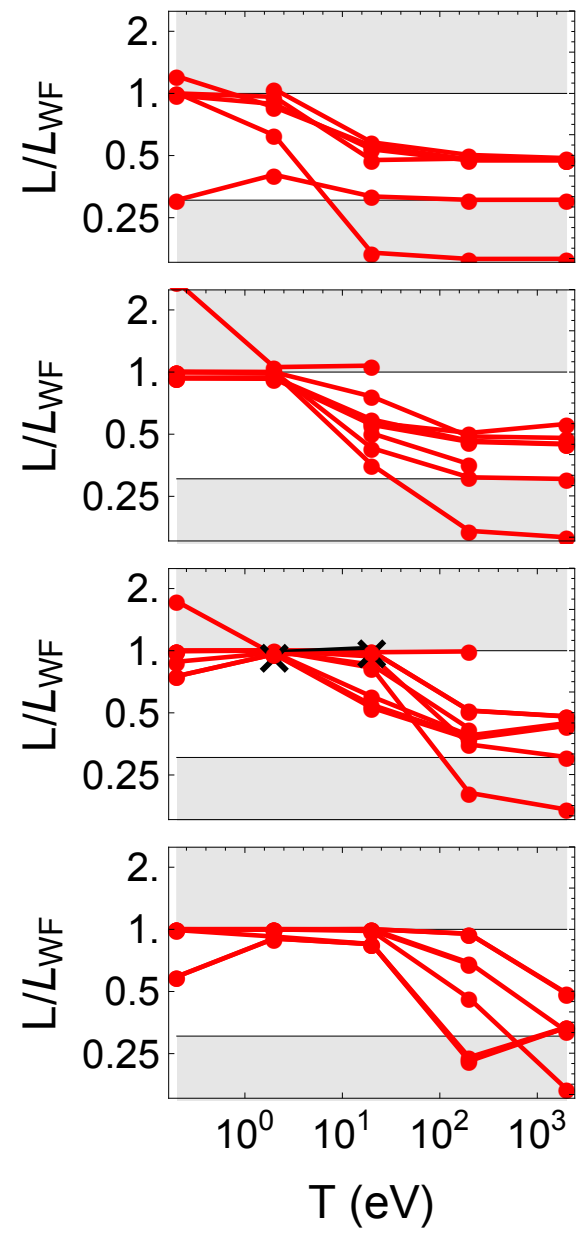

C
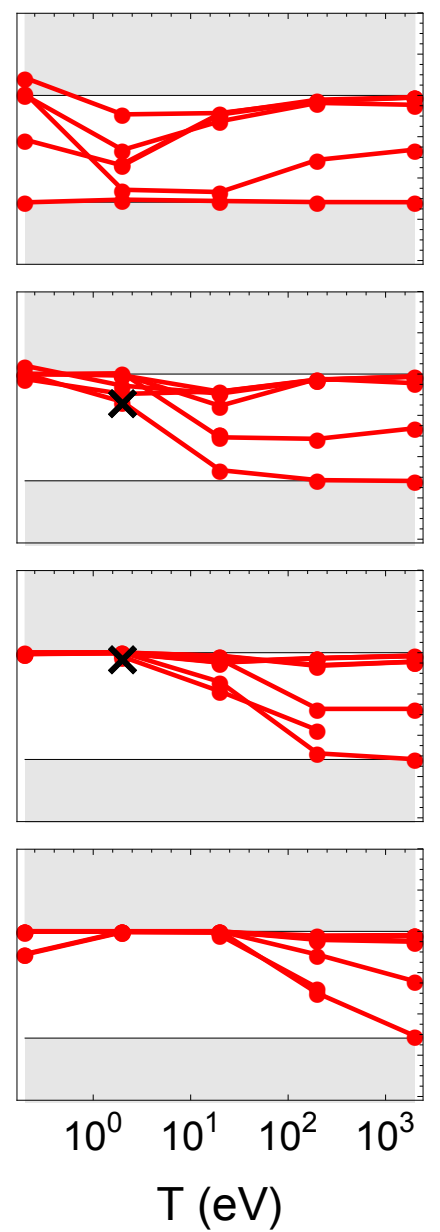

$\mathrm{CH}$
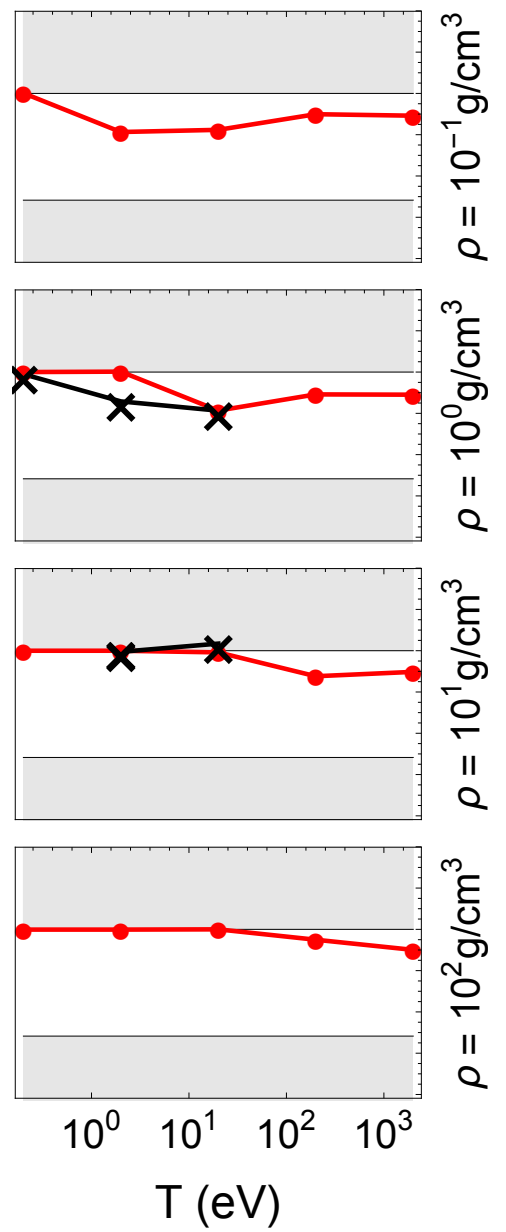

Q

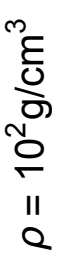

Figure 7: Lorenz number $\left(L=\kappa /\left(\sigma k_{B} T\right)\right)$ divided by the Widermann-Franz limit $\left(L_{W F}=\pi^{2} k_{B}^{2} /\left(3 e^{2}\right)\right)$ of all submitted calculations. The Wiedermann-Franz and Spitzer $\left(L_{S}=k_{B}^{2} / e^{2}\right)$ limits are shown by the upper and lower shaded gray regions, respectively. All the data is shown as circles connected by solid red lines except for three dimensional density functional calculations (black x's), which were the most expensive. 

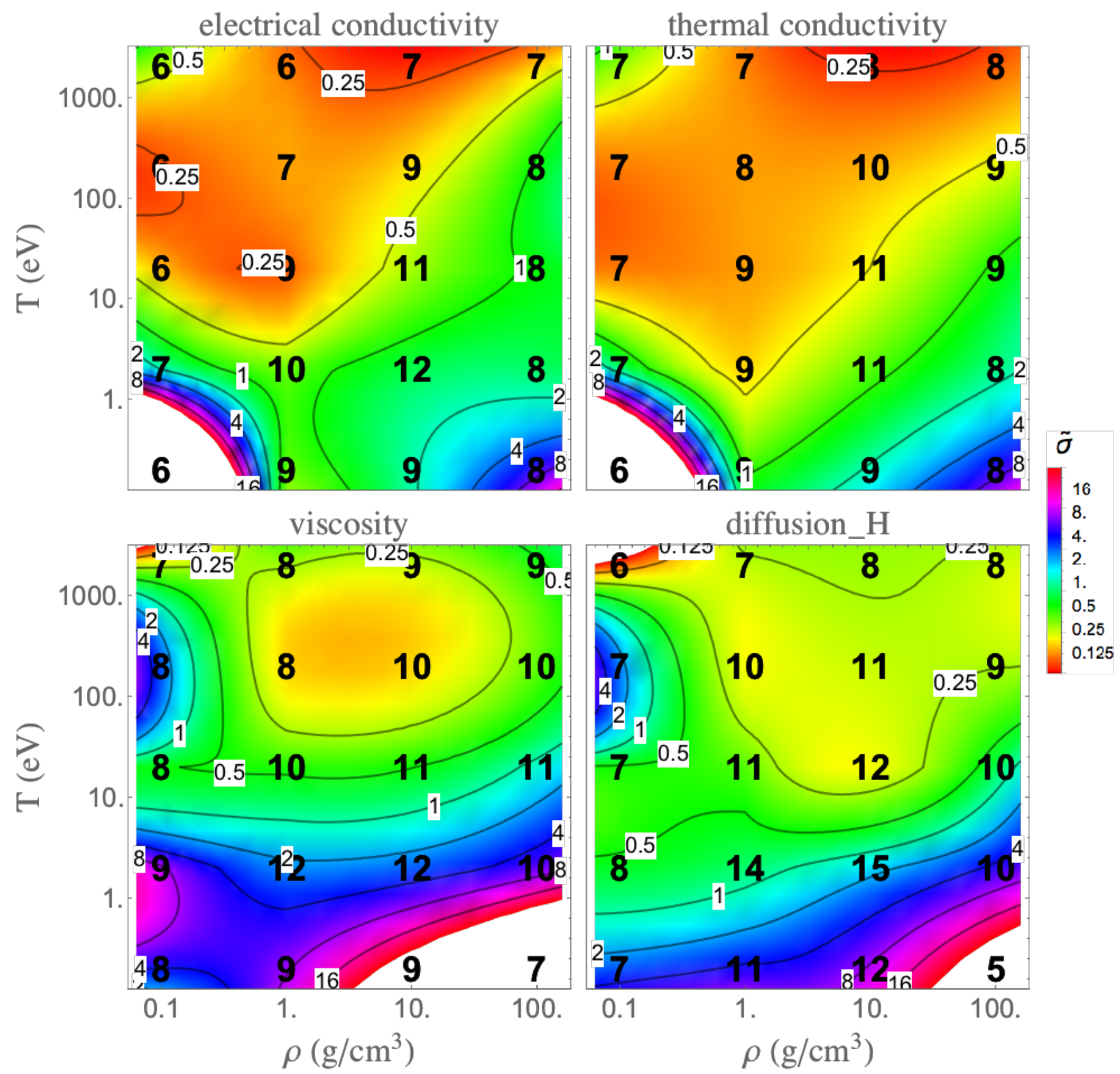

Figure 8: Spread in reported values of transport coefficients for hydrogen. This spread roughly corresponds to the fractional variation in the submitted values. See Eq. 22 for the definition. The large black bold numbers are located at the positions of the workshop cases and their values are the number of submissions at those conditions. Small values (red) indicate agreement among submissions while large values (magenta) indicate disagreement. The larger values correspond to when either the relevant Coulomb coupling parameter or computational expense is large (see Sec. 3). 


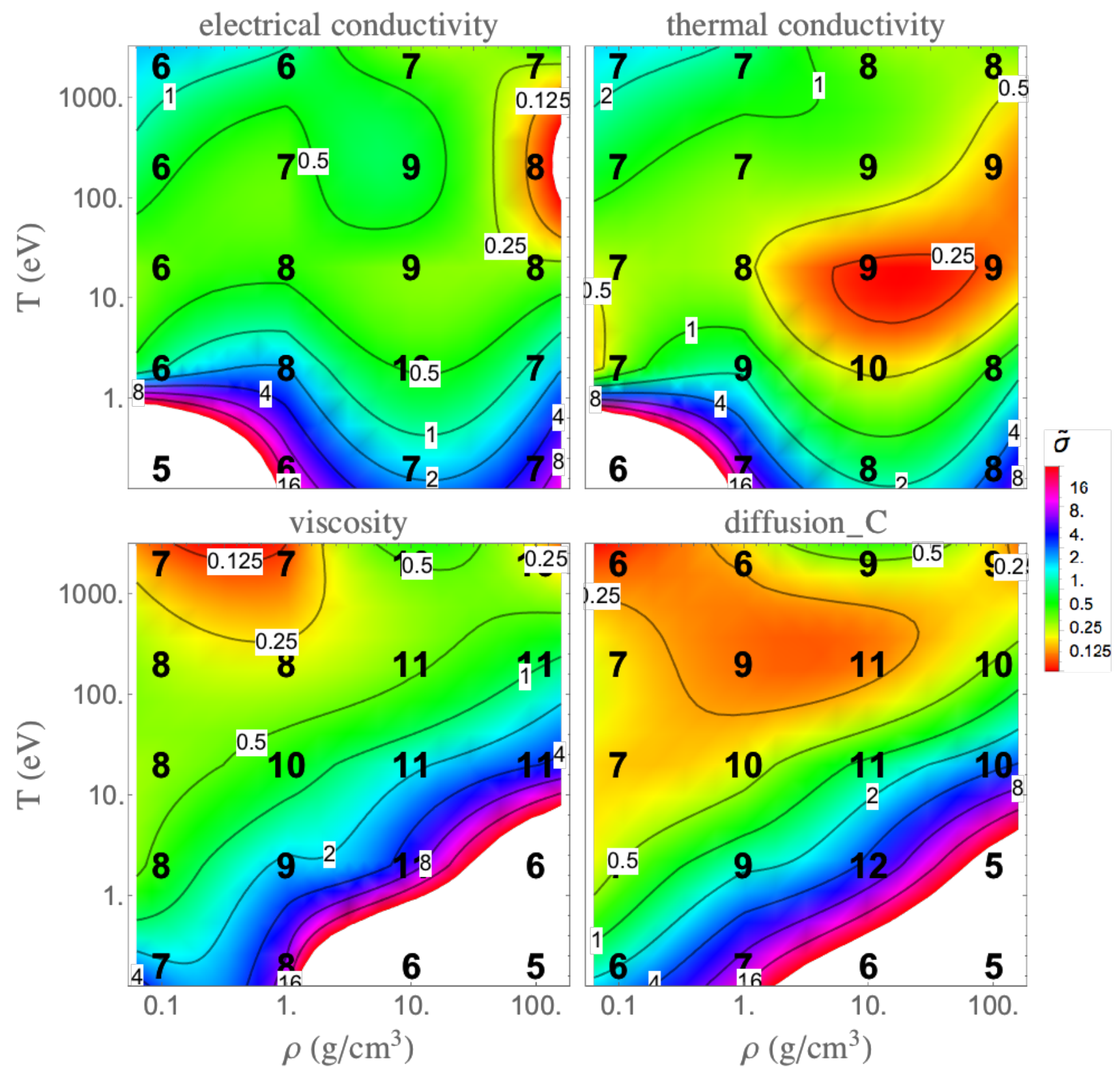

Figure 9: Same as Fig. 8 but for carbon. 


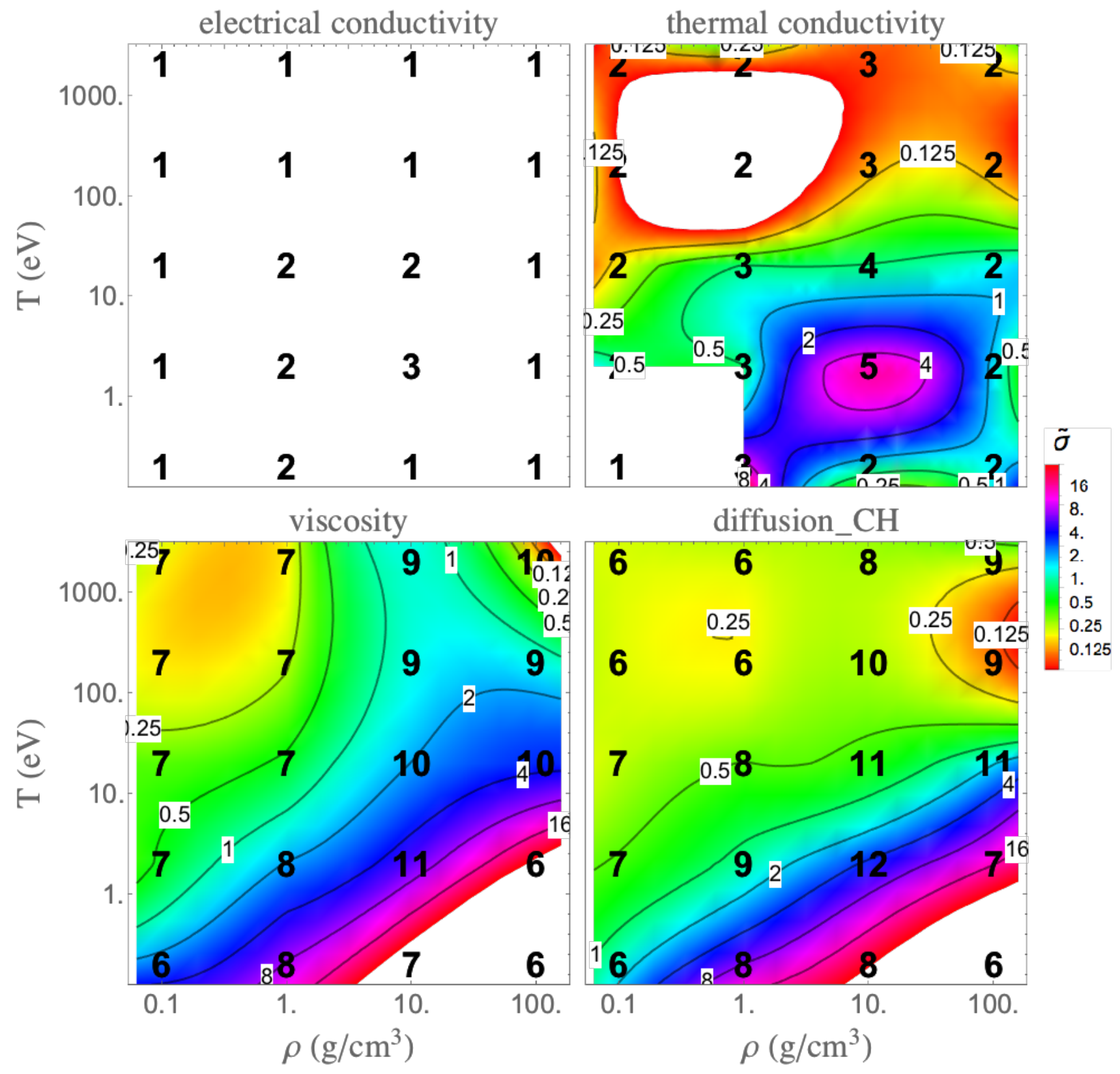

Figure 10: Same as Fig. 8 but for the equimolar carbon-hydrogen mixture. Note, there were not enough electrical conductivity submissions to report a valid spread measure. The reliability of the thermal conductivity spread measure here is also marginal due to having too few submissions. 
temperature in the presence of energy loss mechanisms. Warm dense matter experiments can also rely on charged particle beams for heating $[161,162,20]$ or as a probe $[17,15]$. Unlike the electronic and ionic transport properties, which represent an integration over a distribution (usually thermal) of charged particle velocities, stopping powers must be energy-resolved to track the thermalization of fast fusion products through collisions with the background material. Hence, they more distinctly probe different parts of the underlying collision operator needed for all transport quantities while also having an extra dimension of parameter space to explore.

Over the last few decades there have been many different stopping power experiments in plasmas. These can be divided into experiments involving high-energy, moderate to heavy ions in weakly coupled plasmas [163, 164, 165, 166, 167], moderate-energy, fully-ionized, light ions in weakly coupled plasmas [168, 15, 169, 170, 16], high-energy, fully-ionized, light ions in weakly coupled plasmas [171] moderate-energy, light ions in a moderately coupled plasma [77], and highenergy, light ions in a moderately coupled plasma [17, 18], where high (moderate) energy refers to ions with velocities significantly greater than (approximately equal to) the thermal velocity of the target electrons. While all of these experiments are very useful for benchmarking theoretical predictions, it remains difficult to produce mono-energetic projectiles in a temperature and density gradient-free dense plasma and precisely measure energy losses. Such measurements remain sparse in the highdimensional space of projectile energy, projectile charge, density, temperature, and target material. For example, we are not aware of any such precision measurements of moderate-energy ions in warm dense matter.

To elucidate the many dependencies in the large parameter space, we plot several common stopping power models, varying only one parameter at a time. Note, we have simplified matters by doing this exercise for the uniform electron gas (no ions, nor bound electrons), which differs from the full test problems of this workshop. How to treat bound electrons is a further complicating feature of warm dense matter and an active area of research which increases the uncertainty of stopping power in that regime. For this exercise, we focus on alpha particle stopping in hot dense matter. In particular, the conditions are: the projectile charge, $Z=2$, electron number density, $n_{e}=10^{25} \mathrm{~cm}^{-3}$, electron temperature, $T=1 \mathrm{keV}$, and projectile energy, $E_{p}=3.5 \mathrm{MeV}$. About this common point, one of these four parameters is varied in Figs. 11-14. We show six models: that of Li and Petrasso (LP) [172], including the relatively recent erratum [173], that of Brown, Preston, and Singleton (BPS) [39], that of Maynard and Deutsch (M\&D) [174], Zimmerman's fit to that model (ZMD) [175], the Zwicknagel model (Z) [101], and the quantum mechanical version of the Gould and DeWitt model (qGD) [176]. The LP model is derived from weakly coupled plasma theory and includes higher order terms in the Coulomb logarithm. However, this Coulomb logarithm is given as an ad hoc expression, only valid at weak coupling. The BPS model uses dimensional continuation analysis to get the weakly coupled, non-degenerate limit accurate to sub-leading order in $g=Z e^{2} /(\lambda T)$, where $\lambda$ is the screen-

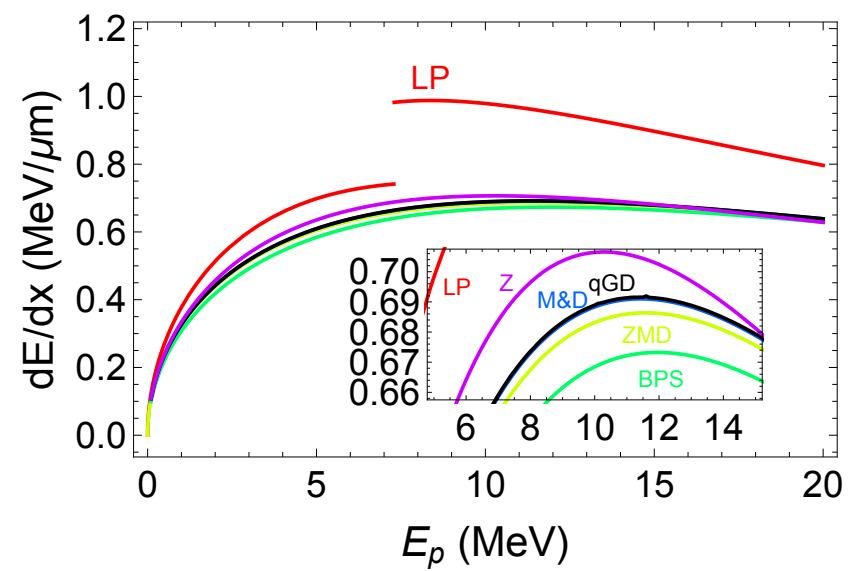

Figure 11: Stopping power of an alpha particle in a uniform electron gas as a function of projectile energy at $n_{e}=10^{25} \mathrm{~cm}^{-3}$ and $T=1 \mathrm{keV}$ for the LiPetrasso (LP) [172], Zwicknagel (Z) [101], Brown-Preston-Singleton (BPS) [39], the quantum Gould-DeWitt (qGD) [176], Maynard-Deutsch (M\&D) [174], and Zimmerman's fit to Maynard-Deutsch (ZMD) [175] models . At these weakly coupled conditions, all models shown accurately produce the high energy limit (with LP doing so by adding a step function correction for higher energies). Two models, M\&D and qGD are indistinguishable, indicating that strong scattering effects are negligible at these conditions.

ing length. The M\&D model depends on linear response theory (small $Z$ ) and the random phase approximation (weak coupling), but can handle any degeneracy. The $\mathrm{Z}$ model starts with a T-Matrix description, but artificially accounts for dynamic screening and plasmon excitations by multiplying the screening length by $\sqrt{1+v^{2} / v_{t h}^{2}}$ in the cross section calculation. This gives the Bohr limit at high energies, but is inaccurate when quantum diffraction is important (the de Broglie wavelength is greater that the classical distance of closest approach). The qGD model adds together the M\&D model with a T-matrix (strong scattering) model (the latter is limited to static screening) and subtracts the statically screened version of M\&D so as to not double count (this model is accurate to at least the same order as BPS, but is valid for all degeneracies),

In Fig. 11, we show the dependence of stopping power on energy. At low energies, the plasma exerts a drag force proportional to the velocity. At high energies, the plasma does not have time to react to the projectile and so the stopping decreases. The Bragg peak, where the projectile velocity is roughly the thermal velocity of the target electrons, is when the stopping is maximized. We see the the LP model stands out by having a discontinuity near the Bragg peak due to it adding a correction term to get the high energy limit, which is multiplied by a Heaviside function. This behavior causes it to overestimate the stopping around the peak. The other models agree with one another within $6 \%$ in this weakly coupled regime.

Figure 12 shows the temperature dependence of the models. Since they are all built around the weakly coupled limit, they agree at high temperatures. At low temperatures, we enter the high energy regime $\left(E_{p} \gg T_{e}\right)$. The correct behavior is that the cold value (which is finite) should be approached. However, the $\mathrm{Z}$ and LP models diverge because they incorrectly include the classical distance of closest approach instead of the de Broglie 


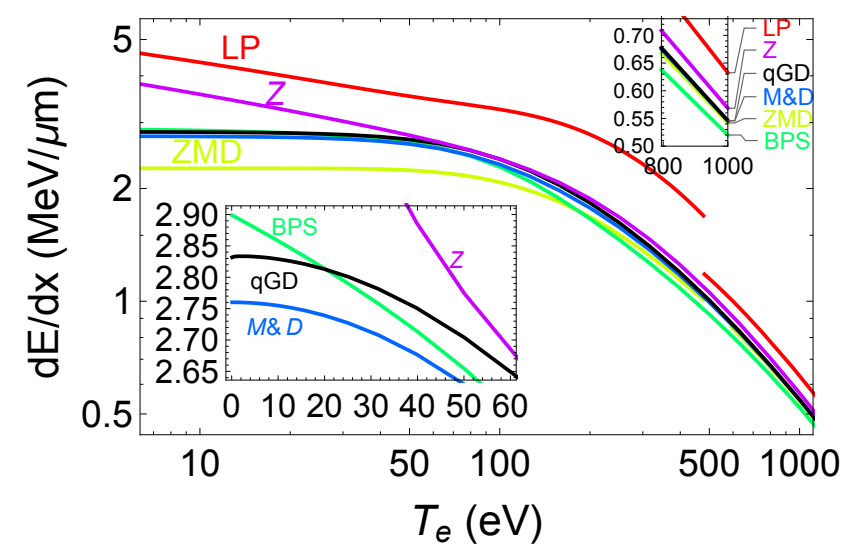

Figure 12: Same as Fig. 11 but fixing the energy at $3.5 \mathrm{MeV}$ and varying the temperature. We see that the $\mathrm{Z}$ model as incorrect behavior at low temperature and Zimmermans fit (ZMD) is off by about $18 \%$ with respect to M\&D in this limit.

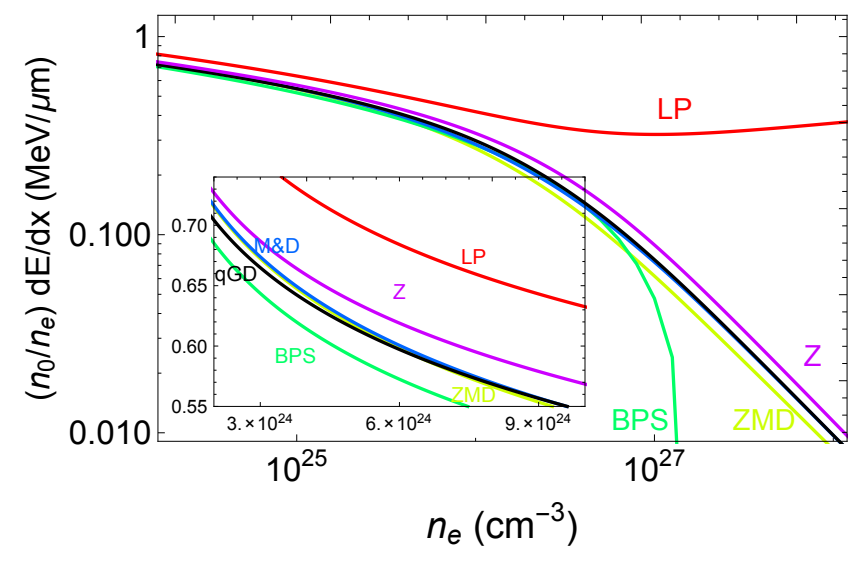

Figure 13: Same as Fig. 11 but fixing the energy at $3.5 \mathrm{MeV}$, varying the electron density, and scaling the stopping power by $n_{0} / n_{e}$, where $n_{0}=10^{25} \mathrm{~cm}^{-3}$. We see that neither BPS nor LP have the correct high density limit since they do not model electron degeneracy.

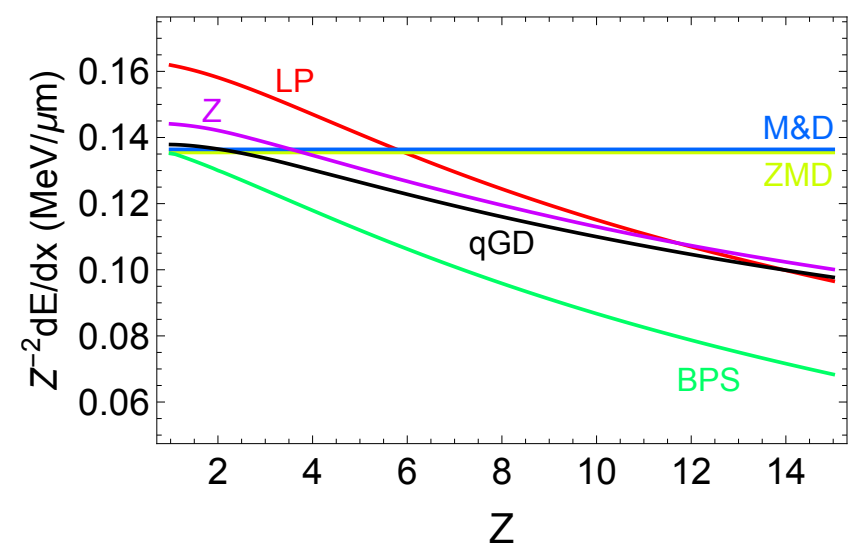

Figure 14: Same as Fig. 11 but fixing the energy at $3.5 \mathrm{MeV}$, varying the alpha particle's charge while keeping the mass fixed, and scaling the stopping power by $Z^{-2}$. Linear models like M\&D and ZMD are unable to capture the strong scattering physics that becomes more important at high $Z$. wavelength in this limit. Also, at low temperatures, Zimmerman's fit can differ from M\&D, although not catastrophically so. For example in Fig. 12, the difference is about $18 \%$.

We also plot the dependence of stopping on density in Fig. 13. We see that the stopping per target electron decreases with density since screening becomes stronger. The differences amongst models that include degeneracy and those that do not also becomes apparent (Note, that although the absolute difference is small in the plot, the relative difference is $34 \%$ at $n_{e}=10^{27} \mathrm{~cm}^{-3}$.

The last parameter to vary is the charge of the projectile, which is shown in Fig. 14. This distinguishes the linear response models (M\&D and ZMD) from those which account for strong scattering. We see that this effect is insignificant for alpha particles or other common fusion products.

All of the above variations are valid for a fully ionized plasma. However, there are often larger uncertainties when there is a partially ionized plasma state. There are two common approaches: mixing a bound electron stopping model (usually fit to cold data [105]) and one of the uniform electron gas models above via a value of the mean ionization, $\bar{Z}$, and the local density approximation (LDA). Both of these methods require some knowledge of the electronic state, either in $\bar{Z}$ or the electron density. Such quantities are acquired via a self-consistent electronic structure calculation (e.g. density functional theory). Zimmerman's model [175] is an example of the first approach; however, it does not give any opinion on what to use for $\bar{Z}$. One option is to use values from More's fit to the electron density at the ion-sphere radius of a Thomas-Fermi atom [57] or from a more sophisticated equation-of-state code like Purgatorio [177, 178, 135], which outputs the total number of electrons with positive energy per atom, but the best practice is to use a $\bar{Z}$ designed for the observable of interest. The one approximation used in warm dense matter for stopping power is the local density approximation (LDA):

$$
\begin{aligned}
\left(\frac{d E}{d x}\right)_{L D A}[n(\mathbf{r})] & =\frac{Z^{2} e^{2} \omega_{p}^{2}}{v^{2}} L_{L D A}[n(\mathbf{r})], \\
L_{L D A}[n(\mathbf{r})] & =\frac{\int d \mathbf{r} n(\mathbf{r}) L_{u n i f}(n(\mathbf{r}))}{\int d \mathbf{r} n(\mathbf{r})},
\end{aligned}
$$

where the dependencies on energy and temperature are suppressed for clarity, the brackets indicate a functional dependence, the integration is done over a microscopic computational domain (usually either an average atom or a box containing some tens to hundreds of atoms), $\omega_{p}^{2}=4 \pi n_{e} / m_{e}$, $n_{e}$ is the volume-averaged electron density, $(d E / d x)_{\text {unif }}=$ $Z^{2} e^{2} \omega_{p}^{2} L_{\text {unif }}(n) / v^{2}$ is the the fully ionized uniform electron gas stopping power (approximations to which were shown in the Figs. 11-14), and $v$ is the projectile velocity. This equation allows us to define a LDA approximation to $\bar{Z}$ via

$$
L_{L D A}[n(\mathbf{r})]=L_{u n i f}\left(\frac{\bar{Z}}{N_{I}} \sum_{i} n_{i}\right),
$$

where the sum is over all $N_{I}$ ion species. Here, for computational speed, we use the ZMD model [175] of the free electron 
stopping number for $L_{\text {unif }}$ on both sides of the equation. The three predictions of $\bar{Z}$ are shown in Fig. 15 for a pure carbon target as a function of temperature for different densities. At low to moderate densities $(\lesssim 10 \mathrm{~g} / \mathrm{cc})$ and low to moderate temperatures $(\lesssim 100 \mathrm{eV})$, the differences between models becomes large. Furthermore, the LDA model is dependent on the projectile energy, while the other models are independent. The accuracy of the LDA model over much of this large parameter space is still largely untested and unknown.

Finally, we show the results of the code comparison workshop. We note that we did not study variations in the ion component of stopping nor different models for the charge state of the projectile, both of which can lead to further uncertainties. In order to avoid plotting results that span many orders of magnitude and to emphasize variations amongst the models, we plot the relative differences between the submitted results and the full Zimmerman model [175] (including bound electrons) using More's fit [57] to $\bar{Z}$ in Figs. 16 and 17 for hydrogen and carbon, respectively (no results were submitted for the mixed $\mathrm{CH}$ case). Almost all submissions were in the average atom category and proceed to make the same local density approximation to account for the inhomogeneous electron density around each ion. So we warn the readers that the variations should be taken as a lower bound for the uncertainty. The greatest variations are seen at low energy and temperature and high densities. Only the BPS submission attempted to model the ion component of the stopping, which is important at the lower energies and high temperatures, so for consistency with the majority that part of the Zimmerman model was removed, even though it is more physical to include it. The outlier at high energies is actually more accurate since there relativistic and Bremsstrahlung effects become more important.

\section{Conclusions and Future Workshops}

We have reported on the results of an inaugural chargeparticle transport workshop, which aimed to assess variations among model predictions for electronic and ionic transport coefficients and velocity-resolved stopping powers. As summarized in Figs. 6-10, 16, and 17, we find significant variation (factors of three or more) for all properties among models that represent the range of available theoretical methods, including the values actually used in the hydrodynamic simulations to design and interpret data from ICF experiments. Agreement among models was generally higher in the classical weakly coupled regime. At low temperatures and densities, uncertainties in the ionization state were the major source of disagreement. For most transport coefficients, typical best-case variations among codes were $20 \%$ in the weakly coupled regime, factors of two in warm dense matter, and worsening to factors of ten or more at low temperatures. It is currently not known what the consequences of such uncertainties are, and further integrated modeling of a wide range of experiments is warranted. However, we emphasize that when conduction or diffusion is small, other terms in the hydrodynamic equations will dominate. The result of this workshop may help inform sensitivity studies that would ultimately quantify how important these variations are.
It is important to note that this workshop was not intended to identify the "best" models. Many of the methods have acknowledged deficiencies or become intractable in some regimes. Rather, the workshop aimed to establish a baseline for model comparison, survey the state-of-the art for a range of modeling approaches and plasma regimes, provide initial estimates of plausible variations to inform sensitivity studies, and begin to identify the important physics that must be included in reliable transport calculations. Future workshops would benefit from broader community participation and could examine in more detail the model assumptions, exploring quantities like interionic and electron-ion potentials, structure factors, and collision cross sections for a more limited set of cases and may eventually expand to include non-equilibrium and high-field effects. The results from this and any future workshops will help to assess uncertainties in hydrodynamic modeling and establish a foundation for reliable transport calculations. Ultimately, uncertainties and model variations in transport, equation of state [2], and radiative properties [10] can be rigorously combined to limit as much as possible the potential for inconsistency and offsetting errors.

\section{Acknowledgements}

We thank Sandia National Labs for hosting the workshop and Steve Haan for providing helpful guidance. SBH was supported by the U.S. Department of Energy, Office of Science Early Career Research Program, Office of Fusion Energy Sciences under Grant No. FWP-14-017426. This work was performed under the auspices of the U.S. Department of Energy by Sandia National Laboratories is managed and operated by NTESS under DOE NNSA contract DE-NA0003525, Lawrence Livermore National Laboratory under Contract DEAC52-07NA27344, and Los Alamos National Laboratory under Contract No. 89233218NCA000001.

\section{Appendix A. Submitted Data}

For completeness, we are including much of the raw data submitted to the workshop in Tab. A.3. Some attendees wished to not make their submissions public, and so those are not included in the table. It is hoped that the data below will help the community further quantify the range of reasonable values of transport coefficients for a variety of conditions. Brief descriptions of and references for the methods can be found in Tab. 2. However, we encourage researchers to directly contact submitters for details of their calculations. 


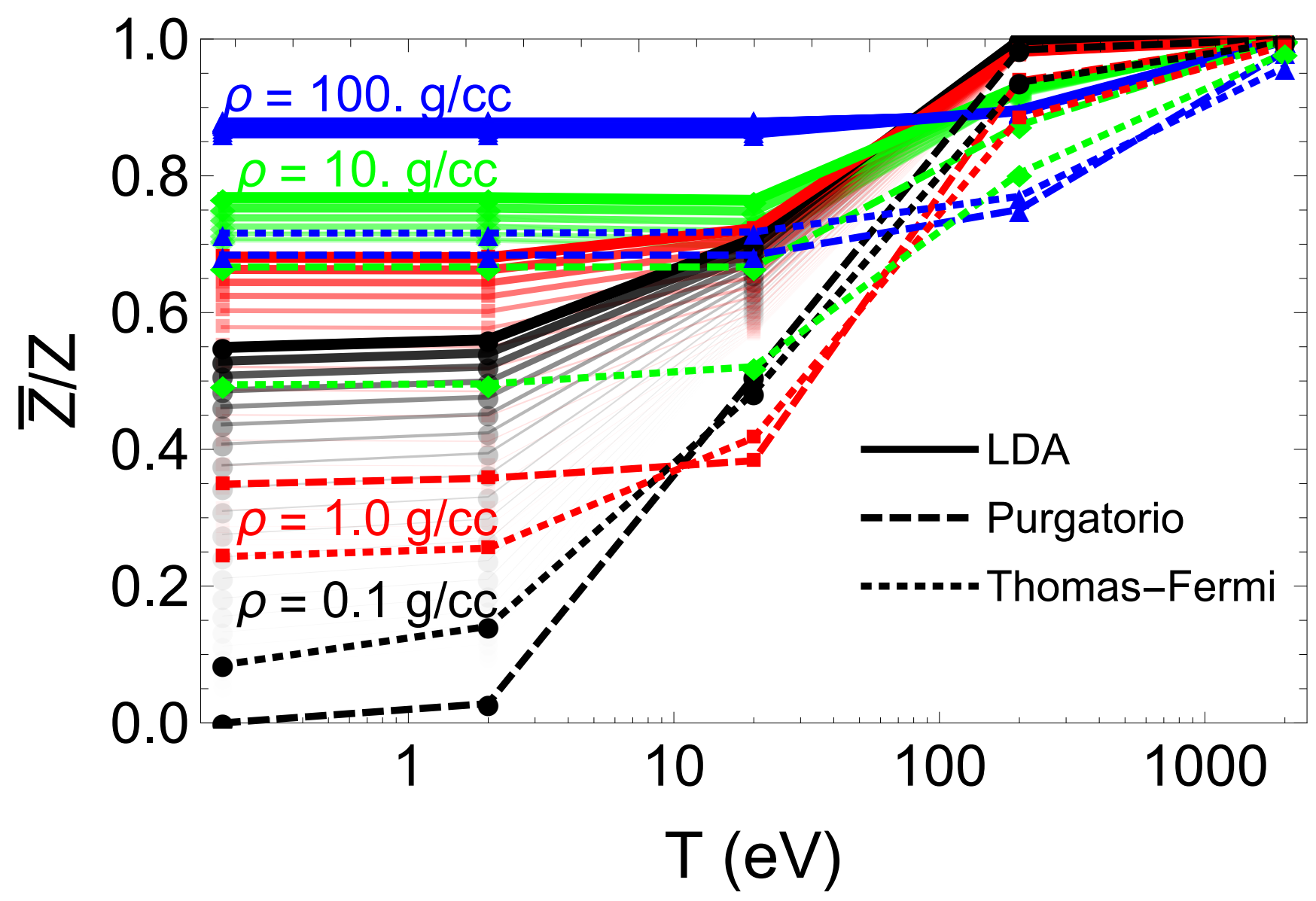

Figure 15: Different $\bar{Z}$ models for a pure carbon target: the stopping power local density approximation (LDA) using Purgatorio's density and the Zimmerman model for free electrons, Purgatorio, an average atom density functional theory code with $\bar{Z}$ calculated from the positive energy electrons, and More's fit to an average atom Thomas-Fermi model. The LDA prediction is not only a function of density and temperature but also the projectile energy. The uppermost curve of each family is for an alpha particle with $E=3.5 \mathrm{MeV}$ and the bottommost and faintest curve is for $E=500 \mathrm{eV}$. Each line is evenly spaced on a logarithmic scale. 


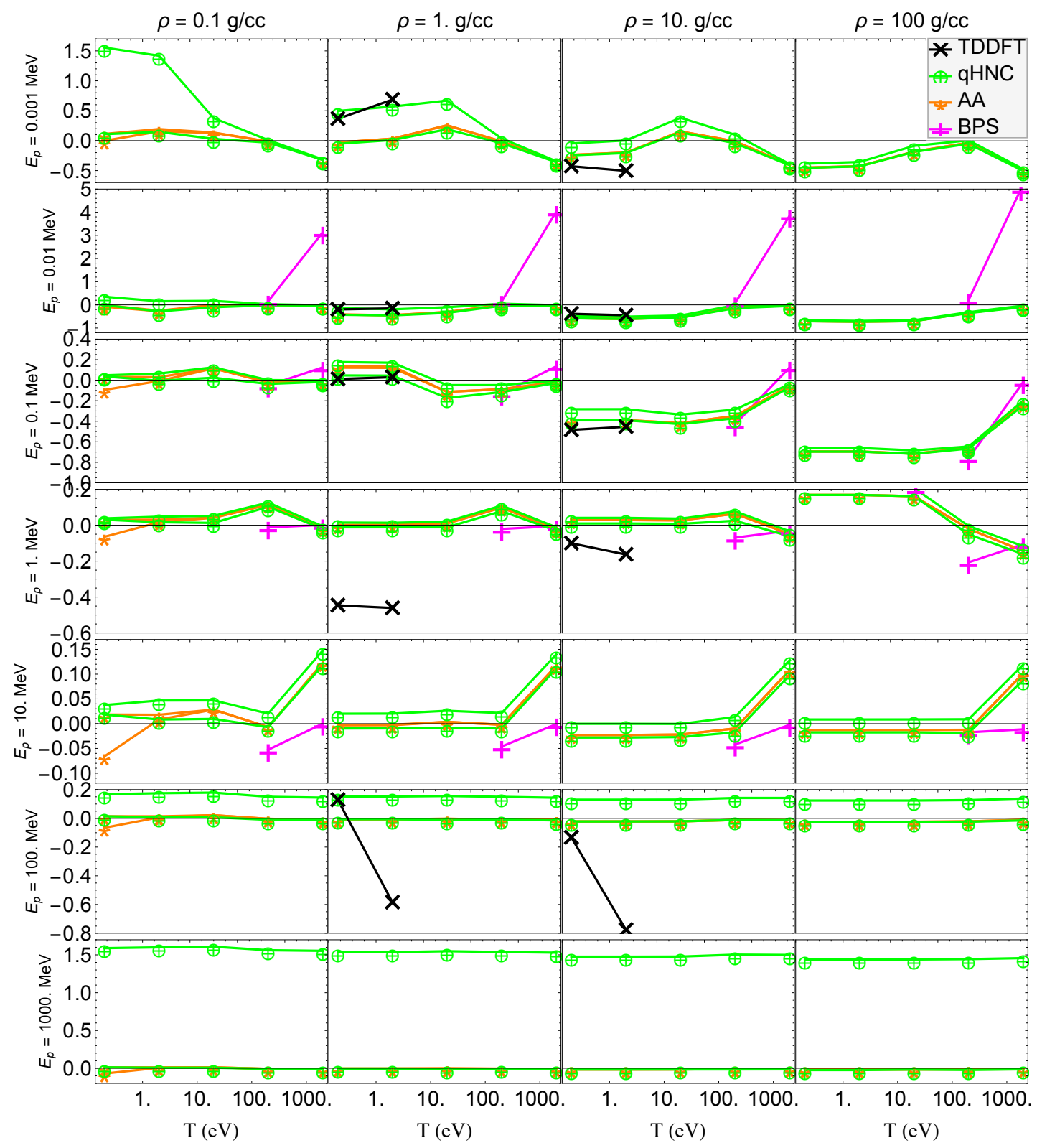

Figure 16: Fractional difference between the electron component of stopping power models and Zimmerman's bound plus free fits [175]. Curves are TDDFT (black), BPS (magenta), and various average atom (dashed green) and pseudo-neutral atom (solid green) implementations. At low energies and high temperatures, the BPS model includes the ion contribution to the stopping, while the other models do not. Likewise, the outlier at high energies is actually more accurate since there relativistic and Bremsstrahlung effects become more important. 


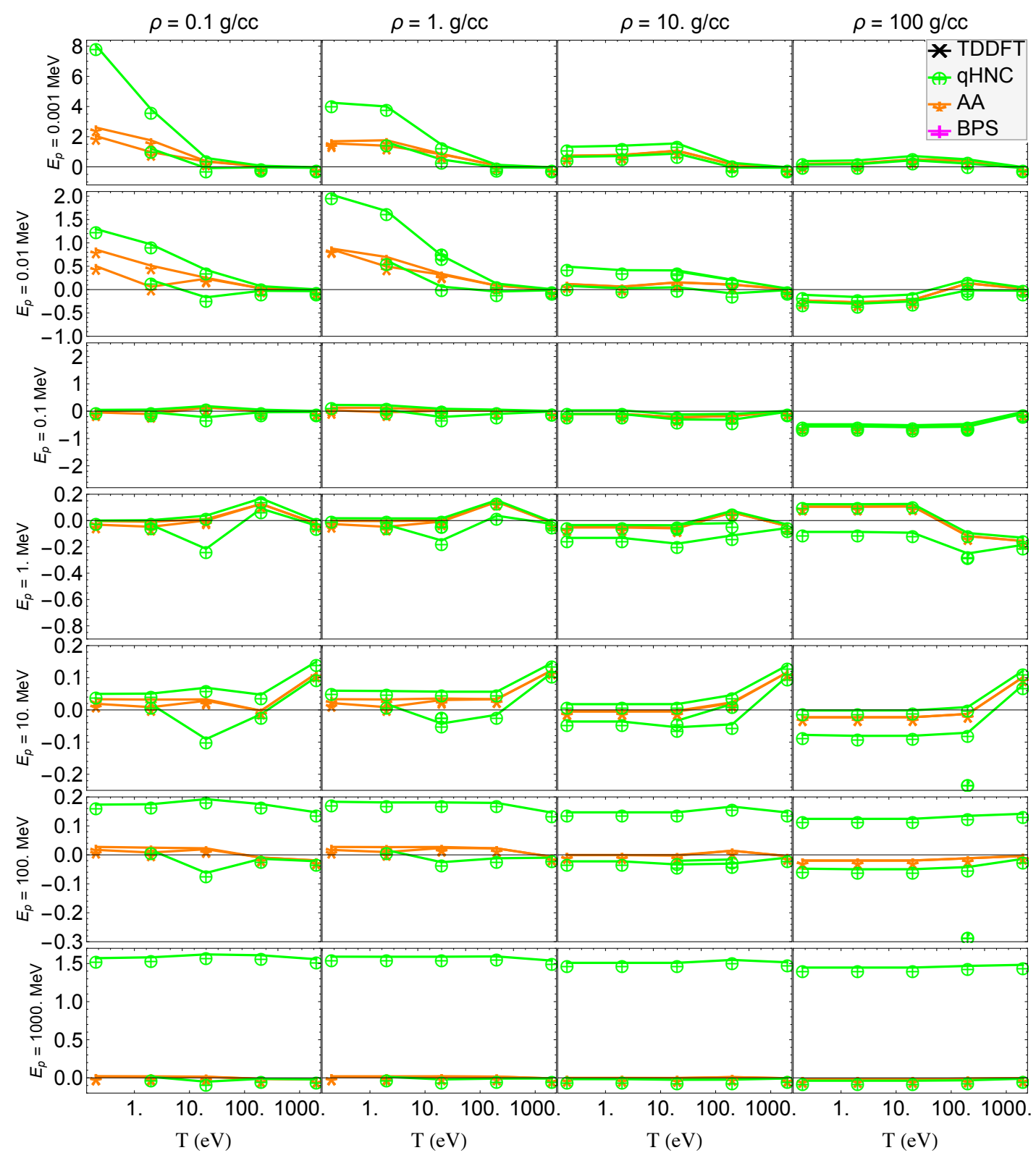

Figure 17: Same as Fig. 16 but for carbon. 
Table A.3: Submitted data to the charged particle transport workshop. The columns are the name of the submitter with short descriptor or reference to differentiate multiple submissions from the same person (see Tab. 2 for more information), the case written as $\mathrm{H}$ for hydrogen, $\mathrm{C}$ for carbon, or $\mathrm{CH}$ for the carbon-hydrogen mixture followed by two numbers (the first is an index for the density in the set $\{0.1,1,10,100\} \mathrm{g} / \mathrm{cm}^{3}$ and the second is an index for the temperature in the set $\{0.2,2,20,200,2000\}$ $\mathrm{eV}$ - for example, $\mathrm{C} 21$ refers to the carbon case at $1 \mathrm{~g} / \mathrm{cm}^{3}$ and $0.2 \mathrm{eV}$ ), electrical conductivity, thermal conductivity, viscosity, diffusion coefficient (self diffusion for the pure substances and inter-diffusion for the mixture), and stopping power at seven different projectile energies. We note that since the 2016 workshop, the values reported here for Starrett and Saumon have been superseded by the updated model in Ref [52].

\begin{tabular}{|c|c|c|c|c|c|c|c|c|c|c|c|c|}
\hline \multirow[t]{2}{*}{ Submitter } & \multirow[t]{2}{*}{ Case } & \multirow{2}{*}{$\begin{array}{c}\sigma \\
1 /(\Omega \mathrm{cm})\end{array}$} & \multirow{2}{*}{$\begin{array}{c}\kappa \\
\mathrm{erg} /(\mathrm{s} \mathrm{cm} \mathrm{K})\end{array}$} & \multirow{2}{*}{$\begin{array}{c}\eta \\
\mathrm{g} /(\mathrm{s} \mathrm{cm})\end{array}$} & \multirow{2}{*}{$\begin{array}{c}D \\
\mathrm{~cm}^{2} / \mathrm{s} \\
\end{array}$} & \multicolumn{7}{|c|}{$d E / d x(\mathrm{eV} / \mathrm{cm})$} \\
\hline & & & & & & $1 \mathrm{keV}$ & $10 \mathrm{keV}$ & $100 \mathrm{keV}$ & $1 \mathrm{MeV}$ & $10 \mathrm{MeV}$ & $100 \mathrm{MeV}$ & $1 \mathrm{GeV}$ \\
\hline Clérouin (PIJ) & H11 & $1.61 \mathrm{e} 3$ & $9.13 \mathrm{e} 5$ & $4.09 \mathrm{e}-4$ & 0.00511 & & & & & & & \\
\hline Hansen (Bemuze) & H11 & & & & & $8.37 \mathrm{e} 7$ & $4.11 \mathrm{e} 8$ & $3.86 \mathrm{e} 8$ & $7.33 \mathrm{e} 7$ & $1.06 \mathrm{e} 7$ & $1.39 \mathrm{e} 6$ & $1.72 \mathrm{e} 5$ \\
\hline Hansen (Muze-k) & H11 & $1.41 \mathrm{e} 3$ & $7.81 \mathrm{e} 5$ & & & $8.4 \mathrm{e} 7$ & $4.09 \mathrm{e} 8$ & $3.85 \mathrm{e} 8$ & $7.33 \mathrm{e} 7$ & $1.06 \mathrm{e} 7$ & $1.39 \mathrm{e} 6$ & $1.72 \mathrm{e} 5$ \\
\hline Hansen (Muze-s) & H11 & $2.65 \mathrm{e}-8$ & $1.82 \mathrm{e}-5$ & & & $7.54 \mathrm{e} 7$ & $3.81 \mathrm{e} 8$ & $3.37 \mathrm{e} 8$ & $6.65 \mathrm{e} 7$ & $9.72 \mathrm{e} 6$ & $1.28 \mathrm{e} 6$ & $1.58 \mathrm{e} 5$ \\
\hline Haxhimali, Rudd & H11 & & & $6.17 \mathrm{e}-4$ & & & & & & & & \\
\hline Copeland [28] & H11 & & & 0.0234 & 0.14 & & & & & & & \\
\hline Copeland [30] & H11 & & & $1.75 \mathrm{e}-4$ & 0.00285 & & & & & & & \\
\hline Copeland [31] & H11 & & & $6.10 \mathrm{e}-4$ & 0.00966 & & & & & & & \\
\hline Kang, Dai (QE) & H11 & $2.36 \mathrm{e}-5$ & & $1.16 \mathrm{e}-4$ & 0.00422 & & & & & & & \\
\hline Copeland [29] & H11 & 493. & $2.81 \mathrm{e} 5$ & & & & & & & & & \\
\hline Clérouin (PIJ) & $\mathrm{H} 12$ & 854. & $4.66 \mathrm{e} 6$ & 0.00383 & 0.0701 & & & & & & & \\
\hline Hansen (Bemuze) & $\mathrm{H} 12$ & 58. & $3.45 \mathrm{e} 5$ & & & $7.87 \mathrm{e} 7$ & $2.92 \mathrm{e} 8$ & $3.69 \mathrm{e} 8$ & $7.23 \mathrm{e} 7$ & $1.05 \mathrm{e} 7$ & $1.38 \mathrm{e} 6$ & $1.71 \mathrm{e} 5$ \\
\hline Hansen (Muze-k) & $\mathrm{H} 12$ & 260. & $1.31 \mathrm{e} 6$ & & & $8.19 \mathrm{e} 7$ & $3.05 \mathrm{e} 8$ & $3.82 \mathrm{e} 8$ & $7.33 \mathrm{e} 7$ & $1.06 \mathrm{e} 7$ & $1.39 \mathrm{e} 6$ & $1.72 \mathrm{e} 5$ \\
\hline Hansen (Muze-s) & $\mathrm{H} 12$ & 331. & $1.61 \mathrm{e} 6$ & & & $7.91 \mathrm{e} 7$ & $2.95 \mathrm{e} 8$ & $3.68 \mathrm{e} 8$ & $7.23 \mathrm{e} 7$ & $1.05 \mathrm{e} 7$ & $1.38 \mathrm{e} 6$ & $1.71 \mathrm{e} 5$ \\
\hline Haxhimali, Rudd & H12 & & & 0.00613 & & & & & & & & \\
\hline Copeland [28] & $\mathrm{H} 12$ & & & 0.0127 & 0.076 & & & & & & & \\
\hline Copeland [30] & $\mathrm{H} 12$ & & & 0.00425 & 0.0686 & & & & & & & \\
\hline Copeland [31] & $\mathrm{H} 12$ & & & 0.00957 & 0.157 & & & & & & & \\
\hline Hou (AAHNC) & $\mathrm{H} 12$ & & & 0.0026 & 0.049 & & & & & & & \\
\hline Kang, Dai (QE) & $\mathrm{H} 12$ & 552. & & $8.07 e-6$ & 0.148 & & & & & & & \\
\hline Copeland [29] & H12 & $1.32 \mathrm{e} 3$ & $4.69 \mathrm{e} 6$ & & & & & & & & & \\
\hline Clérouin (PIJ) & H13 & $8.57 \mathrm{e} 3$ & $2.31 \mathrm{e} 8$ & 0.055 & 0.893 & & & & & & & \\
\hline Hansen (Bemuze) & $\mathrm{H} 13$ & $7.85 \mathrm{e} 3$ & $2.58 \mathrm{e} 8$ & & & $4.47 \mathrm{e} 7$ & $1.35 \mathrm{e} 8$ & $3.02 \mathrm{e} 8$ & $7.43 \mathrm{e} 7$ & $1.08 \mathrm{e} 7$ & $1.41 \mathrm{e} 6$ & $1.74 \mathrm{e} 5$ \\
\hline Hansen (Muze-k) & $\mathrm{H} 13$ & $9.25 \mathrm{e} 3$ & $2.81 \mathrm{e} 8$ & & & $4.93 \mathrm{e} 7$ & $1.49 \mathrm{e} 8$ & $3.29 \mathrm{e} 8$ & $7.65 \mathrm{e} 7$ & $1.1 \mathrm{e} 7$ & $1.43 \mathrm{e} 6$ & $1.75 \mathrm{e} 5$ \\
\hline Hansen (Muze-s) & $\mathrm{H} 13$ & $8.63 \mathrm{e} 3$ & $2.72 \mathrm{e} 8$ & & & $4.91 \mathrm{e} 7$ & $1.49 \mathrm{e} 8$ & $3.29 \mathrm{e} 8$ & $7.64 \mathrm{e} 7$ & $1.1 \mathrm{e} 7$ & $1.43 \mathrm{e} 6$ & $1.75 \mathrm{e} 5$ \\
\hline Haxhimali, Rudd & H13 & & & 0.0683 & & & & & & & & \\
\hline
\end{tabular}

Continued on next page 
Table A.3 - continued from previous page

\begin{tabular}{|c|c|c|c|c|c|c|c|c|c|c|c|c|}
\hline \multirow[t]{2}{*}{ Submitter } & \multirow[t]{2}{*}{ Case } & \multirow{2}{*}{$\begin{array}{c}\sigma \\
1 /(\Omega \mathrm{cm})\end{array}$} & \multirow{2}{*}{$\begin{array}{c}\kappa \\
\mathrm{erg} /(\mathrm{s} \mathrm{cm} \mathrm{K})\end{array}$} & \multirow{2}{*}{$\begin{array}{c}\eta \\
\mathrm{g} /(\mathrm{s} \mathrm{cm})\end{array}$} & \multirow{2}{*}{$\begin{array}{c}D \\
\mathrm{~cm}^{2} / \mathrm{s}\end{array}$} & \multicolumn{7}{|c|}{$d E / d x(\mathrm{eV} / \mathrm{cm})$} \\
\hline & & & & & & $1 \mathrm{keV}$ & $10 \mathrm{keV}$ & $100 \mathrm{keV}$ & $1 \mathrm{MeV}$ & $10 \mathrm{MeV}$ & $100 \mathrm{MeV}$ & $1 \mathrm{GeV}$ \\
\hline Copeland [28] & H13 & & & 0.0957 & 0.574 & & & & & & & \\
\hline Copeland [30] & $\mathrm{H} 13$ & & & 0.0723 & 1.11 & & & & & & & \\
\hline Copeland [31] & H13 & & & 0.0827 & 1.29 & & & & & & & \\
\hline Hou (AAHNC) & $\mathrm{H} 13$ & & & 0.026 & 0.507 & & & & & & & \\
\hline Copeland [29] & H13 & $1.75 \mathrm{e} 4$ & $1.68 \mathrm{e} 8$ & & & & & & & & & \\
\hline Hayes & H14 & & & & & & $1.82 \mathrm{e} 7$ & $4.36 \mathrm{e} 7$ & $5.87 \mathrm{e} 7$ & $1.04 \mathrm{e} 7$ & & \\
\hline Clérouin (PIJ) & H14 & $1.32 \mathrm{e} 5$ & $3.62 \mathrm{e} 10$ & 4.04 & 49.8 & & & & & & & \\
\hline Hansen (Bemuze) & $\mathrm{H} 14$ & $1.37 \mathrm{e} 5$ & $3.91 \mathrm{e} 10$ & & & $4.96 \mathrm{e} 6$ & $1.55 \mathrm{e} 7$ & $4.43 \mathrm{e} 7$ & $6.55 \mathrm{e} 7$ & $1.09 \mathrm{e} 7$ & $1.42 \mathrm{e} 6$ & $1.75 \mathrm{e} 5$ \\
\hline Hansen (Muze-k) & H14 & $1.52 \mathrm{e} 5$ & $4.08 \mathrm{e} 10$ & & & $5.05 \mathrm{e} 6$ & $1.58 \mathrm{e} 7$ & $4.5 \mathrm{e} 7$ & $6.62 \mathrm{e} 7$ & $1.09 \mathrm{e} 7$ & $1.43 \mathrm{e} 6$ & $1.75 \mathrm{e} 5$ \\
\hline Hansen (Muze-s) & $\mathrm{H} 14$ & $1.49 \mathrm{e} 5$ & $4.05 \mathrm{e} 10$ & & & $5.05 \mathrm{e} 6$ & $1.58 \mathrm{e} 7$ & $4.5 \mathrm{e} 7$ & $6.62 \mathrm{e} 7$ & $1.09 \mathrm{e} 7$ & $1.43 \mathrm{e} 6$ & $1.75 \mathrm{e} 5$ \\
\hline Haxhimali, Rudd & H14 & & & 4.11 & & & & & & & & \\
\hline Copeland [28] & H14 & & & 6.51 & 39.1 & & & & & & & \\
\hline Copeland [30] & H14 & & & 4.24 & 57.2 & & & & & & & \\
\hline Copeland [31] & $\mathrm{H} 14$ & & & 4.23 & 58.4 & & & & & & & \\
\hline Hou (AAHNC) & H14 & & & 0.106 & 2.17 & & & & & & & \\
\hline Copeland [29] & $\mathrm{H} 14$ & $2.37 \mathrm{e} 5$ & $2.12 \mathrm{e} 10$ & & & & & & & & & \\
\hline Hayes & H15 & & & & & & $3.61 \mathrm{e} 6$ & $3.03 \mathrm{e} 6$ & $7.6 \mathrm{e} 6$ & $8.8 \mathrm{e} 6$ & & \\
\hline Clérouin (PIJ) & H15 & $2.68 \mathrm{e} 6$ & $7.26 \mathrm{e} 12$ & 704. & $8.69 \mathrm{e} 3$ & & & & & & & \\
\hline Hansen (Bemuze) & H15 & $2.86 \mathrm{e} 6$ & $7.88 \mathrm{e} 12$ & & & $2.69 \mathrm{e} 5$ & $8.49 \mathrm{e} 5$ & $2.65 \mathrm{e} 6$ & $7.43 \mathrm{e} 6$ & $9.84 \mathrm{e} 6$ & $1.42 \mathrm{e} 6$ & $1.75 \mathrm{e} 5$ \\
\hline Hansen (Muze-k) & H15 & $2.98 \mathrm{e} 6$ & 8.e12 & & & $2.7 \mathrm{e} 5$ & $8.53 \mathrm{e} 5$ & $2.66 \mathrm{e} 6$ & $7.47 \mathrm{e} 6$ & $9.88 \mathrm{e} 6$ & $1.42 \mathrm{e} 6$ & $1.75 \mathrm{e} 5$ \\
\hline Hansen (Muze-s) & H15 & $2.95 \mathrm{e} 6$ & $7.97 \mathrm{e} 12$ & & & $2.7 \mathrm{e} 5$ & $8.53 \mathrm{e} 5$ & $2.66 \mathrm{e} 6$ & $7.47 \mathrm{e} 6$ & $9.88 \mathrm{e} 6$ & $1.42 \mathrm{e} 6$ & $1.75 \mathrm{e} 5$ \\
\hline Haxhimali, Rudd & H15 & & & 673. & & & & & & & & \\
\hline Copeland [28] & H15 & & & $1.17 \mathrm{e} 3$ & 7.e3 & & & & & & & \\
\hline Copeland [30] & H15 & & & 677. & $8.57 \mathrm{e} 3$ & & & & & & & \\
\hline Copeland [31] & H15 & & & 681. & $8.82 \mathrm{e} 3$ & & & & & & & \\
\hline Copeland [29] & H15 & $4.69 \mathrm{e} 6$ & $4.2 \mathrm{e} 12$ & & & & & & & & & \\
\hline Clérouin (PIJ) & $\mathrm{H} 21$ & $2.62 \mathrm{e} 4$ & $1.49 \mathrm{e} 7$ & 0.00415 & $8.67 \mathrm{e}-4$ & & & & & & & \\
\hline Baczewski & $\mathrm{H} 21$ & & & & & $2.59 \mathrm{e} 8$ & $8.31 \mathrm{e} 8$ & $2.01 \mathrm{e} 9$ & $3.34 \mathrm{e} 8$ & $3.95 \mathrm{e} 7$ & $1.43 \mathrm{e} 7$ & \\
\hline Hansen (Bemuze) & $\mathrm{H} 21$ & $2.58 \mathrm{e} 4$ & $1.37 \mathrm{e} 7$ & & & $1.8 \mathrm{e} 8$ & $5.94 \mathrm{e} 8$ & $2.08 \mathrm{e} 9$ & $5.96 \mathrm{e} 8$ & $9.29 \mathrm{e} 7$ & $1.26 \mathrm{e} 7$ & $1.59 \mathrm{e} 6$ \\
\hline Hansen (Muze-k) & $\mathrm{H} 21$ & $2.84 \mathrm{e} 4$ & $1.5 \mathrm{e} 7$ & & & $1.84 \mathrm{e} 8$ & $6.04 \mathrm{e} 8$ & $2.26 \mathrm{e} 9$ & $6.04 \mathrm{e} 8$ & $9.36 \mathrm{e} 7$ & $1.26 \mathrm{e} 7$ & $1.59 \mathrm{e} 6$ \\
\hline Hansen (Muze-s) & $\mathrm{H} 21$ & $1.9 \mathrm{e} 4$ & $1.01 \mathrm{e} 7$ & & & $1.84 \mathrm{e} 8$ & $6.03 \mathrm{e} 8$ & $2.23 \mathrm{e} 9$ & $6.03 \mathrm{e} 8$ & $9.35 \mathrm{e} 7$ & $1.26 \mathrm{e} 7$ & $1.59 \mathrm{e} 6$ \\
\hline Clérouin (OFMD) & $\mathrm{H} 21$ & $2.38 \mathrm{e} 4$ & $1.35 \mathrm{e} 7$ & 0.025 & 0.00104 & & & & & & & \\
\hline Haxhimali, Rudd & $\mathrm{H} 21$ & & & 0.00259 & & & & & & & & \\
\hline Sjostrom (KSMD) & $\mathrm{H} 21$ & & & & 0.0016 & & & & & & & \\
\hline Sjostrom (SDMD) & $\mathrm{H} 21$ & $1.61 \mathrm{e} 4$ & $2.5 \mathrm{e} 7$ & & 0.00151 & & & & & & & \\
\hline Sjostrom (TFMD) & $\mathrm{H} 21$ & & & & 0.00108 & & & & & & & \\
\hline Copeland [28] & $\mathrm{H} 21$ & & & 0.406 & 0.244 & & & & & & & \\
\hline Copeland [30] & $\mathrm{H} 21$ & & & $2.97 \mathrm{e}-4$ & $4.71 \mathrm{e}-4$ & & & & & & & \\
\hline Copeland [31] & $\mathrm{H} 21$ & & & $8.34 \mathrm{e}-4$ & 0.00129 & & & & & & & \\
\hline
\end{tabular}


Table A.3 - continued from previous page

\begin{tabular}{|c|c|c|c|c|c|c|c|c|c|c|c|c|}
\hline \multirow[t]{2}{*}{ Submitter } & \multirow[t]{2}{*}{ Case } & \multirow{2}{*}{$\begin{array}{c}\sigma \\
1 /(\Omega \mathrm{cm})\end{array}$} & \multirow{2}{*}{$\begin{array}{c}\kappa \\
\mathrm{erg} /(\mathrm{s} \mathrm{cm} \mathrm{K})\end{array}$} & \multirow{2}{*}{$\begin{array}{c}\eta \\
\mathrm{g} /(\mathrm{s} \mathrm{cm})\end{array}$} & \multirow{2}{*}{$\begin{array}{c}D \\
\mathrm{~cm}^{2} / \mathrm{s}\end{array}$} & \multicolumn{7}{|c|}{$d E / d x(\mathrm{eV} / \mathrm{cm})$} \\
\hline & & & & & & $1 \mathrm{keV}$ & $10 \mathrm{keV}$ & $100 \mathrm{keV}$ & $1 \mathrm{MeV}$ & $10 \mathrm{MeV}$ & $100 \mathrm{MeV}$ & $1 \mathrm{GeV}$ \\
\hline Kang, Dai (QE) & $\mathrm{H} 21$ & $1.63 \mathrm{e} 4$ & & 0.00635 & 0.00161 & & & & & & & \\
\hline Copeland [29] & $\mathrm{H} 21$ & $4.8 \mathrm{e} 3$ & $2.72 \mathrm{e} 6$ & & & & & & & & & \\
\hline Clérouin (PIJ) & $\mathrm{H} 22$ & $1.31 \mathrm{e} 4$ & $7.41 \mathrm{e} 7$ & 0.00737 & 0.0108 & & & & & & & \\
\hline Baczewski & $\mathrm{H} 22$ & & & & & $3.02 \mathrm{e} 8$ & $9.26 \mathrm{e} 8$ & $2.04 \mathrm{e} 9$ & $3.25 \mathrm{e} 8$ & $4.02 \mathrm{e} 7$ & $5.26 \mathrm{e} 6$ & \\
\hline Hansen (Bemuze) & $\mathrm{H} 22$ & $9.05 \mathrm{e} 3$ & $4.8 \mathrm{e} 7$ & & & $1.81 \mathrm{e} 8$ & $5.95 \mathrm{e} 8$ & $2.07 \mathrm{e} 9$ & $5.96 \mathrm{e} 8$ & $9.29 \mathrm{e} 7$ & $1.26 \mathrm{e} 7$ & $1.59 \mathrm{e} 6$ \\
\hline Hansen (Muze-k) & $\mathrm{H} 22$ & $1.07 \mathrm{e} 4$ & $5.63 \mathrm{e} 7$ & & & $1.85 \mathrm{e} 8$ & $6.06 \mathrm{e} 8$ & $2.25 \mathrm{e} 9$ & $6.05 \mathrm{e} 8$ & $9.36 \mathrm{e} 7$ & $1.26 \mathrm{e} 7$ & $1.59 \mathrm{e} 6$ \\
\hline Hansen (Muze-s) & H22 & $7.41 \mathrm{e} 3$ & $3.96 \mathrm{e} 7$ & & & $1.85 \mathrm{e} 8$ & $6.04 \mathrm{e} 8$ & $2.22 \mathrm{e} 9$ & $6.04 \mathrm{e} 8$ & $9.35 \mathrm{e} 7$ & $1.26 \mathrm{e} 7$ & $1.59 \mathrm{e} 6$ \\
\hline Baalrud & $\mathrm{H} 22$ & & & 0.0082 & 0.012 & & & & & & & \\
\hline Clérouin (OFMD) & $\mathrm{H} 22$ & $1.28 \mathrm{e} 4$ & $7.25 \mathrm{e} 7$ & 0.01 & 0.012 & & & & & & & \\
\hline Daligault & $\mathrm{H} 22$ & & & 0.00857 & 0.0122 & & & & & & & \\
\hline Haxhimali, Rudd & $\mathrm{H} 22$ & & & 0.0109 & & & & & & & & \\
\hline Sjostrom (KSMD) & $\mathrm{H} 22$ & & & & 0.0155 & & & & & & & \\
\hline Sjostrom (SDMD) & $\mathrm{H} 22$ & $1.36 \mathrm{e} 4$ & $8.15 \mathrm{e} 7$ & & 0.0188 & & & & & & & \\
\hline Sjostrom (TFMD) & $\mathrm{H} 22$ & & & & 0.0129 & & & & & & & \\
\hline Copeland [28] & $\mathrm{H} 22$ & & & 0.131 & 0.0783 & & & & & & & \\
\hline Copeland [30] & $\mathrm{H} 22$ & & & 0.00457 & 0.0075 & & & & & & & \\
\hline Copeland [31] & $\mathrm{H} 22$ & & & 0.0106 & 0.0169 & & & & & & & \\
\hline Hou (AAHNC) & $\mathrm{H} 22$ & & & 0.006 & 0.01 & & & & & & & \\
\hline $\mathrm{Ma}(\mathrm{eFF})$ & $\mathrm{H} 22$ & $2.49 \mathrm{e} 3$ & & & & & & & & & & \\
\hline Kang, Dai (QE) & $\mathrm{H} 22$ & $1.33 \mathrm{e} 4$ & & $5.57 \mathrm{e}-4$ & 0.017 & & & & & & & \\
\hline Copeland [29] & $\mathrm{H} 22$ & $5.15 \mathrm{e} 3$ & $2.89 \mathrm{e} 7$ & & & & & & & & & \\
\hline Clérouin (PIJ) & $\mathrm{H} 23$ & $1.17 \mathrm{e} 4$ & $5.05 \mathrm{e} 8$ & 0.103 & 0.199 & & & & & & & \\
\hline Hansen (Bemuze) & $\mathrm{H} 23$ & $2.12 \mathrm{e} 4$ & $6.85 \mathrm{e} 8$ & & & $1.44 \mathrm{e} 8$ & $4.53 \mathrm{e} 8$ & $1.38 \mathrm{e} 9$ & $5.88 \mathrm{e} 8$ & $9.26 \mathrm{e} 7$ & $1.25 \mathrm{e} 7$ & $1.58 \mathrm{e} 6$ \\
\hline Hansen (Muze-k) & $\mathrm{H} 23$ & $2.23 \mathrm{e} 4$ & $7.02 \mathrm{e} 8$ & & & $1.52 \mathrm{e} 8$ & $4.8 \mathrm{e} 8$ & $1.48 \mathrm{e} 9$ & $6.01 \mathrm{e} 8$ & $9.37 \mathrm{e} 7$ & $1.26 \mathrm{e} 7$ & $1.59 \mathrm{e} 6$ \\
\hline Hansen (Muze-s) & $\mathrm{H} 23$ & $1.96 \mathrm{e} 4$ & $6.55 \mathrm{e} 8$ & & & $1.52 \mathrm{e} 8$ & $4.8 \mathrm{e} 8$ & $1.48 \mathrm{e} 9$ & $6.01 \mathrm{e} 8$ & $9.37 \mathrm{e} 7$ & $1.26 \mathrm{e} 7$ & $1.59 \mathrm{e} 6$ \\
\hline Baalrud & $\mathrm{H} 23$ & & & 0.11 & 0.168 & & & & & & & \\
\hline Daligault & $\mathrm{H} 23$ & & & 0.104 & 0.18 & & & & & & & \\
\hline Haxhimali, Rudd & $\mathrm{H} 23$ & & & 0.151 & & & & & & & & \\
\hline Sjostrom (SDMD) & $\mathrm{H} 23$ & $2.2 \mathrm{e} 4$ & $1.34 \mathrm{e} 9$ & & 0.305 & & & & & & & \\
\hline Sjostrom (TFMD) & $\mathrm{H} 23$ & & & & 0.238 & & & & & & & \\
\hline Starrett, Saumon & $\mathrm{H} 23$ & $2.4 \mathrm{e} 4$ & $6.87 \mathrm{e} 8$ & & & & & & & & & \\
\hline Copeland [28] & $\mathrm{H} 23$ & & & 0.22 & 0.132 & & & & & & & \\
\hline Copeland [30] & $\mathrm{H} 23$ & & & 0.141 & 0.224 & & & & & & & \\
\hline Copeland [31] & $\mathrm{H} 23$ & & & 0.201 & 0.32 & & & & & & & \\
\hline Hou (AAHNC) & $\mathrm{H} 23$ & & & 0.077 & 0.145 & & & & & & & \\
\hline $\mathrm{Ma}(\mathrm{eFF})$ & $\mathrm{H} 23$ & $1.66 \mathrm{e} 4$ & & & & & & & & & & \\
\hline Copeland [29] & $\mathrm{H} 23$ & $2.29 \mathrm{e} 4$ & $4.62 \mathrm{e} 8$ & & & & & & & & & \\
\hline Hayes & $\mathrm{H} 24$ & & & & & $1.65 \mathrm{e} 8$ & $1.18 \mathrm{e} 8$ & $2.84 \mathrm{e} 8$ & $4.44 \mathrm{e} 8$ & $8.9 \mathrm{e} 7$ & & \\
\hline Clérouin (PIJ) & $\mathrm{H} 24$ & $1.83 \mathrm{e} 5$ & $5.06 \mathrm{e} 10$ & 5.61 & 6.92 & & & & & & & \\
\hline
\end{tabular}


Table A.3 - continued from previous page

\begin{tabular}{|c|c|c|c|c|c|c|c|c|c|c|c|c|}
\hline \multirow[t]{2}{*}{ Submitter } & \multirow[t]{2}{*}{ Case } & \multirow{2}{*}{$\begin{array}{c}\sigma \\
1 /(\Omega \mathrm{cm})\end{array}$} & \multirow{2}{*}{$\begin{array}{c}\kappa \\
\mathrm{erg} /(\mathrm{s} \mathrm{cm} \mathrm{K})\end{array}$} & \multirow{2}{*}{$\begin{array}{c}\eta \\
\mathrm{g} /(\mathrm{s} \mathrm{cm})\end{array}$} & \multirow{2}{*}{$\begin{array}{c}D \\
\mathrm{~cm}^{2} / \mathrm{s} \\
\end{array}$} & \multicolumn{7}{|c|}{$d E / d x(\mathrm{eV} / \mathrm{cm})$} \\
\hline & & & & & & $1 \mathrm{keV}$ & $10 \mathrm{keV}$ & $100 \mathrm{keV}$ & $1 \mathrm{MeV}$ & $10 \mathrm{MeV}$ & $100 \mathrm{MeV}$ & $1 \mathrm{GeV}$ \\
\hline Hansen (Bemuze) & $\mathrm{H} 24$ & $1.94 \mathrm{e} 5$ & $5.58 \mathrm{e} 10$ & & & $3.16 \mathrm{e} 7$ & $9.9 \mathrm{e} 7$ & $2.89 \mathrm{e} 8$ & $4.89 \mathrm{e} 8$ & $9.24 \mathrm{e} 7$ & $1.26 \mathrm{e} 7$ & $1.59 \mathrm{e} 6$ \\
\hline Hansen (Muze-k) & $\mathrm{H} 24$ & $2.29 \mathrm{e} 5$ & $5.96 \mathrm{e} 10$ & & & $3.26 \mathrm{e} 7$ & $1.02 \mathrm{e} 8$ & $2.98 \mathrm{e} 8$ & $4.98 \mathrm{e} 8$ & $9.31 \mathrm{e} 7$ & $1.26 \mathrm{e} 7$ & $1.59 \mathrm{e} 6$ \\
\hline Hansen (Muze-s) & $\mathrm{H} 24$ & $2.25 \mathrm{e} 5$ & $5.92 \mathrm{e} 10$ & & & $3.26 \mathrm{e} 7$ & $1.02 \mathrm{e} 8$ & $2.98 \mathrm{e} 8$ & $4.98 \mathrm{e} 8$ & $9.31 \mathrm{e} 7$ & $1.26 \mathrm{e} 7$ & $1.59 \mathrm{e} 6$ \\
\hline Baalrud & $\mathrm{H} 24$ & & & 6.3 & 8.49 & & & & & & & \\
\hline Daligault & $\mathrm{H} 24$ & & & & 8.25 & & & & & & & \\
\hline Haxhimali, Rudd & $\mathrm{H} 24$ & & & 5.89 & & & & & & & & \\
\hline Sjostrom (SDMD) & $\mathrm{H} 24$ & & & & 8.55 & & & & & & & \\
\hline Sjostrom (TFMD) & $\mathrm{H} 24$ & & & & 8.7 & & & & & & & \\
\hline Starrett, Saumon & $\mathrm{H} 24$ & $1.32 \mathrm{e} 5$ & $2.68 \mathrm{e} 10$ & & & & & & & & & \\
\hline Copeland [28] & $\mathrm{H} 24$ & & & 8.89 & 5.33 & & & & & & & \\
\hline Copeland [30] & $\mathrm{H} 24$ & & & 6.33 & 8.98 & & & & & & & \\
\hline Copeland [31] & $\mathrm{H} 24$ & & & 6.19 & 8.91 & & & & & & & \\
\hline Copeland [29] & $\mathrm{H} 24$ & $3.4 \mathrm{e} 5$ & $3.28 \mathrm{e} 10$ & & & & & & & & & \\
\hline Hayes & $\mathrm{H} 25$ & & & & & $6.1 \mathrm{e} 7$ & $3.5 \mathrm{e} 7$ & $2.45 \mathrm{e} 7$ & $6.1 \mathrm{e} 7$ & $7.38 \mathrm{e} 7$ & & \\
\hline Clérouin (PIJ) & $\mathrm{H} 25$ & $3.27 \mathrm{e} 6$ & $8.89 \mathrm{e} 12$ & 824. & $1.02 \mathrm{e} 3$ & & & & & & & \\
\hline Hansen (Bemuze) & $\mathrm{H} 25$ & $2.74 \mathrm{e} 6$ & $8.71 \mathrm{e} 12$ & & & $2.13 \mathrm{e} 6$ & $6.73 \mathrm{e} 6$ & $2.1 \mathrm{e} 7$ & $5.94 \mathrm{e} 7$ & $8.21 \mathrm{e} 7$ & $1.25 \mathrm{e} 7$ & $1.59 \mathrm{e} 6$ \\
\hline Hansen (Muze-k) & $\mathrm{H} 25$ & $4.03 \mathrm{e} 6$ & $1.02 \mathrm{e} 13$ & & & $2.15 \mathrm{e} 6$ & $6.79 \mathrm{e} 6$ & $2.12 \mathrm{e} 7$ & $5.99 \mathrm{e} 7$ & $8.25 \mathrm{e} 7$ & $1.26 \mathrm{e} 7$ & $1.59 \mathrm{e} 6$ \\
\hline Hansen (Muze-s) & $\mathrm{H} 25$ & $4.01 \mathrm{e} 6$ & $1.02 \mathrm{e} 13$ & & & $2.15 \mathrm{e} 6$ & $6.79 \mathrm{e} 6$ & $2.12 \mathrm{e} 7$ & $5.99 \mathrm{e} 7$ & $8.25 \mathrm{e} 7$ & $1.26 \mathrm{e} 7$ & $1.59 \mathrm{e} 6$ \\
\hline Baalrud & $\mathrm{H} 25$ & & & $1.31 \mathrm{e} 3$ & $1.63 \mathrm{e} 3$ & & & & & & & \\
\hline Haxhimali, Rudd & $\mathrm{H} 25$ & & & 799. & & & & & & & & \\
\hline Copeland [28] & $\mathrm{H} 25$ & & & $1.36 \mathrm{e} 3$ & 814. & & & & & & & \\
\hline Copeland [30] & $\mathrm{H} 25$ & & & 806. & $1.03 \mathrm{e} 3$ & & & & & & & \\
\hline Copeland [31] & $\mathrm{H} 25$ & & & 811. & $1.07 \mathrm{e} 3$ & & & & & & & \\
\hline Copeland [29] & $\mathrm{H} 25$ & $5.74 \mathrm{e} 6$ & $5.15 \mathrm{e} 12$ & & & & & & & & & \\
\hline Clérouin (PIJ) & H31 & $3.2 \mathrm{e} 5$ & $1.81 \mathrm{e} 8$ & 0.0906 & $9.48 \mathrm{e}-5$ & & & & & & & \\
\hline Baczewski & $\mathrm{H} 31$ & & & & & $2.32 \mathrm{e} 8$ & $1.42 \mathrm{e} 9$ & $2.76 \mathrm{e} 9$ & $3.75 \mathrm{e} 9$ & $2.83 \mathrm{e} 8$ & $9.74 \mathrm{e} 7$ & \\
\hline Hansen (Bemuze) & H31 & $3.73 \mathrm{e} 5$ & $1.87 \mathrm{e} 8$ & & & $3.06 \mathrm{e} 8$ & $9.73 \mathrm{e} 8$ & $3.26 \mathrm{e} 9$ & $4.21 \mathrm{e} 9$ & $7.7 \mathrm{e} 8$ & $1.1 \mathrm{e} 8$ & $1.43 \mathrm{e} 7$ \\
\hline Hansen (Muze-k) & H31 & $1.73 \mathrm{e} 6$ & $7.38 \mathrm{e} 8$ & & & $3.09 \mathrm{e} 8$ & $9.83 \mathrm{e} 8$ & $3.27 \mathrm{e} 9$ & $4.29 \mathrm{e} 9$ & $7.74 \mathrm{e} 8$ & $1.1 \mathrm{e} 8$ & $1.43 \mathrm{e} 7$ \\
\hline Hansen (Muze-s) & $\mathrm{H} 31$ & $1.57 \mathrm{e} 6$ & $6.7 \mathrm{e} 8$ & & & $3.09 \mathrm{e} 8$ & $9.83 \mathrm{e} 8$ & $3.27 \mathrm{e} 9$ & $4.29 \mathrm{e} 9$ & $7.74 \mathrm{e} 8$ & $1.1 \mathrm{e} 8$ & $1.43 \mathrm{e} 7$ \\
\hline Clérouin (OFMD) & $\mathrm{H} 31$ & $2.88 \mathrm{e} 5$ & $1.63 \mathrm{e} 8$ & 0.098 & $1.06 \mathrm{e}-4$ & & & & & & & \\
\hline Haxhimali, Rudd & H31 & & & 138. & & & & & & & & \\
\hline Sjostrom (KSMD) & H31 & & & & $1.70 \mathrm{e}-4$ & & & & & & & \\
\hline Sjostrom (SDMD) & $\mathrm{H} 31$ & $5.8 \mathrm{e} 5$ & $5.7 \mathrm{e} 8$ & & $1.20 \mathrm{e}-4$ & & & & & & & \\
\hline Sjostrom (TFMD) & H31 & & & & $1.00 \mathrm{e}-4$ & & & & & & & \\
\hline Copeland [28] & $\mathrm{H} 31$ & & & 5.39 & 0.324 & & & & & & & \\
\hline Copeland [30] & $\mathrm{H} 31$ & & & $6.59 \mathrm{e}-4$ & $1.02 \mathrm{e}-4$ & & & & & & & \\
\hline Copeland [31] & H31 & & & 0.00162 & $2.47 e-4$ & & & & & & & \\
\hline Kang (PIMD) & $\mathrm{H} 31$ & & & & $3.07 \mathrm{e}-4$ & & & & & & & \\
\hline Kang, Dai (QE) & $\mathrm{H} 31$ & $3.81 \mathrm{e} 5$ & & 2.15 & $2.23 \mathrm{e}-4$ & & & & & & & \\
\hline
\end{tabular}


Table A.3 - continued from previous page

\begin{tabular}{|c|c|c|c|c|c|c|c|c|c|c|c|c|}
\hline \multirow[t]{2}{*}{ Submitter } & \multirow[t]{2}{*}{ Case } & \multirow{2}{*}{$\begin{array}{c}\sigma \\
1 /(\Omega \mathrm{cm})\end{array}$} & \multirow{2}{*}{$\begin{array}{c}\kappa \\
\mathrm{erg} /(\mathrm{s} \mathrm{cm} \mathrm{K})\end{array}$} & \multirow{2}{*}{$\begin{array}{c}\eta \\
\mathrm{g} /(\mathrm{s} \mathrm{cm})\end{array}$} & \multirow{2}{*}{$\begin{array}{c}D \\
\mathrm{~cm}^{2} / \mathrm{s}\end{array}$} & \multicolumn{7}{|c|}{$d E / d x(\mathrm{eV} / \mathrm{cm})$} \\
\hline & & & & & & $1 \mathrm{keV}$ & $10 \mathrm{keV}$ & $100 \mathrm{keV}$ & $1 \mathrm{MeV}$ & $10 \mathrm{MeV}$ & $100 \mathrm{MeV}$ & $1 \mathrm{GeV}$ \\
\hline Copeland [29] & $\mathrm{H} 31$ & $4.8 \mathrm{e} 4$ & $2.72 \mathrm{e} 7$ & & & & & & & & & \\
\hline Clérouin (PIJ) & H32 & $2.18 \mathrm{e} 5$ & $1.24 \mathrm{e} 9$ & 0.0281 & 0.00279 & & & & & & & \\
\hline Baczewski & H32 & & & & & $1.91 \mathrm{e} 8$ & $1.37 \mathrm{e} 9$ & $2.92 \mathrm{e} 9$ & $3.49 \mathrm{e} 9$ & $2.12 \mathrm{e} 8$ & $2.51 \mathrm{e} 7$ & \\
\hline Desjarlais & H32 & $2.46 \mathrm{e} 5$ & $1.37 \mathrm{e} 9$ & & & & & & & & & \\
\hline Hansen (Bemuze) & H32 & $1.62 \mathrm{e} 5$ & $8.98 \mathrm{e} 8$ & & & $3.06 \mathrm{e} 8$ & $9.73 \mathrm{e} 8$ & $3.26 \mathrm{e} 9$ & $4.21 \mathrm{e} 9$ & $7.7 \mathrm{e} 8$ & $1.1 \mathrm{e} 8$ & $1.43 \mathrm{e} 7$ \\
\hline Hansen (Muze-k) & H32 & $3.74 \mathrm{e} 5$ & $2.04 \mathrm{e} 9$ & & & $3.09 \mathrm{e} 8$ & $9.83 \mathrm{e} 8$ & $3.27 \mathrm{e} 9$ & $4.29 \mathrm{e} 9$ & $7.74 \mathrm{e} 8$ & $1.1 \mathrm{e} 8$ & $1.43 \mathrm{e} 7$ \\
\hline Hansen (Muze-s) & H32 & $3.43 \mathrm{e} 5$ & $1.87 \mathrm{e} 9$ & & & $3.09 \mathrm{e} 8$ & $9.83 \mathrm{e} 8$ & $3.27 \mathrm{e} 9$ & $4.29 \mathrm{e} 9$ & $7.74 \mathrm{e} 8$ & $1.1 \mathrm{e} 8$ & $1.43 \mathrm{e} 7$ \\
\hline Baalrud & H32 & & & 0.0188 & 0.0026 & & & & & & & \\
\hline Clérouin (OFMD) & H32 & $2.36 \mathrm{e} 5$ & $1.34 \mathrm{e} 9$ & 0.0248 & 0.00276 & & & & & & & \\
\hline Daligault & H32 & & & 0.0289 & 0.00295 & & & & & & & \\
\hline Haxhimali, Rudd & H32 & & & 0.0331 & & & & & & & & \\
\hline Sjostrom (KSMD) & H32 & & & & 0.0031 & & & & & & & \\
\hline Sjostrom (SDMD) & H32 & $1.95 \mathrm{e} 5$ & $1.06 \mathrm{e} 9$ & & 0.0029 & & & & & & & \\
\hline Sjostrom (TFMD) & H32 & & & & 0.0028 & & & & & & & \\
\hline Starrett, Saumon & $\mathrm{H} 32$ & $2.5 \mathrm{e} 5$ & $1.41 \mathrm{e} 9$ & & & & & & & & & \\
\hline Copeland [28] & H32 & & & 1.71 & 0.102 & & & & & & & \\
\hline Copeland [30] & H32 & & & 0.00868 & 0.00141 & & & & & & & \\
\hline Copeland [31] & H32 & & & 0.016 & 0.00254 & & & & & & & \\
\hline Hou (AAHNC) & H32 & & & 0.0191 & 0.0025 & & & & & & & \\
\hline $\mathrm{Ma}(\mathrm{eFF})$ & H32 & $1.94 \mathrm{e} 4$ & & & & & & & & & & \\
\hline Kang (PIMD) & H32 & & & & 0.00322 & & & & & & & \\
\hline Kang, Dai (QE) & H32 & $2.29 \mathrm{e} 5$ & & 0.023 & 0.00319 & & & & & & & \\
\hline Copeland [29] & H32 & $4.8 \mathrm{e} 4$ & $2.72 \mathrm{e} 8$ & & & & & & & & & \\
\hline Clérouin (PIJ) & $\mathrm{H} 33$ & $1.08 \mathrm{e} 5$ & $6.09 \mathrm{e} 9$ & 0.208 & 0.0348 & & & & & & & \\
\hline Desjarlais & H33 & $1.4 \mathrm{e} 5$ & $8.19 \mathrm{e} 9$ & & & & & & & & & \\
\hline Hansen (Bemuze) & H33 & $1.87 \mathrm{e} 5$ & $6.36 \mathrm{e} 9$ & & & $3.09 \mathrm{e} 8$ & $9.79 \mathrm{e} 8$ & $3.17 \mathrm{e} 9$ & $4.19 \mathrm{e} 9$ & $7.7 \mathrm{e} 8$ & $1.1 \mathrm{e} 8$ & $1.43 \mathrm{e} 7$ \\
\hline Hansen (Muze-k) & $\mathrm{H} 33$ & $2.47 \mathrm{e} 5$ & $7.41 \mathrm{e} 9$ & & & $3.13 \mathrm{e} 8$ & $9.91 \mathrm{e} 8$ & $3.22 \mathrm{e} 9$ & $4.27 \mathrm{e} 9$ & $7.74 \mathrm{e} 8$ & $1.1 \mathrm{e} 8$ & $1.43 \mathrm{e} 7$ \\
\hline Hansen (Muze-s) & H33 & $2.28 \mathrm{e} 5$ & $7.07 \mathrm{e} 9$ & & & $3.13 \mathrm{e} 8$ & $9.91 \mathrm{e} 8$ & $3.22 \mathrm{e} 9$ & $4.27 \mathrm{e} 9$ & $7.74 \mathrm{e} 8$ & $1.1 \mathrm{e} 8$ & $1.43 \mathrm{e} 7$ \\
\hline Baalrud & $\mathrm{H} 33$ & & & 0.222 & 0.034 & & & & & & & \\
\hline Clérouin (OFMD) & $\mathrm{H} 33$ & $1.16 \mathrm{e} 5$ & $6.55 \mathrm{e} 9$ & 0.225 & 0.0394 & & & & & & & \\
\hline Daligault & H33 & & & 0.23 & 0.0362 & & & & & & & \\
\hline Haxhimali, Rudd & H33 & & & 0.293 & & & & & & & & \\
\hline Sjostrom (SDMD) & H33 & $1.4 \mathrm{e} 5$ & $7.8 \mathrm{e} 9$ & & 0.0395 & & & & & & & \\
\hline Sjostrom (TFMD) & H33 & & & & 0.04 & & & & & & & \\
\hline Starrett, Saumon & $\mathrm{H} 33$ & $1.49 \mathrm{e} 5$ & $7.23 \mathrm{e} 9$ & & & & & & & & & \\
\hline Copeland [28] & $\mathrm{H} 33$ & & & 0.722 & 0.0433 & & & & & & & \\
\hline Copeland [30] & H33 & & & 0.208 & 0.0338 & & & & & & & \\
\hline Copeland [31] & $\mathrm{H} 33$ & & & 0.322 & 0.0529 & & & & & & & \\
\hline Hou (AAHNC) & $\mathrm{H} 33$ & & & 0.172 & 0.0326 & & & & & & & \\
\hline
\end{tabular}


Table A.3 - continued from previous page

\begin{tabular}{|c|c|c|c|c|c|c|c|c|c|c|c|c|}
\hline \multirow[t]{2}{*}{ Submitter } & \multirow[t]{2}{*}{ Case } & \multirow{2}{*}{$\begin{array}{c}\sigma \\
1 /(\Omega \mathrm{cm})\end{array}$} & \multirow{2}{*}{$\begin{array}{c}\kappa \\
\mathrm{erg} /(\mathrm{s} \mathrm{cm} \mathrm{K})\end{array}$} & \multirow{2}{*}{$\begin{array}{c}\eta \\
\mathrm{g} /(\mathrm{s} \mathrm{cm})\end{array}$} & \multirow{2}{*}{$\begin{array}{c}D \\
\mathrm{~cm}^{2} / \mathrm{s}\end{array}$} & \multicolumn{7}{|c|}{$d E / d x(\mathrm{eV} / \mathrm{cm})$} \\
\hline & & & & & & $1 \mathrm{keV}$ & $10 \mathrm{keV}$ & $100 \mathrm{keV}$ & $1 \mathrm{MeV}$ & $10 \mathrm{MeV}$ & $100 \mathrm{MeV}$ & $1 \mathrm{GeV}$ \\
\hline $\mathrm{Ma}(\mathrm{eFF})$ & H33 & $7.2 \mathrm{e} 4$ & & & & & & & & & & \\
\hline Copeland [29] & H33 & $5.99 \mathrm{e} 4$ & $2.81 \mathrm{e} 9$ & & & & & & & & & \\
\hline Hayes & H34 & & & & & $9.43 \mathrm{e} 8$ & $5.86 \mathrm{e} 8$ & $1.28 \mathrm{e} 9$ & $2.86 \mathrm{e} 9$ & $7.42 \mathrm{e} 8$ & & \\
\hline Clérouin (PIJ) & H34 & $2.71 \mathrm{e} 5$ & $7.89 \mathrm{e} 10$ & 8.58 & 1.16 & & & & & & & \\
\hline Hansen (Bemuze) & H34 & $5.17 \mathrm{e} 5$ & $1.14 \mathrm{e} 11$ & & & $1.48 \mathrm{e} 8$ & $4.66 \mathrm{e} 8$ & $1.41 \mathrm{e} 9$ & $3.15 \mathrm{e} 9$ & $7.61 \mathrm{e} 8$ & $1.1 \mathrm{e} 8$ & $1.42 \mathrm{e} 7$ \\
\hline Hansen (Muze-k) & H34 & $5.47 \mathrm{e} 5$ & $1.16 \mathrm{e} 11$ & & & $1.53 \mathrm{e} 8$ & $4.82 \mathrm{e} 8$ & $1.46 \mathrm{e} 9$ & $3.27 \mathrm{e} 9$ & $7.67 \mathrm{e} 8$ & $1.1 \mathrm{e} 8$ & $1.43 \mathrm{e} 7$ \\
\hline Hansen (Muze-s) & H34 & $5.32 \mathrm{e} 5$ & $1.15 \mathrm{e} 11$ & & & $1.53 \mathrm{e} 8$ & $4.82 \mathrm{e} 8$ & $1.46 \mathrm{e} 9$ & $3.27 \mathrm{e} 9$ & $7.67 \mathrm{e} 8$ & $1.1 \mathrm{e} 8$ & $1.43 \mathrm{e} 7$ \\
\hline Baalrud & H34 & & & 9.26 & 1.31 & & & & & & & \\
\hline Clérouin (OFMD) & H34 & $2.7 \mathrm{e} 5$ & $7.84 \mathrm{e} 10$ & 11.5 & 1.5 & & & & & & & \\
\hline Daligault & H34 & & & 8.66 & 1.34 & & & & & & & \\
\hline Haxhimali, Rudd & H34 & & & 9.48 & & & & & & & & \\
\hline Sjostrom (SDMD) & H34 & $3.2 \mathrm{e} 5$ & $1.8 \mathrm{e} 11$ & & 1.37 & & & & & & & \\
\hline Sjostrom (TFMD) & H34 & & & & 1.38 & & & & & & & \\
\hline Starrett, Saumon & H34 & $2.57 \mathrm{e} 5$ & $6.11 \mathrm{e} 10$ & & & & & & & & & \\
\hline Copeland [28] & H34 & & & 13.6 & 0.819 & & & & & & & \\
\hline Copeland [30] & H34 & & & 10.8 & 1.62 & & & & & & & \\
\hline Copeland [31] & H34 & & & 10.5 & 1.58 & & & & & & & \\
\hline Copeland [29] & H34 & $5.39 \mathrm{e} 5$ & $6.26 \mathrm{e} 10$ & & & & & & & & & \\
\hline Hayes & H35 & & & & & $3.61 \mathrm{e} 8$ & $2.52 \mathrm{e} 8$ & $1.87 \mathrm{e} 8$ & $4.58 \mathrm{e} 8$ & $5.96 \mathrm{e} 8$ & & \\
\hline Clérouin (PIJ) & H35 & $4.19 \mathrm{e} 6$ & $1.14 \mathrm{e} 13$ & 996. & 123. & & & & & & & \\
\hline Hansen (Bemuze) & H35 & $5.26 \mathrm{e} 6$ & $1.33 \mathrm{e} 13$ & & & $1.57 \mathrm{e} 7$ & $4.95 \mathrm{e} 7$ & $1.55 \mathrm{e} 8$ & $4.43 \mathrm{e} 8$ & $6.56 \mathrm{e} 8$ & $1.09 \mathrm{e} 8$ & $1.42 \mathrm{e} 7$ \\
\hline Hansen (Muze-k) & H35 & $5.5 \mathrm{e} 6$ & $1.35 \mathrm{e} 13$ & & & $1.59 \mathrm{e} 7$ & $5.02 \mathrm{e} 7$ & $1.57 \mathrm{e} 8$ & $4.49 \mathrm{e} 8$ & $6.62 \mathrm{e} 8$ & $1.09 \mathrm{e} 8$ & $1.43 \mathrm{e} 7$ \\
\hline Hansen (Muze-s) & H35 & $5.48 \mathrm{e} 6$ & $1.35 \mathrm{e} 13$ & & & $1.59 \mathrm{e} 7$ & $5.02 \mathrm{e} 7$ & $1.57 \mathrm{e} 8$ & $4.49 \mathrm{e} 8$ & $6.62 \mathrm{e} 8$ & $1.09 \mathrm{e} 8$ & $1.43 \mathrm{e} 7$ \\
\hline Baalrud & H35 & & & $1.33 \mathrm{e} 3$ & 167. & & & & & & & \\
\hline Clérouin (OFMD) & H35 & $4.14 \mathrm{e} 6$ & $1.13 \mathrm{e} 13$ & 825. & 218. & & & & & & & \\
\hline Haxhimali, Rudd & H35 & & & 987. & & & & & & & & \\
\hline Copeland [28] & H35 & & & $1.63 \mathrm{e} 3$ & 97.6 & & & & & & & \\
\hline Copeland [30] & H35 & & & 1.e3 & 131. & & & & & & & \\
\hline Copeland [31] & H35 & & & $1.01 \mathrm{e} 3$ & 135. & & & & & & & \\
\hline Copeland [29] & H35 & $7.45 \mathrm{e} 6$ & $7.18 \mathrm{e} 12$ & & & & & & & & & \\
\hline Clérouin (PIJ) & H41 & $3.51 \mathrm{e} 6$ & $1.99 \mathrm{e} 9$ & & & & & & & & & \\
\hline Hansen (Bemuze) & H41 & 8.e6 & $4.5 \mathrm{e} 9$ & & & $4.51 \mathrm{e} 8$ & $1.43 \mathrm{e} 9$ & $4.55 \mathrm{e} 9$ & $1.56 \mathrm{e} 10$ & $6.01 \mathrm{e} 9$ & $9.37 \mathrm{e} 8$ & $1.26 \mathrm{e} 8$ \\
\hline Hansen (Muze-k) & H41 & $1.42 \mathrm{e} 8$ & $4.75 \mathrm{e} 10$ & & & $4.54 \mathrm{e} 8$ & $1.44 \mathrm{e} 9$ & $4.57 \mathrm{e} 9$ & $1.56 \mathrm{e} 10$ & $6.04 \mathrm{e} 9$ & $9.38 \mathrm{e} 8$ & $1.27 \mathrm{e} 8$ \\
\hline Hansen (Muze-s) & H41 & $1.37 \mathrm{e} 8$ & $4.58 \mathrm{e} 10$ & & & $4.54 \mathrm{e} 8$ & $1.44 \mathrm{e} 9$ & $4.57 \mathrm{e} 9$ & $1.56 \mathrm{e} 10$ & $6.04 \mathrm{e} 9$ & $9.38 \mathrm{e} 8$ & $1.27 \mathrm{e} 8$ \\
\hline Clérouin (OFMD) & H41 & $1.9 \mathrm{e} 6$ & $1.08 \mathrm{e} 9$ & & & & & & & & & \\
\hline Haxhimali, Rudd & H41 & & & $7.34 \mathrm{e} 5$ & & & & & & & & \\
\hline Copeland [28] & H41 & & & 61.8 & 0.371 & & & & & & & \\
\hline Copeland [30] & H41 & & & $4.54 \mathrm{e}-4$ & $7.03 e-6$ & & & & & & & \\
\hline Copeland [31] & H41 & & & 0.00391 & $5.88 \mathrm{e}-5$ & & & & & & & \\
\hline
\end{tabular}


Table A.3 - continued from previous page

\begin{tabular}{|c|c|c|c|c|c|c|c|c|c|c|c|c|}
\hline \multirow[t]{2}{*}{ Submitter } & \multirow[t]{2}{*}{ Case } & \multirow{2}{*}{$\begin{array}{c}\sigma \\
1 /(\Omega \mathrm{cm})\end{array}$} & \multirow{2}{*}{$\begin{array}{c}\kappa \\
\operatorname{erg} /(\mathrm{s} \mathrm{cm} \mathrm{K})\end{array}$} & \multirow{2}{*}{$\begin{array}{c}\eta \\
\mathrm{g} /(\mathrm{s} \mathrm{cm})\end{array}$} & \multirow{2}{*}{$\begin{array}{c}D \\
\mathrm{~cm}^{2} / \mathrm{s}\end{array}$} & \multicolumn{7}{|c|}{$d E / d x(\mathrm{eV} / \mathrm{cm})$} \\
\hline & & & & & & $1 \mathrm{keV}$ & $10 \mathrm{keV}$ & $100 \mathrm{keV}$ & $1 \mathrm{MeV}$ & $10 \mathrm{MeV}$ & $100 \mathrm{MeV}$ & $1 \mathrm{GeV}$ \\
\hline Kang, Dai (QE) & H41 & $3.94 \mathrm{e} 6$ & & 50. & & & & & & & & \\
\hline Copeland [29] & H41 & $4.8 \mathrm{e} 5$ & $2.72 \mathrm{e} 8$ & & & & & & & & & \\
\hline Clérouin (PIJ) & $\mathrm{H} 42$ & $3.51 \mathrm{e} 6$ & $1.99 \mathrm{e} 10$ & 0.232 & $6.97 \mathrm{e}-4$ & & & & & & & \\
\hline Hansen (Bemuze) & H42 & $5.62 \mathrm{e} 6$ & $2.94 \mathrm{e} 10$ & & & $4.51 \mathrm{e} 8$ & $1.43 \mathrm{e} 9$ & $4.55 \mathrm{e} 9$ & $1.56 \mathrm{e} 10$ & $6.01 \mathrm{e} 9$ & $9.37 \mathrm{e} 8$ & $1.26 \mathrm{e} 8$ \\
\hline Hansen (Muze-k) & H42 & $7.46 \mathrm{e} 6$ & $3.82 \mathrm{e} 10$ & & & $4.54 \mathrm{e} 8$ & $1.44 \mathrm{e} 9$ & $4.57 \mathrm{e} 9$ & $1.56 \mathrm{e} 10$ & $6.04 \mathrm{e} 9$ & $9.38 \mathrm{e} 8$ & $1.27 \mathrm{e} 8$ \\
\hline Hansen (Muze-s) & H42 & $7.22 \mathrm{e} 6$ & $3.69 \mathrm{e} 10$ & & & $4.54 \mathrm{e} 8$ & $1.44 \mathrm{e} 9$ & $4.57 \mathrm{e} 9$ & $1.56 \mathrm{e} 10$ & $6.04 \mathrm{e} 9$ & $9.38 \mathrm{e} 8$ & $1.27 \mathrm{e} 8$ \\
\hline Clérouin (OFMD) & H42 & $2.11 \mathrm{e} 6$ & $1.2 \mathrm{e} 10$ & 0.228 & $6.80 \mathrm{e}-4$ & & & & & & & \\
\hline Haxhimali, Rudd & $\mathrm{H} 42$ & & & 0.239 & & & & & & & & \\
\hline Copeland [28] & H42 & & & 19.5 & 0.117 & & & & & & & \\
\hline Copeland [30] & $\mathrm{H} 42$ & & & 0.0224 & $3.56 \mathrm{e}-4$ & & & & & & & \\
\hline Copeland [31] & $\mathrm{H} 42$ & & & 0.0329 & $5.15 \mathrm{e}-4$ & & & & & & & \\
\hline Hou (AAHNC) & $\mathrm{H} 42$ & & & 0.103 & $7.00 \mathrm{e}-4$ & & & & & & & \\
\hline Kang (PIMD) & H42 & & & & $8.13 \mathrm{e}-4$ & & & & & & & \\
\hline Kang, Dai (QE) & $\mathrm{H} 42$ & $2.1 \mathrm{e} 6$ & & 0.238 & $8.06 \mathrm{e}-4$ & & & & & & & \\
\hline Copeland [29] & H42 & $4.8 \mathrm{e} 5$ & $2.72 \mathrm{e} 9$ & & & & & & & & & \\
\hline Clérouin (PIJ) & H43 & $1.51 \mathrm{e} 6$ & $8.58 \mathrm{e} 10$ & 0.548 & 0.00825 & & & & & & & \\
\hline Hansen (Bemuze) & H43 & $3.7 \mathrm{e} 6$ & $1.78 \mathrm{e} 11$ & & & $4.52 \mathrm{e} 8$ & $1.43 \mathrm{e} 9$ & $4.55 \mathrm{e} 9$ & $1.55 \mathrm{e} 10$ & $6.01 \mathrm{e} 9$ & $9.37 \mathrm{e} 8$ & $1.27 \mathrm{e} 8$ \\
\hline Hansen (Muze-k) & H43 & $3.83 \mathrm{e} 6$ & $1.84 \mathrm{e} 11$ & & & $4.54 \mathrm{e} 8$ & $1.44 \mathrm{e} 9$ & $4.57 \mathrm{e} 9$ & $1.55 \mathrm{e} 10$ & $6.04 \mathrm{e} 9$ & $9.38 \mathrm{e} 8$ & $1.27 \mathrm{e} 8$ \\
\hline Hansen (Muze-s) & $\mathrm{H} 43$ & $3.7 \mathrm{e} 6$ & $1.78 \mathrm{e} 11$ & & & $4.54 \mathrm{e} 8$ & $1.44 \mathrm{e} 9$ & $4.57 \mathrm{e} 9$ & $1.55 \mathrm{e} 10$ & $6.04 \mathrm{e} 9$ & $9.38 \mathrm{e} 8$ & $1.27 \mathrm{e} 8$ \\
\hline Baalrud & $\mathrm{H} 43$ & & & 0.528 & 0.00795 & & & & & & & \\
\hline Clérouin (OFMD) & $\mathrm{H} 43$ & $1.54 \mathrm{e} 6$ & $8.74 \mathrm{e} 10$ & 0.468 & 0.00845 & & & & & & & \\
\hline Daligault & $\mathrm{H} 43$ & & & 0.547 & 0.00843 & & & & & & & \\
\hline Haxhimali, Rudd & $\mathrm{H} 43$ & & & 0.735 & & & & & & & & \\
\hline Starrett, Saumon & $\mathrm{H} 43$ & $1.43 \mathrm{e} 6$ & $8.02 \mathrm{e} 10$ & & & & & & & & & \\
\hline Copeland [28] & $\mathrm{H} 43$ & & & 6.32 & 0.0379 & & & & & & & \\
\hline Copeland [30] & $\mathrm{H} 43$ & & & 0.371 & 0.00608 & & & & & & & \\
\hline Copeland [31] & $\mathrm{H} 43$ & & & 0.513 & 0.00825 & & & & & & & \\
\hline Hou (AAHNC) & $\mathrm{H} 43$ & & & 0.403 & 0.0073 & & & & & & & \\
\hline Copeland [29] & $\mathrm{H} 43$ & $4.85 \mathrm{e} 5$ & $2.7 \mathrm{e} 10$ & & & & & & & & & \\
\hline Hayes & $\mathrm{H} 44$ & & & & & $7.13 \mathrm{e} 9$ & $2.54 \mathrm{e} 9$ & $3.02 \mathrm{e} 9$ & $1.02 \mathrm{e} 10$ & $5.97 \mathrm{e} 9$ & & \\
\hline Clérouin (PIJ) & $\mathrm{H} 44$ & $7.66 \mathrm{e} 5$ & $4.13 \mathrm{e} 11$ & 12.1 & 0.209 & & & & & & & \\
\hline Hansen (Bemuze) & $\mathrm{H} 44$ & $3.3 \mathrm{e} 6$ & $4.49 \mathrm{e} 11$ & & & $4.27 \mathrm{e} 8$ & $1.35 \mathrm{e} 9$ & $4.22 \mathrm{e} 9$ & $1.22 \mathrm{e} 10$ & $5.96 \mathrm{e} 9$ & $9.36 \mathrm{e} 8$ & $1.26 \mathrm{e} 8$ \\
\hline Hansen (Muze-k) & $\mathrm{H} 44$ & $3.5 \mathrm{e} 6$ & $4.56 \mathrm{e} 11$ & & & $4.35 \mathrm{e} 8$ & $1.38 \mathrm{e} 9$ & $4.31 \mathrm{e} 9$ & $1.26 \mathrm{e} 10$ & $6 . e 9$ & $9.38 \mathrm{e} 8$ & $1.27 \mathrm{e} 8$ \\
\hline Hansen (Muze-s) & H44 & $3.4 \mathrm{e} 6$ & $4.53 \mathrm{e} 11$ & & & $4.35 \mathrm{e} 8$ & $1.38 \mathrm{e} 9$ & $4.31 \mathrm{e} 9$ & $1.26 \mathrm{e} 10$ & $6 . \mathrm{e} 9$ & $9.38 \mathrm{e} 8$ & $1.27 \mathrm{e} 8$ \\
\hline Baalrud & $\mathrm{H} 44$ & & & 14.3 & 0.212 & & & & & & & \\
\hline Clérouin (OFMD) & $\mathrm{H} 44$ & $7.72 \mathrm{e} 5$ & $4.17 \mathrm{e} 11$ & 35. & 0.243 & & & & & & & \\
\hline Daligault & $\mathrm{H} 44$ & & & 14.5 & 0.222 & & & & & & & \\
\hline Haxhimali, Rudd & $\mathrm{H} 44$ & & & 15.6 & & & & & & & & \\
\hline Starrett, Saumon & $\mathrm{H} 44$ & $1.11 \mathrm{e} 6$ & $4.27 \mathrm{e} 11$ & & & & & & & & & \\
\hline
\end{tabular}


Table A.3 - continued from previous page

\begin{tabular}{|c|c|c|c|c|c|c|c|c|c|c|c|c|}
\hline \multirow[t]{2}{*}{ Submitter } & \multirow[t]{2}{*}{ Case } & \multirow{2}{*}{$\begin{array}{c}\sigma \\
1 /(\Omega \mathrm{cm})\end{array}$} & \multirow{2}{*}{$\begin{array}{c}\kappa \\
\operatorname{erg} /(\mathrm{s} \mathrm{cm} \mathrm{K})\end{array}$} & \multirow{2}{*}{$\begin{array}{c}\eta \\
\mathrm{g} /(\mathrm{s} \mathrm{cm})\end{array}$} & \multirow{2}{*}{$\begin{array}{c}D \\
\mathrm{~cm}^{2} / \mathrm{s}\end{array}$} & \multicolumn{7}{|c|}{$d E / d x(\mathrm{eV} / \mathrm{cm})$} \\
\hline & & & & & & $1 \mathrm{keV}$ & $10 \mathrm{keV}$ & $100 \mathrm{keV}$ & $1 \mathrm{MeV}$ & $10 \mathrm{MeV}$ & $100 \mathrm{MeV}$ & $1 \mathrm{GeV}$ \\
\hline Copeland [28] & $\mathrm{H} 44$ & & & 22.2 & 0.133 & & & & & & & \\
\hline Copeland [30] & H44 & & & 16.5 & 0.257 & & & & & & & \\
\hline Copeland [31] & H44 & & & 17.2 & 0.269 & & & & & & & \\
\hline Copeland [29] & H44 & $8.8 \mathrm{e} 5$ & $2.31 \mathrm{e} 11$ & & & & & & & & & \\
\hline Hayes & H45 & & & & & & $2.11 \mathrm{e} 9$ & $1.26 \mathrm{e} 9$ & $3.03 \mathrm{e} 9$ & $4.46 \mathrm{e} 9$ & & \\
\hline Clérouin (PIJ) & H45 & $5.82 \mathrm{e} 6$ & $1.62 \mathrm{e} 13$ & $1.27 \mathrm{e} 3$ & 15.6 & & & & & & & \\
\hline Hansen (Bemuze) & H45 & $1.15 \mathrm{e} 7$ & $2.19 \mathrm{e} 13$ & & & $9.79 \mathrm{e} 7$ & $3.09 \mathrm{e} 8$ & $9.7 \mathrm{e} 8$ & $2.84 \mathrm{e} 9$ & $4.91 \mathrm{e} 9$ & $9.27 \mathrm{e} 8$ & $1.26 \mathrm{e} 8$ \\
\hline Hansen (Muze-k) & H45 & $1.16 \mathrm{e} 7$ & $2.2 \mathrm{e} 13$ & & & 1.e8 & $3.16 \mathrm{e} 8$ & $9.91 \mathrm{e} 8$ & $2.9 \mathrm{e} 9$ & $4.97 \mathrm{e} 9$ & $9.31 \mathrm{e} 8$ & $1.26 \mathrm{e} 8$ \\
\hline Hansen (Muze-s) & $\mathrm{H} 45$ & $1.16 \mathrm{e} 7$ & $2.2 \mathrm{e} 13$ & & & 1.e8 & $3.16 \mathrm{e} 8$ & $9.91 \mathrm{e} 8$ & $2.9 \mathrm{e} 9$ & $4.97 \mathrm{e} 9$ & $9.31 \mathrm{e} 8$ & $1.26 \mathrm{e} 8$ \\
\hline Baalrud & H45 & & & $1.49 \mathrm{e} 3$ & 19.3 & & & & & & & \\
\hline Clérouin (OFMD) & H45 & $5.8 \mathrm{e} 6$ & $1.6 \mathrm{e} 13$ & $4 . \mathrm{e} 3$ & 24.9 & & & & & & & \\
\hline Haxhimali, Rudd & $\mathrm{H} 45$ & & & $1.29 \mathrm{e} 3$ & & & & & & & & \\
\hline Copeland [28] & H45 & & & $2.04 \mathrm{e} 3$ & 12.2 & & & & & & & \\
\hline Copeland [30] & H45 & & & $1.33 \mathrm{e} 3$ & 18. & & & & & & & \\
\hline Copeland [31] & $\mathrm{H} 45$ & & & $1.33 \mathrm{e} 3$ & 18.3 & & & & & & & \\
\hline Copeland [29] & H45 & $1.08 \mathrm{e} 7$ & $1.03 \mathrm{e} 13$ & & & & & & & & & \\
\hline Clérouin (PIJ) & C11 & 100. & $5.68 \mathrm{e} 4$ & $3.19 \mathrm{e}-4$ & 0.00462 & & & & & & & \\
\hline Hansen (Muze-k) & C11 & 7.95 & $2.75 \mathrm{e} 3$ & & & $3.23 \mathrm{e} 7$ & $1.05 \mathrm{e} 8$ & $9.69 \mathrm{e} 7$ & $2.56 \mathrm{e} 7$ & $4.37 \mathrm{e} 6$ & $6.05 \mathrm{e} 5$ & $7.71 \mathrm{e} 4$ \\
\hline Hansen (Muze-s) & C11 & $3.8 \mathrm{e}-7$ & $2.62 \mathrm{e}-4$ & & & $2.72 \mathrm{e} 7$ & $8.5 \mathrm{e} 7$ & $9 . \mathrm{e} 7$ & $2.49 \mathrm{e} 7$ & $4.31 \mathrm{e} 6$ & $5.99 \mathrm{e} 5$ & $7.65 \mathrm{e} 4$ \\
\hline Haxhimali, Rudd & C11 & & & $8.42 \mathrm{e}-4$ & & & & & & & & \\
\hline Copeland [28] & C11 & & & 0.00783 & 0.047 & & & & & & & \\
\hline Copeland [30] & $\mathrm{C} 11$ & & & $1.89 \mathrm{e}-4$ & 0.0031 & & & & & & & \\
\hline Copeland [31] & $\mathrm{C} 11$ & & & $9.60 \mathrm{e}-4$ & 0.0152 & & & & & & & \\
\hline Copeland [29] & $\mathrm{C} 11$ & 61.2 & $3.56 \mathrm{e} 4$ & & & & & & & & & \\
\hline Clérouin (PIJ) & $\mathrm{C} 12$ & 284. & $8.77 \mathrm{e} 5$ & 0.00211 & 0.036 & & & & & & & \\
\hline Hansen (Bemuze) & $\mathrm{C} 12$ & 432. & $1.14 \mathrm{e} 6$ & & & $2.67 \mathrm{e} 7$ & $8.19 \mathrm{e} 7$ & $9.48 \mathrm{e} 7$ & $2.53 \mathrm{e} 7$ & $4.35 \mathrm{e} 6$ & $6.03 \mathrm{e} 5$ & $7.69 \mathrm{e} 4$ \\
\hline Hansen (Muze-k) & $\mathrm{C} 12$ & 451. & $1.17 \mathrm{e} 6$ & & & $3.34 \mathrm{e} 7$ & $1.03 \mathrm{e} 8$ & $1 . \mathrm{e} 8$ & $2.59 \mathrm{e} 7$ & $4.41 \mathrm{e} 6$ & $6.08 \mathrm{e} 5$ & $7.74 \mathrm{e} 4$ \\
\hline Hansen (Muze-s) & $\mathrm{C} 12$ & 89.8 & $4.12 \mathrm{e} 5$ & & & $2.4 \mathrm{e} 7$ & $7.22 \mathrm{e} 7$ & $8.82 \mathrm{e} 7$ & $2.49 \mathrm{e} 7$ & $4.31 \mathrm{e} 6$ & $5.98 \mathrm{e} 5$ & $7.64 \mathrm{e} 4$ \\
\hline Haxhimali, Rudd & C12 & & & 0.00349 & & & & & & & & \\
\hline Copeland [28] & C12 & & & 0.0069 & 0.0414 & & & & & & & \\
\hline Copeland [30] & $\mathrm{C} 12$ & & & 0.00215 & 0.0349 & & & & & & & \\
\hline Copeland [31] & $\mathrm{C} 12$ & & & 0.00525 & 0.0855 & & & & & & & \\
\hline Hou (AAHNC) & $\mathrm{C} 12$ & & & 0.0026 & 0.046 & & & & & & & \\
\hline Copeland [29] & $\mathrm{C} 12$ & 586. & $1.16 \mathrm{e} 6$ & & & & & & & & & \\
\hline Clérouin (PIJ) & C13 & $3.6 \mathrm{e} 3$ & $1.53 \mathrm{e} 8$ & 0.00594 & 0.0989 & & & & & & & \\
\hline Hansen (Bemuze) & C13 & $2.55 \mathrm{e} 3$ & $1.18 \mathrm{e} 8$ & & & $1.5 \mathrm{e} 7$ & $4.44 \mathrm{e} 7$ & $8.59 \mathrm{e} 7$ & $2.37 \mathrm{e} 7$ & $4.27 \mathrm{e} 6$ & $5.96 \mathrm{e} 5$ & $7.61 \mathrm{e} 4$ \\
\hline Hansen (Muze-k) & $\mathrm{C} 13$ & $2.64 \mathrm{e} 3$ & $1.21 \mathrm{e} 8$ & & & $2.25 \mathrm{e} 7$ & $6.66 \mathrm{e} 7$ & $1.27 \mathrm{e} 8$ & $3.05 \mathrm{e} 7$ & $4.85 \mathrm{e} 6$ & $6.5 \mathrm{e} 5$ & $8.14 \mathrm{e} 4$ \\
\hline Hansen (Muze-s) & C13 & $2.49 \mathrm{e} 3$ & $1.16 \mathrm{e} 8$ & & & $2.21 \mathrm{e} 7$ & $6.56 \mathrm{e} 7$ & $1.25 \mathrm{e} 8$ & $3.02 \mathrm{e} 7$ & $4.83 \mathrm{e} 6$ & $6.48 \mathrm{e} 5$ & $8.11 \mathrm{e} 4$ \\
\hline Haxhimali, Rudd & $\mathrm{C} 13$ & & & 0.00847 & & & & & & & & \\
\hline
\end{tabular}


Table A.3 - continued from previous page

\begin{tabular}{|c|c|c|c|c|c|c|c|c|c|c|c|c|}
\hline \multirow[t]{2}{*}{ Submitter } & \multirow[t]{2}{*}{ Case } & \multirow{2}{*}{$\begin{array}{c}\sigma \\
1 /(\Omega \mathrm{cm})\end{array}$} & \multirow{2}{*}{$\begin{array}{c}\kappa \\
\mathrm{erg} /(\mathrm{s} \mathrm{cm} \mathrm{K})\end{array}$} & \multirow{2}{*}{$\begin{array}{c}\eta \\
\mathrm{g} /(\mathrm{s} \mathrm{cm})\end{array}$} & \multirow{2}{*}{$\begin{array}{c}D \\
\mathrm{~cm}^{2} / \mathrm{s}\end{array}$} & \multicolumn{7}{|c|}{$d E / d x(\mathrm{eV} / \mathrm{cm})$} \\
\hline & & & & & & $1 \mathrm{keV}$ & $10 \mathrm{keV}$ & $100 \mathrm{keV}$ & $1 \mathrm{MeV}$ & $10 \mathrm{MeV}$ & $100 \mathrm{MeV}$ & $1 \mathrm{GeV}$ \\
\hline Copeland [28] & $\mathrm{C} 13$ & & & 0.0158 & 0.0948 & & & & & & & \\
\hline Copeland [30] & $\mathrm{C} 13$ & & & 0.00569 & 0.0927 & & & & & & & \\
\hline Copeland [31] & $\mathrm{C} 13$ & & & 0.00951 & 0.156 & & & & & & & \\
\hline Hou (AAHNC) & $\mathrm{C} 13$ & & & 0.0073 & 0.141 & & & & & & & \\
\hline Copeland [29] & $\mathrm{C} 13$ & $5.12 \mathrm{e} 3$ & $9.88 \mathrm{e} 7$ & & & & & & & & & \\
\hline Clérouin (PIJ) & $\mathrm{C} 14$ & $3.93 \mathrm{e} 4$ & $2.05 \mathrm{e} 10$ & 0.0433 & 0.835 & & & & & & & \\
\hline Hansen (Bemuze) & $\mathrm{C} 14$ & $2.48 \mathrm{e} 4$ & $1.34 \mathrm{e} 10$ & & & $2.59 \mathrm{e} 6$ & $8.1 \mathrm{e} 6$ & $2.31 \mathrm{e} 7$ & $3.37 \mathrm{e} 7$ & $5.54 \mathrm{e} 6$ & $7.21 \mathrm{e} 5$ & $8.86 \mathrm{e} 4$ \\
\hline Hansen (Muze-k) & $\mathrm{C} 14$ & $2.61 \mathrm{e} 4$ & $1.39 \mathrm{e} 10$ & & & $2.73 \mathrm{e} 6$ & $8.52 \mathrm{e} 6$ & $2.42 \mathrm{e} 7$ & $3.48 \mathrm{e} 7$ & $5.6 \mathrm{e} 6$ & $7.24 \mathrm{e} 5$ & $8.85 \mathrm{e} 4$ \\
\hline Hansen (Muze-s) & $\mathrm{C} 14$ & $2.59 \mathrm{e} 4$ & $1.38 \mathrm{e} 10$ & & & $2.73 \mathrm{e} 6$ & $8.52 \mathrm{e} 6$ & $2.42 \mathrm{e} 7$ & $3.48 \mathrm{e} 7$ & $5.6 \mathrm{e} 6$ & $7.24 \mathrm{e} 5$ & $8.85 \mathrm{e} 4$ \\
\hline Haxhimali, Rudd & $\mathrm{C} 14$ & & & 0.0593 & & & & & & & & \\
\hline Copeland [28] & $\mathrm{C} 14$ & & & 0.0736 & 0.442 & & & & & & & \\
\hline Copeland [30] & $\mathrm{C} 14$ & & & 0.0582 & 0.923 & & & & & & & \\
\hline Copeland [31] & $\mathrm{C} 14$ & & & 0.058 & 0.914 & & & & & & & \\
\hline Hou (AAHNC) & $\mathrm{C} 14$ & & & 0.0275 & 0.651 & & & & & & & \\
\hline Copeland [29] & $\mathrm{C} 14$ & $5.03 \mathrm{e} 4$ & $1.39 \mathrm{e} 10$ & & & & & & & & & \\
\hline Clérouin (PIJ) & $\mathrm{C} 15$ & $6.7 \mathrm{e} 5$ & $3.42 \mathrm{e} 12$ & 3.8 & 47. & & & & & & & \\
\hline Hansen (Bemuze) & $\mathrm{C} 15$ & $4.32 \mathrm{e} 5$ & $2.4 \mathrm{e} 12$ & & & $1.41 \mathrm{e} 5$ & $4.44 \mathrm{e} 5$ & $1.39 \mathrm{e} 6$ & $3.88 \mathrm{e} 6$ & $5.11 \mathrm{e} 6$ & $7.29 \mathrm{e} 5$ & $8.97 \mathrm{e} 4$ \\
\hline Hansen (Muze-k) & $\mathrm{C} 15$ & $4.39 \mathrm{e} 5$ & $2.43 \mathrm{e} 12$ & & & $1.43 \mathrm{e} 5$ & $4.51 \mathrm{e} 5$ & $1.41 \mathrm{e} 6$ & $3.94 \mathrm{e} 6$ & $5.16 \mathrm{e} 6$ & $7.31 \mathrm{e} 5$ & $8.97 \mathrm{e} 4$ \\
\hline Hansen (Muze-s) & $\mathrm{C} 15$ & $4.38 \mathrm{e} 5$ & $2.43 \mathrm{e} 12$ & & & $1.43 \mathrm{e} 5$ & $4.51 \mathrm{e} 5$ & $1.41 \mathrm{e} 6$ & $3.94 \mathrm{e} 6$ & $5.16 \mathrm{e} 6$ & $7.31 \mathrm{e} 5$ & $8.97 \mathrm{e} 4$ \\
\hline Haxhimali, Rudd & $\mathrm{C} 15$ & & & 3.73 & & & & & & & & \\
\hline Copeland [28] & $\mathrm{C} 15$ & & & 5.72 & 34.3 & & & & & & & \\
\hline Copeland [30] & $\mathrm{C} 15$ & & & 3.84 & 52.8 & & & & & & & \\
\hline Copeland [31] & $\mathrm{C} 15$ & & & 3.76 & 52.6 & & & & & & & \\
\hline Copeland [29] & $\mathrm{C} 15$ & $8.2 \mathrm{e} 5$ & $2.54 \mathrm{e} 12$ & & & & & & & & & \\
\hline Clérouin (PIJ) & $\mathrm{C} 21$ & $2.01 \mathrm{e} 3$ & $1.14 \mathrm{e} 6$ & 0.00645 & $2.73 e-4$ & & & & & & & \\
\hline Hansen (Muze-k) & $\mathrm{C} 21$ & 6.45 & $4.01 \mathrm{e} 3$ & & & $1.2 \mathrm{e} 8$ & $4.47 \mathrm{e} 8$ & $9.06 \mathrm{e} 8$ & $2.5 \mathrm{e} 8$ & $4.31 \mathrm{e} 7$ & $5.99 \mathrm{e} 6$ & $7.64 \mathrm{e} 5$ \\
\hline Hansen (Muze-s) & $\mathrm{C} 21$ & $6.6 \mathrm{e} 3$ & $3.54 \mathrm{e} 6$ & & & $1.14 \mathrm{e} 8$ & $4.43 \mathrm{e} 8$ & $8.34 \mathrm{e} 8$ & $2.44 \mathrm{e} 8$ & $4.26 \mathrm{e} 7$ & $5.93 \mathrm{e} 6$ & $7.59 \mathrm{e} 5$ \\
\hline Clérouin (OFMD) & $\mathrm{C} 21$ & $2.71 \mathrm{e} 3$ & $1.54 \mathrm{e} 6$ & 0.0017 & $8.00 \mathrm{e}-4$ & & & & & & & \\
\hline Haxhimali, Rudd & $\mathrm{C} 21$ & & & 0.00128 & & & & & & & & \\
\hline Copeland [28] & $\mathrm{C} 21$ & & & 0.362 & 0.217 & & & & & & & \\
\hline Copeland [30] & $\mathrm{C} 21$ & & & $1.40 \mathrm{e}-4$ & $2.19 \mathrm{e}-4$ & & & & & & & \\
\hline Copeland [31] & $\mathrm{C} 21$ & & & $8.44 \mathrm{e}-4$ & 0.00128 & & & & & & & \\
\hline Copeland [29] & $\mathrm{C} 21$ & 406. & $2.3 \mathrm{e} 5$ & & & & & & & & & \\
\hline Clérouin (PIJ) & $\mathrm{C} 22$ & $1.26 \mathrm{e} 3$ & $7.09 \mathrm{e} 6$ & 0.00395 & 0.00484 & & & & & & & \\
\hline Desjarlais & $\mathrm{C} 22$ & 850. & $3.7 \mathrm{e} 6$ & & & & & & & & & \\
\hline Hansen (Bemuze) & $\mathrm{C} 22$ & 78.9 & $4.41 \mathrm{e} 5$ & & & $1.15 \mathrm{e} 8$ & $4.04 \mathrm{e} 8$ & $8.42 \mathrm{e} 8$ & $2.43 \mathrm{e} 8$ & $4.25 \mathrm{e} 7$ & $5.93 \mathrm{e} 6$ & $7.59 \mathrm{e} 5$ \\
\hline Hansen (Muze-k) & $\mathrm{C} 22$ & 253. & $1.26 \mathrm{e} 6$ & & & $1.21 \mathrm{e} 8$ & $4.23 \mathrm{e} 8$ & $8.99 \mathrm{e} 8$ & $2.5 \mathrm{e} 8$ & $4.31 \mathrm{e} 7$ & $5.99 \mathrm{e} 6$ & $7.64 \mathrm{e} 5$ \\
\hline Hansen (Muze-s) & $\mathrm{C} 22$ & 394. & $1.79 \mathrm{e} 6$ & & & $1.05 \mathrm{e} 8$ & $3.72 \mathrm{e} 8$ & $7.69 \mathrm{e} 8$ & $2.39 \mathrm{e} 8$ & $4.21 \mathrm{e} 7$ & $5.89 \mathrm{e} 6$ & $7.55 \mathrm{e} 5$ \\
\hline Baalrud & $\mathrm{C} 22$ & & & 0.00274 & 0.00395 & & & & & & & \\
\hline
\end{tabular}


Table A.3 - continued from previous page

\begin{tabular}{|c|c|c|c|c|c|c|c|c|c|c|c|c|}
\hline \multirow[t]{2}{*}{ Submitter } & \multirow[t]{2}{*}{ Case } & \multirow{2}{*}{$\begin{array}{c}\sigma \\
1 /(\Omega \mathrm{cm})\end{array}$} & \multirow{2}{*}{$\begin{array}{c}\kappa \\
\operatorname{erg} /(\mathrm{s} \mathrm{cm} \mathrm{K})\end{array}$} & \multirow{2}{*}{$\begin{array}{c}\eta \\
\mathrm{g} /(\mathrm{s} \mathrm{cm})\end{array}$} & \multirow{2}{*}{$\begin{array}{c}D \\
\mathrm{~cm}^{2} / \mathrm{s}\end{array}$} & \multicolumn{7}{|c|}{$d E / d x(\mathrm{eV} / \mathrm{cm})$} \\
\hline & & & & & & $1 \mathrm{keV}$ & $10 \mathrm{keV}$ & $100 \mathrm{keV}$ & $1 \mathrm{MeV}$ & $10 \mathrm{MeV}$ & $100 \mathrm{MeV}$ & $1 \mathrm{GeV}$ \\
\hline Clérouin (OFMD) & $\mathrm{C} 22$ & $1.3 \mathrm{e} 3$ & $7.25 \mathrm{e} 6$ & 0.0087 & 0.0067 & & & & & & & \\
\hline Haxhimali, Rudd & $\mathrm{C} 22$ & & & 0.00683 & & & & & & & & \\
\hline Sjostrom (TFMD) & $\mathrm{C} 22$ & & & & 0.0066 & & & & & & & \\
\hline Copeland [28] & $\mathrm{C} 22$ & & & 0.124 & 0.0746 & & & & & & & \\
\hline Copeland [30] & $\mathrm{C} 22$ & & & 0.00163 & 0.00266 & & & & & & & \\
\hline Copeland [31] & $\mathrm{C} 22$ & & & 0.00719 & 0.0114 & & & & & & & \\
\hline Copeland [29] & $\mathrm{C} 22$ & 626. & $3.58 \mathrm{e} 6$ & & & & & & & & & \\
\hline Grabowski & $\mathrm{C} 23$ & & & & & & $3.75 \mathrm{e} 8$ & $7.86 \mathrm{e} 8$ & $2.51 \mathrm{e} 8$ & $4.19 \mathrm{e} 7$ & & \\
\hline Clérouin (PIJ) & $\mathrm{C} 23$ & $4.3 \mathrm{e} 3$ & $1.71 \mathrm{e} 8$ & 0.0204 & 0.0321 & & & & & & & \\
\hline Dharma-wardana & $\mathrm{C} 23$ & $1.96 \mathrm{e} 3$ & & & & & & & & & & \\
\hline Hansen (Bemuze) & $\mathrm{C} 23$ & $4.55 \mathrm{e} 3$ & $2.12 \mathrm{e} 8$ & & & $7.12 \mathrm{e} 7$ & $2.19 \mathrm{e} 8$ & $5.67 \mathrm{e} 8$ & $2.18 \mathrm{e} 8$ & $4.07 \mathrm{e} 7$ & $5.76 \mathrm{e} 6$ & $7.41 \mathrm{e} 5$ \\
\hline Hansen (Muze-k) & $\mathrm{C} 23$ & $4.91 \mathrm{e} 3$ & $2.24 \mathrm{e} 8$ & & & $8.88 \mathrm{e} 7$ & $2.76 \mathrm{e} 8$ & $7.46 \mathrm{e} 8$ & $2.57 \mathrm{e} 8$ & $4.4 \mathrm{e} 7$ & $6.07 \mathrm{e} 6$ & $7.72 \mathrm{e} 5$ \\
\hline Hansen (Muze-s) & $\mathrm{C} 23$ & $4.54 \mathrm{e} 3$ & $2.12 \mathrm{e} 8$ & & & $8.77 \mathrm{e} 7$ & $2.72 \mathrm{e} 8$ & $7.33 \mathrm{e} 8$ & $2.55 \mathrm{e} 8$ & $4.38 \mathrm{e} 7$ & $6.05 \mathrm{e} 6$ & $7.7 \mathrm{e} 5$ \\
\hline Baalrud & $\mathrm{C} 23$ & & & 0.022 & 0.0362 & & & & & & & \\
\hline Daligault & $\mathrm{C} 23$ & & & 0.0229 & 0.0374 & & & & & & & \\
\hline Haxhimali, Rudd & $\mathrm{C} 23$ & & & 0.031 & & & & & & & & \\
\hline Sjostrom (TFMD) & $\mathrm{C} 23$ & & & & 0.052 & & & & & & & \\
\hline Starrett, Saumon & $\mathrm{C} 23$ & $3.19 \mathrm{e} 3$ & $9.23 \mathrm{e} 7$ & & & & & & & & & \\
\hline Copeland [28] & $\mathrm{C} 23$ & & & 0.0971 & 0.0583 & & & & & & & \\
\hline Copeland [30] & $\mathrm{C} 23$ & & & 0.0161 & 0.0264 & & & & & & & \\
\hline Copeland [31] & $\mathrm{C} 23$ & & & 0.0356 & 0.0572 & & & & & & & \\
\hline Hou (AAHNC) & $\mathrm{C} 23$ & & & 0.0203 & 0.0372 & & & & & & & \\
\hline Copeland [29] & $\mathrm{C} 23$ & $6.25 \mathrm{e} 3$ & $1.75 \mathrm{e} 8$ & & & & & & & & & \\
\hline Clérouin (PIJ) & $\mathrm{C} 24$ & $5.02 \mathrm{e} 4$ & $2.7 \mathrm{e} 10$ & 0.111 & 0.201 & & & & & & & \\
\hline Dharma-wardana & $\mathrm{C} 24$ & $5.85 \mathrm{e} 4$ & & & & & & & & & & \\
\hline Hansen (Bemuze) & $\mathrm{C} 24$ & $3.59 \mathrm{e} 4$ & $1.91 \mathrm{e} 10$ & & & $1.66 \mathrm{e} 7$ & $5.19 \mathrm{e} 7$ & $1.5 \mathrm{e} 8$ & $2.46 \mathrm{e} 8$ & $4.67 \mathrm{e} 7$ & $6.36 \mathrm{e} 6$ & $8.02 \mathrm{e} 5$ \\
\hline Hansen (Muze-k) & $\mathrm{C} 24$ & $3.62 \mathrm{e} 4$ & $1.92 \mathrm{e} 10$ & & & $1.88 \mathrm{e} 7$ & $5.88 \mathrm{e} 7$ & $1.7 \mathrm{e} 8$ & $2.72 \mathrm{e} 8$ & $4.9 \mathrm{e} 7$ & $6.58 \mathrm{e} 6$ & $8.23 \mathrm{e} 5$ \\
\hline Hansen (Muze-s) & $\mathrm{C} 24$ & $3.56 \mathrm{e} 4$ & $1.9 \mathrm{e} 10$ & & & $1.87 \mathrm{e} 7$ & $5.87 \mathrm{e} 7$ & $1.7 \mathrm{e} 8$ & $2.71 \mathrm{e} 8$ & $4.9 \mathrm{e} 7$ & $6.58 \mathrm{e} 6$ & $8.22 \mathrm{e} 5$ \\
\hline Haxhimali, Rudd & $\mathrm{C} 24$ & & & 0.152 & & & & & & & & \\
\hline Sjostrom (SDMD) & $\mathrm{C} 24$ & & & & 0.22 & & & & & & & \\
\hline Sjostrom (TFMD) & $\mathrm{C} 24$ & & & & 0.22 & & & & & & & \\
\hline Copeland [28] & $\mathrm{C} 24$ & & & 0.216 & 0.129 & & & & & & & \\
\hline Copeland [30] & $\mathrm{C} 24$ & & & 0.12 & 0.195 & & & & & & & \\
\hline Copeland [31] & $\mathrm{C} 24$ & & & 0.149 & 0.241 & & & & & & & \\
\hline Hou (AAHNC) & $\mathrm{C} 24$ & & & 0.097 & 0.184 & & & & & & & \\
\hline Copeland [29] & $\mathrm{C} 24$ & $6.83 \mathrm{e} 4$ & $1.88 \mathrm{e} 10$ & & & & & & & & & \\
\hline Clérouin (PIJ) & $\mathrm{C} 25$ & $8.28 \mathrm{e} 5$ & $4.24 \mathrm{e} 12$ & 5.33 & 6.6 & & & & & & & \\
\hline Hansen (Bemuze) & $\mathrm{C} 25$ & $5.5 \mathrm{e} 5$ & $3.03 \mathrm{e} 12$ & & & $1.15 \mathrm{e} 6$ & $3.64 \mathrm{e} 6$ & $1.14 \mathrm{e} 7$ & $3.21 \mathrm{e} 7$ & $4.37 \mathrm{e} 7$ & $6.55 \mathrm{e} 6$ & $8.24 \mathrm{e} 5$ \\
\hline Hansen (Muze-k) & $\mathrm{C} 25$ & $5.46 \mathrm{e} 5$ & $3.01 \mathrm{e} 12$ & & & $1.17 \mathrm{e} 6$ & $3.68 \mathrm{e} 6$ & $1.15 \mathrm{e} 7$ & $3.24 \mathrm{e} 7$ & $4.4 \mathrm{e} 7$ & $6.57 \mathrm{e} 6$ & $8.25 \mathrm{e} 5$ \\
\hline
\end{tabular}


Table A.3 - continued from previous page

\begin{tabular}{|c|c|c|c|c|c|c|c|c|c|c|c|c|}
\hline \multirow[t]{2}{*}{ Submitter } & \multirow[t]{2}{*}{ Case } & \multirow{2}{*}{$\begin{array}{c}\sigma \\
1 /(\Omega \mathrm{cm})\end{array}$} & \multirow{2}{*}{$\begin{array}{c}\kappa \\
\mathrm{erg} /(\mathrm{s} \mathrm{cm} \mathrm{K})\end{array}$} & \multirow{2}{*}{$\begin{array}{c}\eta \\
\mathrm{g} /(\mathrm{s} \mathrm{cm})\end{array}$} & \multirow{2}{*}{$\begin{array}{c}D \\
\mathrm{~cm}^{2} / \mathrm{s}\end{array}$} & \multicolumn{7}{|c|}{$d E / d x(\mathrm{eV} / \mathrm{cm})$} \\
\hline & & & & & & $1 \mathrm{keV}$ & $10 \mathrm{keV}$ & $100 \mathrm{keV}$ & $1 \mathrm{MeV}$ & $10 \mathrm{MeV}$ & $100 \mathrm{MeV}$ & $1 \mathrm{GeV}$ \\
\hline Hansen (Muze-s) & $\mathrm{C} 25$ & $5.45 \mathrm{e} 5$ & $3.01 \mathrm{e} 12$ & & & $1.17 \mathrm{e} 6$ & $3.68 \mathrm{e} 6$ & $1.15 \mathrm{e} 7$ & $3.24 \mathrm{e} 7$ & $4.4 \mathrm{e} 7$ & $6.57 \mathrm{e} 6$ & $8.25 \mathrm{e} 5$ \\
\hline Haxhimali, Rudd & $\mathrm{C} 25$ & & & 5.38 & & & & & & & & \\
\hline Copeland [28] & $\mathrm{C} 25$ & & & 7.68 & 4.61 & & & & & & & \\
\hline Copeland [30] & $\mathrm{C} 25$ & & & 5.78 & 8.41 & & & & & & & \\
\hline Copeland [31] & $\mathrm{C} 25$ & & & 5.41 & 7.91 & & & & & & & \\
\hline Copeland [29] & $\mathrm{C} 25$ & $1.02 \mathrm{e} 6$ & $3.16 \mathrm{e} 12$ & & & & & & & & & \\
\hline Clérouin (PIJ) & $\mathrm{C} 31$ & $1.12 \mathrm{e} 4$ & $6.36 \mathrm{e} 6$ & & & & & & & & & \\
\hline Hansen (Bemuze) & $\mathrm{C} 31$ & $1.03 \mathrm{e} 4$ & $5.83 \mathrm{e} 6$ & & & $2.44 \mathrm{e} 8$ & $7.83 \mathrm{e} 8$ & $2.91 \mathrm{e} 9$ & $1.87 \mathrm{e} 9$ & $3.75 \mathrm{e} 8$ & $5.43 \mathrm{e} 7$ & $7.09 \mathrm{e} 6$ \\
\hline Hansen (Muze-k) & $\mathrm{C} 31$ & $6.54 \mathrm{e} 4$ & $3.65 \mathrm{e} 7$ & & & $2.54 \mathrm{e} 8$ & $8.11 \mathrm{e} 8$ & $2.91 \mathrm{e} 9$ & $2.05 \mathrm{e} 9$ & $3.88 \mathrm{e} 8$ & $5.55 \mathrm{e} 7$ & $7.2 \mathrm{e} 6$ \\
\hline Hansen (Muze-s) & $\mathrm{C} 31$ & $5.29 \mathrm{e} 4$ & $2.96 \mathrm{e} 7$ & & & $2.53 \mathrm{e} 8$ & $8.09 \mathrm{e} 8$ & $2.91 \mathrm{e} 9$ & $2.04 \mathrm{e} 9$ & $3.87 \mathrm{e} 8$ & $5.55 \mathrm{e} 7$ & $7.2 \mathrm{e} 6$ \\
\hline Clérouin (OFMD) & $\mathrm{C} 31$ & $2.4 \mathrm{e} 4$ & $1.36 \mathrm{e} 7$ & & & & & & & & & \\
\hline Haxhimali, Rudd & $\mathrm{C} 31$ & & & $1.19 \mathrm{e} 5$ & & & & & & & & \\
\hline Sjostrom (TFMD) & $\mathrm{C} 31$ & & & & $2.50 \mathrm{e}-5$ & & & & & & & \\
\hline Copeland [28] & $\mathrm{C} 31$ & & & 11.9 & 0.714 & & & & & & & \\
\hline Copeland [30] & $\mathrm{C} 31$ & & & $1.46 \mathrm{e}-5$ & $2.26 \mathrm{e}-6$ & & & & & & & \\
\hline Copeland [31] & $\mathrm{C} 31$ & & & 0.00131 & $1.94 \mathrm{e}-4$ & & & & & & & \\
\hline Copeland [29] & $\mathrm{C} 31$ & $4.03 \mathrm{e} 3$ & $2.28 \mathrm{e} 6$ & & & & & & & & & \\
\hline Clérouin (PIJ) & $\mathrm{C} 32$ & $1.12 \mathrm{e} 4$ & $6.35 \mathrm{e} 7$ & 0.0815 & $4.59 \mathrm{e}-4$ & & & & & & & \\
\hline Dharma-wardana & $\mathrm{C} 32$ & $7.11 \mathrm{e} 3$ & & & & & & & & & & \\
\hline Desjarlais & $\mathrm{C} 32$ & $1.61 \mathrm{e} 4$ & $9.01 \mathrm{e} 7$ & & & & & & & & & \\
\hline Hansen (Bemuze) & $\mathrm{C} 32$ & $8.22 \mathrm{e} 3$ & $4.65 \mathrm{e} 7$ & & & $2.44 \mathrm{e} 8$ & $7.83 \mathrm{e} 8$ & $2.9 \mathrm{e} 9$ & $1.87 \mathrm{e} 9$ & $3.75 \mathrm{e} 8$ & $5.43 \mathrm{e} 7$ & $7.09 \mathrm{e} 6$ \\
\hline Hansen (Muze-k) & $\mathrm{C} 32$ & $1.34 \mathrm{e} 4$ & $7.55 \mathrm{e} 7$ & & & $2.54 \mathrm{e} 8$ & $8.12 \mathrm{e} 8$ & $2.91 \mathrm{e} 9$ & $2.05 \mathrm{e} 9$ & $3.88 \mathrm{e} 8$ & $5.55 \mathrm{e} 7$ & $7.2 \mathrm{e} 6$ \\
\hline Hansen (Muze-s) & $\mathrm{C} 32$ & $1.15 \mathrm{e} 4$ & $6.49 \mathrm{e} 7$ & & & $2.53 \mathrm{e} 8$ & $8.1 \mathrm{e} 8$ & $2.91 \mathrm{e} 9$ & $2.04 \mathrm{e} 9$ & $3.87 \mathrm{e} 8$ & $5.55 \mathrm{e} 7$ & $7.2 \mathrm{e} 6$ \\
\hline Baalrud & $\mathrm{C} 32$ & & & 0.00564 & $8.25 \mathrm{e}-4$ & & & & & & & \\
\hline Clérouin (OFMD) & $\mathrm{C} 32$ & $1.24 \mathrm{e} 4$ & $7.05 \mathrm{e} 7$ & 0.0465 & $7.10 \mathrm{e}-4$ & & & & & & & \\
\hline Daligault & $\mathrm{C} 32$ & & & 0.0422 & $8.53 e-4$ & & & & & & & \\
\hline Haxhimali, Rudd & $\mathrm{C} 32$ & & & 0.0256 & & & & & & & & \\
\hline Sjostrom (KSMD) & $\mathrm{C} 32$ & & & & 0.00101 & & & & & & & \\
\hline Sjostrom (TFMD) & $\mathrm{C} 32$ & & & & $6.90 \mathrm{e}-4$ & & & & & & & \\
\hline Starrett, Saumon & $\mathrm{C} 32$ & $1.17 \mathrm{e} 4$ & $6.34 \mathrm{e} 7$ & & & & & & & & & \\
\hline Copeland [28] & $\mathrm{C} 32$ & & & 3.78 & 0.227 & & & & & & & \\
\hline Copeland [30] & $\mathrm{C} 32$ & & & 0.00217 & $3.39 \mathrm{e}-4$ & & & & & & & \\
\hline Copeland [31] & $\mathrm{C} 32$ & & & 0.00892 & 0.00136 & & & & & & & \\
\hline Hou (AAHNC) & $\mathrm{C} 32$ & & & 0.019 & $6.00 \mathrm{e}-4$ & & & & & & & \\
\hline Copeland [29] & $\mathrm{C} 32$ & $4.08 \mathrm{e} 3$ & $2.32 \mathrm{e} 7$ & & & & & & & & & \\
\hline Grabowski & $\mathrm{C} 33$ & & & & & & $9.48 \mathrm{e} 8$ & $2.88 \mathrm{e} 9$ & $2.09 \mathrm{e} 9$ & $3.76 \mathrm{e} 8$ & $5.44 \mathrm{e} 7$ & \\
\hline Clérouin (PIJ) & $\mathrm{C} 33$ & $9.28 \mathrm{e} 3$ & $5.09 \mathrm{e} 8$ & 0.0587 & 0.0075 & & & & & & & \\
\hline Dharma-wardana & $\mathrm{C} 33$ & $7.44 \mathrm{e} 3$ & & & & & & & & & & \\
\hline Hansen (Bemuze) & $\mathrm{C} 33$ & $1.31 \mathrm{e} 4$ & $6.68 \mathrm{e} 8$ & & & $2.26 \mathrm{e} 8$ & $7.16 \mathrm{e} 8$ & $2.28 \mathrm{e} 9$ & $1.77 \mathrm{e} 9$ & $3.68 \mathrm{e} 8$ & $5.37 \mathrm{e} 7$ & $7.03 \mathrm{e} 6$ \\
\hline
\end{tabular}


Table A.3 - continued from previous page

\begin{tabular}{|c|c|c|c|c|c|c|c|c|c|c|c|c|}
\hline \multirow[t]{2}{*}{ Submitter } & \multirow[t]{2}{*}{ Case } & \multirow{2}{*}{$\begin{array}{c}\sigma \\
1 /(\Omega \mathrm{cm})\end{array}$} & \multirow{2}{*}{$\begin{array}{c}\kappa \\
\mathrm{erg} /(\mathrm{s} \mathrm{cm} \mathrm{K})\end{array}$} & \multirow{2}{*}{$\begin{array}{c}\eta \\
\mathrm{g} /(\mathrm{s} \mathrm{cm})\end{array}$} & \multirow{2}{*}{$\begin{array}{c}D \\
\mathrm{~cm}^{2} / \mathrm{s} \\
\end{array}$} & \multicolumn{7}{|c|}{$d E / d x(\mathrm{eV} / \mathrm{cm})$} \\
\hline & & & & & & $1 \mathrm{keV}$ & $10 \mathrm{keV}$ & $100 \mathrm{keV}$ & $1 \mathrm{MeV}$ & $10 \mathrm{MeV}$ & $100 \mathrm{MeV}$ & $1 \mathrm{GeV}$ \\
\hline Hansen (Muze-k) & C33 & $1.35 \mathrm{e} 4$ & $6.85 \mathrm{e} 8$ & & & $2.49 \mathrm{e} 8$ & $7.89 \mathrm{e} 8$ & $2.54 \mathrm{e} 9$ & $2.03 \mathrm{e} 9$ & $3.88 \mathrm{e} 8$ & $5.55 \mathrm{e} 7$ & $7.2 \mathrm{e} 6$ \\
\hline Hansen (Muze-s) & C33 & $1.23 \mathrm{e} 4$ & $6.32 \mathrm{e} 8$ & & & $2.48 \mathrm{e} 8$ & $7.86 \mathrm{e} 8$ & $2.53 \mathrm{e} 9$ & $2.02 \mathrm{e} 9$ & $3.87 \mathrm{e} 8$ & $5.54 \mathrm{e} 7$ & $7.19 \mathrm{e} 6$ \\
\hline Baalrud & C33 & & & 0.047 & 0.00711 & & & & & & & \\
\hline Clérouin (OFMD) & C33 & $9.43 \mathrm{e} 3$ & $5.15 \mathrm{e} 8$ & 0.045 & 0.0082 & & & & & & & \\
\hline Daligault & C33 & & & 0.0651 & 0.00752 & & & & & & & \\
\hline Haxhimali, Rudd & C33 & & & 0.0851 & & & & & & & & \\
\hline Sjostrom (TFMD) & C33 & & & & 0.0082 & & & & & & & \\
\hline Starrett, Saumon & C33 & $1.33 \mathrm{e} 4$ & $4.9 \mathrm{e} 8$ & & & & & & & & & \\
\hline Copeland [28] & C33 & & & 1.31 & 0.0784 & & & & & & & \\
\hline Copeland [30] & C33 & & & 0.026 & 0.00424 & & & & & & & \\
\hline Copeland [31] & C33 & & & 0.0794 & 0.0126 & & & & & & & \\
\hline Hou (AAHNC) & C33 & & & 0.048 & 0.0079 & & & & & & & \\
\hline Copeland [29] & C33 & $7.91 \mathrm{e} 3$ & $4.17 \mathrm{e} 8$ & & & & & & & & & \\
\hline Grabowski & C34 & & & & & & $3.29 \mathrm{e} 8$ & $9.81 \mathrm{e} 8$ & $1.68 \mathrm{e} 9$ & $4.02 \mathrm{e} 8$ & $5.55 \mathrm{e} 7$ & \\
\hline Clérouin (PIJ) & C34 & $7.54 \mathrm{e} 4$ & $3.72 \mathrm{e} 10$ & 0.342 & 0.0557 & & & & & & & \\
\hline Dharma-wardana & C34 & $1.66 \mathrm{e} 4$ & & & & & & & & & & \\
\hline Hansen (Bemuze) & C34 & $5.48 \mathrm{e} 4$ & $2.92 \mathrm{e} 10$ & & & $8 . e 7$ & $2.51 \mathrm{e} 8$ & $7.51 \mathrm{e} 8$ & $1.52 \mathrm{e} 9$ & $3.77 \mathrm{e} 8$ & $5.47 \mathrm{e} 7$ & $7.13 \mathrm{e} 6$ \\
\hline Hansen (Muze-k) & C34 & $5.53 \mathrm{e} 4$ & $2.94 \mathrm{e} 10$ & & & $9.62 \mathrm{e} 7$ & $3.03 \mathrm{e} 8$ & $9.04 \mathrm{e} 8$ & $1.82 \mathrm{e} 9$ & $4.04 \mathrm{e} 8$ & $5.72 \mathrm{e} 7$ & $7.37 \mathrm{e} 6$ \\
\hline Hansen (Muze-s) & C34 & $5.37 \mathrm{e} 4$ & $2.87 \mathrm{e} 10$ & & & $9.6 \mathrm{e} 7$ & $3.02 \mathrm{e} 8$ & $9.02 \mathrm{e} 8$ & $1.82 \mathrm{e} 9$ & $4.03 \mathrm{e} 8$ & $5.72 \mathrm{e} 7$ & $7.37 \mathrm{e} 6$ \\
\hline Baalrud & C34 & & & 0.342 & 0.0562 & & & & & & & \\
\hline Clérouin (OFMD) & C34 & $7.74 \mathrm{e} 4$ & $3.79 \mathrm{e} 10$ & 0.38 & 0.064 & & & & & & & \\
\hline Daligault & C34 & & & 0.343 & 0.0589 & & & & & & & \\
\hline Haxhimali, Rudd & C34 & & & 0.478 & & & & & & & & \\
\hline Sjostrom (TFMD) & C34 & & & & 0.069 & & & & & & & \\
\hline Starrett, Saumon & C34 & $4.6 \mathrm{e} 4$ & $1.1 \mathrm{e} 10$ & & & & & & & & & \\
\hline Copeland [28] & C34 & & & 1.09 & 0.0652 & & & & & & & \\
\hline Copeland [30] & C34 & & & 0.297 & 0.0485 & & & & & & & \\
\hline Copeland [31] & C34 & & & 0.466 & 0.076 & & & & & & & \\
\hline Hou (AAHNC) & C34 & & & 0.329 & 0.0408 & & & & & & & \\
\hline Copeland [29] & C34 & $1 . e 5$ & $3.03 \mathrm{e} 10$ & & & & & & & & & \\
\hline Clérouin (PIJ) & C35 & $1.07 \mathrm{e} 6$ & $5.49 \mathrm{e} 12$ & 7.61 & 1.24 & & & & & & & \\
\hline Dharma-wardana & C35 & 10.5 & & & & & & & & & & \\
\hline Hansen (Bemuze) & C35 & $7.13 \mathrm{e} 5$ & $3.92 \mathrm{e} 12$ & & & $8.7 \mathrm{e} 6$ & $2.75 \mathrm{e} 7$ & $8.6 \mathrm{e} 7$ & $2.45 \mathrm{e} 8$ & $3.54 \mathrm{e} 8$ & $5.72 \mathrm{e} 7$ & $7.41 \mathrm{e} 6$ \\
\hline Hansen (Muze-k) & $\mathrm{C} 35$ & $7.31 \mathrm{e} 5$ & $3.99 \mathrm{e} 12$ & & & $8.86 \mathrm{e} 6$ & $2.8 \mathrm{e} 7$ & $8.75 \mathrm{e} 7$ & $2.49 \mathrm{e} 8$ & $3.58 \mathrm{e} 8$ & $5.75 \mathrm{e} 7$ & $7.43 \mathrm{e} 6$ \\
\hline Hansen (Muze-s) & C35 & $7.29 \mathrm{e} 5$ & $3.99 \mathrm{e} 12$ & & & $8.86 \mathrm{e} 6$ & $2.8 \mathrm{e} 7$ & $8.75 \mathrm{e} 7$ & $2.49 \mathrm{e} 8$ & $3.58 \mathrm{e} 8$ & $5.75 \mathrm{e} 7$ & $7.43 \mathrm{e} 6$ \\
\hline Baalrud & C35 & & & 9.05 & 1.4 & & & & & & & \\
\hline Clérouin (OFMD) & C35 & $1.09 \mathrm{e} 6$ & $5.59 \mathrm{e} 12$ & 9. & 1.41 & & & & & & & \\
\hline Haxhimali, Rudd & C35 & & & 8.89 & & & & & & & & \\
\hline Copeland [28] & $\mathrm{C} 35$ & & & 11.6 & 0.697 & & & & & & & \\
\hline
\end{tabular}


Table A.3 - continued from previous page

\begin{tabular}{|c|c|c|c|c|c|c|c|c|c|c|c|c|}
\hline \multirow[t]{2}{*}{ Submitter } & \multirow[t]{2}{*}{ Case } & \multirow{2}{*}{$\begin{array}{c}\sigma \\
1 /(\Omega \mathrm{cm})\end{array}$} & \multirow{2}{*}{$\begin{array}{c}\kappa \\
\operatorname{erg} /(\mathrm{s} \mathrm{cm} \mathrm{K})\end{array}$} & \multirow{2}{*}{$\begin{array}{c}\eta \\
\mathrm{g} /(\mathrm{s} \mathrm{cm})\end{array}$} & \multirow{2}{*}{$\begin{array}{c}D \\
\mathrm{~cm}^{2} / \mathrm{s}\end{array}$} & \multicolumn{7}{|c|}{$d E / d x(\mathrm{eV} / \mathrm{cm})$} \\
\hline & & & & & & $1 \mathrm{keV}$ & $10 \mathrm{keV}$ & $100 \mathrm{keV}$ & $1 \mathrm{MeV}$ & $10 \mathrm{MeV}$ & $100 \mathrm{MeV}$ & $1 \mathrm{GeV}$ \\
\hline Copeland [30] & $\mathrm{C} 35$ & & & 10. & 1.55 & & & & & & & \\
\hline Copeland [31] & $\mathrm{C} 35$ & & & 8.87 & 1.36 & & & & & & & \\
\hline Hou (AAHNC) & C35 & & & 2.66 & 0.531 & & & & & & & \\
\hline Copeland [29] & C35 & $1.33 \mathrm{e} 6$ & $4.03 \mathrm{e} 12$ & & & & & & & & & \\
\hline Clérouin (PIJ) & C41 & $8.91 \mathrm{e} 4$ & $5.06 \mathrm{e} 7$ & & & & & & & & & \\
\hline Hansen (Bemuze) & C41 & $5.81 \mathrm{e} 4$ & $3.28 \mathrm{e} 7$ & & & $3.85 \mathrm{e} 8$ & $1.22 \mathrm{e} 9$ & $3.93 \mathrm{e} 9$ & 1.e10 & $3.04 \mathrm{e} 9$ & $4.76 \mathrm{e} 8$ & $6.41 \mathrm{e} 7$ \\
\hline Hansen (Muze-k) & $\mathrm{C} 41$ & $3.38 \mathrm{e} 6$ & $1.48 \mathrm{e} 9$ & & & $4.01 \mathrm{e} 8$ & $1.27 \mathrm{e} 9$ & $4.07 \mathrm{e} 9$ & $1.21 \mathrm{e} 10$ & $3.22 \mathrm{e} 9$ & $4.9 \mathrm{e} 8$ & $6.55 \mathrm{e} 7$ \\
\hline Hansen (Muze-s) & C41 & $3.2 \mathrm{e} 6$ & $1.41 \mathrm{e} 9$ & & & $4.01 \mathrm{e} 8$ & $1.27 \mathrm{e} 9$ & $4.07 \mathrm{e} 9$ & $1.21 \mathrm{e} 10$ & $3.22 \mathrm{e} 9$ & $4.9 \mathrm{e} 8$ & $6.55 \mathrm{e} 7$ \\
\hline Clérouin (OFMD) & $\mathrm{C} 41$ & $3.03 \mathrm{e} 5$ & $1.72 \mathrm{e} 8$ & & & & & & & & & \\
\hline Copeland [28] & $\mathrm{C} 41$ & & & 230. & 1.38 & & & & & & & \\
\hline Copeland [30] & C41 & & & $3.32 \mathrm{e}-6$ & $5.14 \mathrm{e}-8$ & & & & & & & \\
\hline Copeland [31] & $\mathrm{C} 41$ & & & 0.00263 & $3.87 \mathrm{e}-5$ & & & & & & & \\
\hline Copeland [29] & C41 & $4.03 \mathrm{e} 4$ & $2.28 \mathrm{e} 7$ & & & & & & & & & \\
\hline Clérouin (PIJ) & $\mathrm{C} 42$ & $8.91 \mathrm{e} 4$ & $5.06 \mathrm{e} 8$ & & & & & & & & & \\
\hline Hansen (Bemuze) & $\mathrm{C} 42$ & $3.49 \mathrm{e} 4$ & $1.98 \mathrm{e} 8$ & & & $3.84 \mathrm{e} 8$ & $1.22 \mathrm{e} 9$ & $3.93 \mathrm{e} 9$ & 1.e10 & $3.03 \mathrm{e} 9$ & $4.75 \mathrm{e} 8$ & $6.41 \mathrm{e} 7$ \\
\hline Hansen (Muze-k) & $\mathrm{C} 42$ & $2.51 \mathrm{e} 5$ & $1.41 \mathrm{e} 9$ & & & $4.01 \mathrm{e} 8$ & $1.27 \mathrm{e} 9$ & $4.07 \mathrm{e} 9$ & $1.21 \mathrm{e} 10$ & $3.22 \mathrm{e} 9$ & $4.9 \mathrm{e} 8$ & $6.55 \mathrm{e} 7$ \\
\hline Hansen (Muze-s) & $\mathrm{C} 42$ & $2.39 \mathrm{e} 5$ & $1.35 \mathrm{e} 9$ & & & $4.01 \mathrm{e} 8$ & $1.27 \mathrm{e} 9$ & $4.07 \mathrm{e} 9$ & $1.21 \mathrm{e} 10$ & $3.22 \mathrm{e} 9$ & $4.9 \mathrm{e} 8$ & $6.55 \mathrm{e} 7$ \\
\hline Clérouin (OFMD) & $\mathrm{C} 42$ & $1.28 \mathrm{e} 5$ & $7.26 \mathrm{e} 8$ & & & & & & & & & \\
\hline Haxhimali, Rudd & $\mathrm{C} 42$ & & & $2.12 \mathrm{e} 4$ & & & & & & & & \\
\hline Copeland [28] & $\mathrm{C} 42$ & & & 72.8 & 0.437 & & & & & & & \\
\hline Copeland [30] & $\mathrm{C} 42$ & & & 0.00105 & $1.62 \mathrm{e}-5$ & & & & & & & \\
\hline Copeland [31] & $\mathrm{C} 42$ & & & 0.0159 & $2.38 \mathrm{e}-4$ & & & & & & & \\
\hline Copeland [29] & $\mathrm{C} 42$ & $4.03 \mathrm{e} 4$ & $2.28 \mathrm{e} 8$ & & & & & & & & & \\
\hline Clérouin (PIJ) & $\mathrm{C} 43$ & $8.9 \mathrm{e} 4$ & $5.05 \mathrm{e} 9$ & 0.464 & 0.00151 & & & & & & & \\
\hline Hansen (Bemuze) & $\mathrm{C} 43$ & $6.24 \mathrm{e} 4$ & $3.51 \mathrm{e} 9$ & & & $3.85 \mathrm{e} 8$ & $1.22 \mathrm{e} 9$ & $3.92 \mathrm{e} 9$ & $9.91 \mathrm{e} 9$ & $3.03 \mathrm{e} 9$ & $4.75 \mathrm{e} 8$ & $6.41 \mathrm{e} 7$ \\
\hline Hansen (Muze-k) & $\mathrm{C} 43$ & $7.68 \mathrm{e} 4$ & $4.3 \mathrm{e} 9$ & & & $4.02 \mathrm{e} 8$ & $1.27 \mathrm{e} 9$ & $4.07 \mathrm{e} 9$ & $1.21 \mathrm{e} 10$ & $3.22 \mathrm{e} 9$ & $4.9 \mathrm{e} 8$ & $6.55 \mathrm{e} 7$ \\
\hline Hansen (Muze-s) & $\mathrm{C} 43$ & $7.43 \mathrm{e} 4$ & $4.16 \mathrm{e} 9$ & & & $4.01 \mathrm{e} 8$ & $1.27 \mathrm{e} 9$ & $4.07 \mathrm{e} 9$ & $1.21 \mathrm{e} 10$ & $3.22 \mathrm{e} 9$ & $4.9 \mathrm{e} 8$ & $6.55 \mathrm{e} 7$ \\
\hline Baalrud & $\mathrm{C} 43$ & & & 0.11 & 0.00162 & & & & & & & \\
\hline Clérouin (OFMD) & $\mathrm{C} 43$ & $9.72 \mathrm{e} 4$ & $5.52 \mathrm{e} 9$ & 0.43 & 0.0017 & & & & & & & \\
\hline Daligault & C43 & & & 0.414 & 0.00175 & & & & & & & \\
\hline Haxhimali, Rudd & $\mathrm{C} 43$ & & & 0.342 & & & & & & & & \\
\hline Starrett, Saumon & $\mathrm{C} 43$ & $6.43 \mathrm{e} 4$ & $3.49 \mathrm{e} 9$ & & & & & & & & & \\
\hline Copeland [28] & $\mathrm{C} 43$ & & & 23.1 & 0.139 & & & & & & & \\
\hline Copeland [30] & $\mathrm{C} 43$ & & & 0.0481 & $7.65 \mathrm{e}-4$ & & & & & & & \\
\hline Copeland [31] & $\mathrm{C} 43$ & & & 0.125 & 0.00195 & & & & & & & \\
\hline Hou (AAHNC) & $\mathrm{C} 43$ & & & 0.192 & 0.0017 & & & & & & & \\
\hline Copeland [29] & $\mathrm{C} 43$ & $4.18 \mathrm{e} 4$ & $2.37 \mathrm{e} 9$ & & & & & & & & & \\
\hline Grabowski & $\mathrm{C} 44$ & & & & & & $9.69 \mathrm{e} 8$ & $3.01 \mathrm{e} 9$ & $7.38 \mathrm{e} 9$ & $2.53 \mathrm{e} 9$ & $3.61 \mathrm{e} 8$ & \\
\hline Clérouin (PIJ) & $\mathrm{C} 44$ & $1.08 \mathrm{e} 5$ & $5.57 \mathrm{e} 10$ & 1.1 & 0.0163 & & & & & & & \\
\hline
\end{tabular}


Table A.3 - continued from previous page

\begin{tabular}{|c|c|c|c|c|c|c|c|c|c|c|c|c|}
\hline \multirow[t]{2}{*}{ Submitter } & \multirow[t]{2}{*}{ Case } & \multirow{2}{*}{$\begin{array}{c}\sigma \\
1 /(\Omega \mathrm{cm})\end{array}$} & \multirow{2}{*}{$\begin{array}{c}\kappa \\
\mathrm{erg} /(\mathrm{s} \mathrm{cm} \mathrm{K})\end{array}$} & \multirow{2}{*}{$\begin{array}{c}\eta \\
\mathrm{g} /(\mathrm{s} \mathrm{cm})\end{array}$} & \multirow{2}{*}{$\begin{array}{c}D \\
\mathrm{~cm}^{2} / \mathrm{s}\end{array}$} & \multicolumn{7}{|c|}{$d E / d x(\mathrm{eV} / \mathrm{cm})$} \\
\hline & & & & & & $1 \mathrm{keV}$ & $10 \mathrm{keV}$ & $100 \mathrm{keV}$ & $1 \mathrm{MeV}$ & $10 \mathrm{MeV}$ & $100 \mathrm{MeV}$ & $1 \mathrm{GeV}$ \\
\hline Hansen (Bemuze) & $\mathrm{C} 44$ & $1.05 \mathrm{e} 5$ & $5.68 \mathrm{e} 10$ & & & $2.89 \mathrm{e} 8$ & $9.12 \mathrm{e} 8$ & $2.82 \mathrm{e} 9$ & $7.45 \mathrm{e} 9$ & $3.03 \mathrm{e} 9$ & $4.77 \mathrm{e} 8$ & $6.43 \mathrm{e} 7$ \\
\hline Hansen (Muze-k) & $\mathrm{C} 44$ & $1.16 \mathrm{e} 5$ & $6.14 \mathrm{e} 10$ & & & $3.33 \mathrm{e} 8$ & $1.05 \mathrm{e} 9$ & $3.26 \mathrm{e} 9$ & $8.77 \mathrm{e} 9$ & $3.22 \mathrm{e} 9$ & $4.92 \mathrm{e} 8$ & $6.57 \mathrm{e} 7$ \\
\hline Hansen (Muze-s) & $\mathrm{C} 44$ & $1.12 \mathrm{e} 5$ & $5.99 \mathrm{e} 10$ & & & $3.32 \mathrm{e} 8$ & $1.05 \mathrm{e} 9$ & $3.26 \mathrm{e} 9$ & $8.75 \mathrm{e} 9$ & $3.22 \mathrm{e} 9$ & $4.92 \mathrm{e} 8$ & $6.57 \mathrm{e} 7$ \\
\hline Baalrud & $\mathrm{C} 44$ & & & 1.1 & 0.0179 & & & & & & & \\
\hline Clérouin (OFMD) & $\mathrm{C} 44$ & $1.03 \mathrm{e} 5$ & $5.37 \mathrm{e} 10$ & 1.3 & 0.0171 & & & & & & & \\
\hline Daligault & $\mathrm{C} 44$ & & & 1.17 & 0.0186 & & & & & & & \\
\hline Haxhimali, Rudd & $\mathrm{C} 44$ & & & 1.55 & & & & & & & & \\
\hline Starrett, Saumon & $\mathrm{C} 44$ & $1.02 \mathrm{e} 5$ & $3.08 \mathrm{e} 10$ & & & & & & & & & \\
\hline Copeland [28] & $\mathrm{C} 44$ & & & 8.54 & 0.0512 & & & & & & & \\
\hline Copeland [30] & $\mathrm{C} 44$ & & & 0.712 & 0.0117 & & & & & & & \\
\hline Copeland [31] & $\mathrm{C} 44$ & & & 1.36 & 0.0218 & & & & & & & \\
\hline Hou (AAHNC) & $\mathrm{C} 44$ & & & 0.776 & 0.0157 & & & & & & & \\
\hline Copeland [29] & $\mathrm{C} 44$ & $1.34 \mathrm{e} 5$ & $5.86 \mathrm{e} 10$ & & & & & & & & & \\
\hline Clérouin (PIJ) & $\mathrm{C} 45$ & $1.38 \mathrm{e} 6$ & $6.97 \mathrm{e} 12$ & 13.1 & 0.252 & & & & & & & \\
\hline Hansen (Bemuze) & $\mathrm{C} 45$ & $1.01 \mathrm{e} 6$ & $5.49 \mathrm{e} 12$ & & & $5.71 \mathrm{e} 7$ & $1.8 \mathrm{e} 8$ & $5.65 \mathrm{e} 8$ & $1.64 \mathrm{e} 9$ & $2.69 \mathrm{e} 9$ & $4.88 \mathrm{e} 8$ & $6.57 \mathrm{e} 7$ \\
\hline Hansen (Muze-k) & $\mathrm{C} 45$ & $1.05 \mathrm{e} 6$ & $5.71 \mathrm{e} 12$ & & & $5.94 \mathrm{e} 7$ & $1.88 \mathrm{e} 8$ & $5.88 \mathrm{e} 8$ & $1.7 \mathrm{e} 9$ & $2.75 \mathrm{e} 9$ & $4.93 \mathrm{e} 8$ & $6.61 \mathrm{e} 7$ \\
\hline Hansen (Muze-s) & $\mathrm{C} 45$ & $1.05 \mathrm{e} 6$ & $5.68 \mathrm{e} 12$ & & & $5.94 \mathrm{e} 7$ & $1.88 \mathrm{e} 8$ & $5.88 \mathrm{e} 8$ & $1.7 \mathrm{e} 9$ & $2.75 \mathrm{e} 9$ & $4.93 \mathrm{e} 8$ & $6.61 \mathrm{e} 7$ \\
\hline Baalrud & $\mathrm{C} 45$ & & & 15. & 0.242 & & & & & & & \\
\hline Clérouin (OFMD) & $\mathrm{C} 45$ & $1.34 \mathrm{e} 6$ & $6.84 \mathrm{e} 12$ & 17.8 & 0.253 & & & & & & & \\
\hline Haxhimali, Rudd & $\mathrm{C} 45$ & & & 17.9 & & & & & & & & \\
\hline Copeland [28] & $\mathrm{C} 45$ & & & 22.2 & 0.133 & & & & & & & \\
\hline Copeland [30] & $\mathrm{C} 45$ & & & 17.3 & 0.275 & & & & & & & \\
\hline Copeland [31] & $\mathrm{C} 45$ & & & 17.4 & 0.274 & & & & & & & \\
\hline Hou (AAHNC) & $\mathrm{C} 45$ & & & 8.69 & 0.171 & & & & & & & \\
\hline Copeland [29] & $\mathrm{C} 45$ & $1.72 \mathrm{e} 6$ & $5.59 \mathrm{e} 12$ & & & & & & & & & \\
\hline Clérouin (PIJ) & $\mathrm{CH} 11$ & 211. & $1.2 \mathrm{e} 5$ & $3.51 \mathrm{e}-4$ & 0.0105 & & & & & & & \\
\hline Haxhimali, Rudd & $\mathrm{CH} 11$ & & & $9.50 \mathrm{e}-4$ & & & & & & & & \\
\hline Marciante & $\mathrm{CH} 11$ & & & & 0.0255 & & & & & & & \\
\hline Copeland [28] & $\mathrm{CH} 11$ & & & 0.00842 & 0.104 & & & & & & & \\
\hline Copeland [30] & CH11 & & & $2.01 \mathrm{e}-4$ & 0.00742 & & & & & & & \\
\hline Copeland [31] & $\mathrm{CH} 11$ & & & $9.24 \mathrm{e}-4$ & 0.0312 & & & & & & & \\
\hline Clérouin (PIJ) & $\mathrm{CH} 12$ & 312. & $1.15 \mathrm{e} 6$ & 0.00268 & 0.13 & & & & & & & \\
\hline Haxhimali, Rudd & $\mathrm{CH} 12$ & & & 0.00456 & & & & & & & & \\
\hline Marciante & $\mathrm{CH} 12$ & & & & 0.24 & & & & & & & \\
\hline Copeland [28] & CH12 & & & 0.00777 & 0.105 & & & & & & & \\
\hline Copeland [30] & $\mathrm{CH} 12$ & & & 0.00286 & 0.117 & & & & & & & \\
\hline Copeland [31] & $\mathrm{CH} 12$ & & & 0.0066 & 0.26 & & & & & & & \\
\hline Clérouin (PIJ) & $\mathrm{CH} 13$ & $4.66 \mathrm{e} 3$ & $1.76 \mathrm{e} 8$ & 0.01 & 0.63 & & & & & & & \\
\hline Haxhimali, Rudd & $\mathrm{CH} 13$ & & & 0.0136 & & & & & & & & \\
\hline
\end{tabular}


Table A.3 - continued from previous page

\begin{tabular}{|c|c|c|c|c|c|c|c|c|c|c|c|c|}
\hline \multirow[t]{2}{*}{ Submitter } & \multirow[t]{2}{*}{ Case } & \multirow{2}{*}{$\begin{array}{c}\sigma \\
1 /(\Omega \mathrm{cm})\end{array}$} & \multirow{2}{*}{$\begin{array}{c}\kappa \\
\mathrm{erg} /(\mathrm{s} \mathrm{cm} \mathrm{K})\end{array}$} & \multirow{2}{*}{$\begin{array}{c}\eta \\
\mathrm{g} /(\mathrm{s} \mathrm{cm})\end{array}$} & \multirow{2}{*}{$\begin{array}{c}D \\
\mathrm{~cm}^{2} / \mathrm{s}\end{array}$} & \multicolumn{7}{|c|}{$d E / d x(\mathrm{eV} / \mathrm{cm})$} \\
\hline & & & & & & $1 \mathrm{keV}$ & $10 \mathrm{keV}$ & $100 \mathrm{keV}$ & $1 \mathrm{MeV}$ & $10 \mathrm{MeV}$ & $100 \mathrm{MeV}$ & $1 \mathrm{GeV}$ \\
\hline Marciante & $\mathrm{CH} 13$ & & & & 0.947 & & & & & & & \\
\hline Copeland [28] & $\mathrm{CH} 13$ & & & 0.023 & 0.393 & & & & & & & \\
\hline Copeland [30] & $\mathrm{CH} 13$ & & & 0.012 & 0.636 & & & & & & & \\
\hline Copeland [31] & $\mathrm{CH} 13$ & & & 0.0166 & 0.832 & & & & & & & \\
\hline Clérouin (PIJ) & $\mathrm{CH} 14$ & $5.56 \mathrm{e} 4$ & $2.5 \mathrm{e} 10$ & 0.201 & 19.8 & & & & & & & \\
\hline Haxhimali, Rudd & $\mathrm{CH} 14$ & & & 0.203 & & & & & & & & \\
\hline Copeland [28] & $\mathrm{CH} 14$ & & & 0.284 & 9.13 & & & & & & & \\
\hline Copeland [30] & $\mathrm{CH} 14$ & & & 0.23 & 16.4 & & & & & & & \\
\hline Copeland [31] & $\mathrm{CH} 14$ & & & 0.207 & 15. & & & & & & & \\
\hline Clérouin (PIJ) & $\mathrm{CH} 15$ & $1.02 \mathrm{e} 6$ & $4.51 \mathrm{e} 12$ & 24.6 & $2.74 \mathrm{e} 3$ & & & & & & & \\
\hline Haxhimali, Rudd & $\mathrm{CH} 15$ & & & 21.6 & & & & & & & & \\
\hline Copeland [28] & $\mathrm{CH} 15$ & & & 33.4 & $1.22 \mathrm{e} 3$ & & & & & & & \\
\hline Copeland [30] & $\mathrm{CH} 15$ & & & 22. & $1.62 \mathrm{e} 3$ & & & & & & & \\
\hline Copeland [31] & $\mathrm{CH} 15$ & & & 21.9 & $1.65 \mathrm{e} 3$ & & & & & & & \\
\hline Clérouin (PIJ) & $\mathrm{CH} 21$ & $4.11 \mathrm{e} 3$ & $2.33 \mathrm{e} 6$ & 0.00496 & 0.00126 & & & & & & & \\
\hline Desjarlais & $\mathrm{CH} 21$ & 130. & $7.2 \mathrm{e} 4$ & & & & & & & & & \\
\hline Clérouin (OFMD) & $\mathrm{CH} 21$ & & & 0.0025 & $2.80 \mathrm{e}-4$ & & & & & & & \\
\hline Haxhimali, Rudd & $\mathrm{CH} 21$ & & & 0.00147 & & & & & & & & \\
\hline Marciante & $\mathrm{CH} 21$ & & & & 0.00235 & & & & & & & \\
\hline Copeland [28] & $\mathrm{CH} 21$ & & & 0.312 & 0.388 & & & & & & & \\
\hline Copeland [30] & $\mathrm{CH} 21$ & & & $1.83 \mathrm{e}-4$ & $6.33 e-4$ & & & & & & & \\
\hline Copeland [31] & $\mathrm{CH} 21$ & & & $8.76 \mathrm{e}-4$ & 0.00281 & & & & & & & \\
\hline Clérouin (PIJ) & $\mathrm{CH} 22$ & $2.44 \mathrm{e} 3$ & $1.39 \mathrm{e} 7$ & 0.00461 & 0.0147 & & & & & & & \\
\hline Desjarlais & $\mathrm{CH} 22$ & $1.61 \mathrm{e} 3$ & $6.58 \mathrm{e} 6$ & & & & & & & & & \\
\hline Clérouin (OFMD) & $\mathrm{CH} 22$ & & & 0.0083 & 0.0242 & & & & & & & \\
\hline Haxhimali, Rudd & $\mathrm{CH} 22$ & & & 0.00847 & & & & & & & & \\
\hline Marciante & $\mathrm{CH} 22$ & & & & 0.029 & & & & & & & \\
\hline Sjostrom (TFMD) & $\mathrm{CH} 22$ & & & & 0.037 & & & & & & & \\
\hline Copeland [28] & $\mathrm{CH} 22$ & & & 0.105 & 0.13 & & & & & & & \\
\hline Copeland [30] & $\mathrm{CH} 22$ & & & 0.00231 & 0.00955 & & & & & & & \\
\hline Copeland [31] & $\mathrm{CH} 22$ & & & 0.00833 & 0.0313 & & & & & & & \\
\hline Clérouin (PIJ) & $\mathrm{CH} 23$ & $5.53 \mathrm{e} 3$ & $2.04 \mathrm{e} 8$ & 0.031 & 0.176 & & & & & & & \\
\hline Desjarlais & $\mathrm{CH} 23$ & $5.1 \mathrm{e} 3$ & $1.88 \mathrm{e} 8$ & & & & & & & & & \\
\hline Haxhimali, Rudd & $\mathrm{CH} 23$ & & & 0.0451 & & & & & & & & \\
\hline Marciante & $\mathrm{CH} 23$ & & & & 0.233 & & & & & & & \\
\hline Sjostrom (TFMD) & $\mathrm{CH} 23$ & & & & 0.47 & & & & & & & \\
\hline Copeland [28] & $\mathrm{CH} 23$ & & & 0.104 & 0.139 & & & & & & & \\
\hline Copeland [30] & $\mathrm{CH} 23$ & & & 0.0303 & 0.152 & & & & & & & \\
\hline Copeland [31] & $\mathrm{CH} 23$ & & & 0.0562 & 0.269 & & & & & & & \\
\hline
\end{tabular}


Table A.3 - continued from previous page

\begin{tabular}{|c|c|c|c|c|c|c|c|c|c|c|c|c|}
\hline \multirow[t]{2}{*}{ Submitter } & \multirow[t]{2}{*}{ Case } & \multirow{2}{*}{$\begin{array}{c}\sigma \\
1 /(\Omega \mathrm{cm})\end{array}$} & \multirow{2}{*}{$\begin{array}{c}\kappa \\
\mathrm{erg} /(\mathrm{s} \mathrm{cm} \mathrm{K})\end{array}$} & \multirow{2}{*}{$\begin{array}{c}\eta \\
\mathrm{g} /(\mathrm{s} \mathrm{cm})\end{array}$} & \multirow{2}{*}{$\begin{array}{c}D \\
\mathrm{~cm}^{2} / \mathrm{s}\end{array}$} & \multicolumn{7}{|c|}{$d E / d x(\mathrm{eV} / \mathrm{cm})$} \\
\hline & & & & & & $1 \mathrm{keV}$ & $10 \mathrm{keV}$ & $100 \mathrm{keV}$ & $1 \mathrm{MeV}$ & $10 \mathrm{MeV}$ & $100 \mathrm{MeV}$ & $1 \mathrm{GeV}$ \\
\hline Clérouin (PIJ) & $\mathrm{CH} 24$ & $7.24 \mathrm{e} 4$ & $3.2 \mathrm{e} 10$ & 0.312 & 2.34 & & & & & & & \\
\hline Haxhimali, Rudd & $\mathrm{CH} 24$ & & & 0.387 & & & & & & & & \\
\hline Copeland [28] & $\mathrm{CH} 24$ & & & 0.576 & 1.55 & & & & & & & \\
\hline Copeland [30] & $\mathrm{CH} 24$ & & & 0.402 & 2.75 & & & & & & & \\
\hline Copeland [31] & $\mathrm{CH} 24$ & & & 0.411 & 2.77 & & & & & & & \\
\hline Clérouin (PIJ) & $\mathrm{CH} 25$ & $1.26 \mathrm{e} 6$ & $5.55 \mathrm{e} 12$ & 31.4 & 344. & & & & & & & \\
\hline Haxhimali, Rudd & $\mathrm{CH} 25$ & & & 28. & & & & & & & & \\
\hline Copeland [28] & $\mathrm{CH} 25$ & & & 41.7 & 150. & & & & & & & \\
\hline Copeland [30] & $\mathrm{CH} 25$ & & & 29.3 & 215. & & & & & & & \\
\hline Copeland [31] & $\mathrm{CH} 25$ & & & 28.3 & 213. & & & & & & & \\
\hline Clérouin (PIJ) & CH31 & $2.47 \mathrm{e} 4$ & $1.4 \mathrm{e} 7$ & & & & & & & & & \\
\hline Clérouin (OFMD) & CH31 & & & 0.17 & $2.10 \mathrm{e}-5$ & & & & & & & \\
\hline Haxhimali, Rudd & CH31 & & & 0.0982 & & & & & & & & \\
\hline Marciante & $\mathrm{CH} 31$ & & & & $1.15 \mathrm{e}-4$ & & & & & & & \\
\hline Marciante & $\mathrm{CH} 41$ & & & & $1.25 \mathrm{e}-6$ & & & & & & & \\
\hline Sjostrom (TFMD) & CH31 & & & & $2.50 \mathrm{e}-4$ & & & & & & & \\
\hline Copeland [28] & CH31 & & & 8.6 & 1.07 & & & & & & & \\
\hline Copeland [30] & CH31 & & & $4.90 \mathrm{e}-5$ & $4.15 e-5$ & & & & & & & \\
\hline Copeland [31] & $\mathrm{CH} 31$ & & & 0.00141 & $4.44 \mathrm{e}-4$ & & & & & & & \\
\hline Clérouin (PIJ) & CH32 & $2.47 \mathrm{e} 4$ & $1.4 \mathrm{e} 8$ & 0.049 & 0.00259 & & & & & & & \\
\hline Meyer, Collins & CH32 & $1.83 \mathrm{e} 4$ & $1.04 \mathrm{e} 8$ & 0.0266 & $1.90 \mathrm{e}-4$ & & & & & & & \\
\hline $\mathrm{Hu}(\mathrm{QMD})$ & $\mathrm{CH} 32$ & $2.25 \mathrm{e} 4$ & $1.26 \mathrm{e} 8$ & & & & & & & & & \\
\hline Baalrud & CH32 & & & 0.00702 & 0.0026 & & & & & & & \\
\hline Clérouin (OFMD) & CH32 & & & 0.041 & 0.00201 & & & & & & & \\
\hline Daligault & $\mathrm{CH} 32$ & & & 0.0309 & 0.00261 & & & & & & & \\
\hline Haxhimali, Rudd & CH32 & & & 0.00254 & & & & & & & & \\
\hline Marciante & CH32 & & & & 0.00342 & & & & & & & \\
\hline Marciante & $\mathrm{CH} 42$ & & & & $3.66 \mathrm{e}-4$ & & & & & & & \\
\hline Sjostrom (TFMD) & $\mathrm{CH} 32$ & & & & 0.0035 & & & & & & & \\
\hline Hu (Spitzer-Lee-More) & CH32 & & $1.54 \mathrm{e} 6$ & & & & & & & & & \\
\hline Copeland [28] & $\mathrm{CH} 32$ & & & 2.73 & 0.339 & & & & & & & \\
\hline Copeland [30] & $\mathrm{CH} 32$ & & & 0.00335 & 0.00129 & & & & & & & \\
\hline Copeland [31] & CH32 & & & 0.0105 & 0.00378 & & & & & & & \\
\hline Clérouin (PIJ) & $\mathrm{CH} 33$ & $1.79 \mathrm{e} 4$ & $9.96 \mathrm{e} 8$ & 0.0753 & 0.0362 & & & & & & & \\
\hline $\mathrm{Hu}(\mathrm{QMD})$ & CH33 & $1.76 \mathrm{e} 4$ & $1.08 \mathrm{e} 9$ & & & & & & & & & \\
\hline Baalrud & $\mathrm{CH} 33$ & & & 0.0596 & 0.0276 & & & & & & & \\
\hline Clérouin (OFMD) & $\mathrm{CH} 33$ & & & 0.0831 & 0.0364 & & & & & & & \\
\hline Daligault & $\mathrm{CH} 33$ & & & 0.0796 & 0.0302 & & & & & & & \\
\hline Haxhimali, Rudd & CH33 & & & 0.0116 & & & & & & & & \\
\hline
\end{tabular}


Table A.3 - continued from previous page

\begin{tabular}{|c|c|c|c|c|c|c|c|c|c|c|c|c|}
\hline \multirow[t]{2}{*}{ Submitter } & \multirow[t]{2}{*}{ Case } & \multirow{2}{*}{$\begin{array}{c}\sigma \\
1 /(\Omega \mathrm{cm})\end{array}$} & \multirow{2}{*}{$\begin{array}{c}\kappa \\
\mathrm{erg} /(\mathrm{s} \mathrm{cm} \mathrm{K})\end{array}$} & \multirow{2}{*}{$\begin{array}{c}\eta \\
\mathrm{g} /(\mathrm{s} \mathrm{cm})\end{array}$} & \multirow{2}{*}{$\begin{array}{c}D \\
\mathrm{~cm}^{2} / \mathrm{s}\end{array}$} & \multicolumn{7}{|c|}{$d E / d x(\mathrm{eV} / \mathrm{cm})$} \\
\hline & & & & & & $1 \mathrm{keV}$ & $10 \mathrm{keV}$ & $100 \mathrm{keV}$ & $1 \mathrm{MeV}$ & $10 \mathrm{MeV}$ & $100 \mathrm{MeV}$ & $1 \mathrm{GeV}$ \\
\hline Marciante & $\mathrm{CH} 33$ & & & & 0.0505 & & & & & & & \\
\hline Marciante & $\mathrm{CH} 43$ & & & & 0.00752 & & & & & & & \\
\hline Sjostrom (TFMD) & $\mathrm{CH} 33$ & & & & 0.055 & & & & & & & \\
\hline Hu (Spitzer-Lee-More) & $\mathrm{CH} 33$ & & $4.35 \mathrm{e} 8$ & & & & & & & & & \\
\hline Copeland [28] & $\mathrm{CH} 33$ & & & 0.99 & 0.119 & & & & & & & \\
\hline Copeland [30] & $\mathrm{CH} 33$ & & & 0.048 & 0.0234 & & & & & & & \\
\hline Copeland [31] & $\mathrm{CH} 33$ & & & 0.115 & 0.0519 & & & & & & & \\
\hline Clérouin (PIJ) & $\mathrm{CH} 34$ & $1.02 \mathrm{e} 5$ & $4.35 \mathrm{e} 10$ & 0.7 & 0.315 & & & & & & & \\
\hline Baalrud & $\mathrm{CH} 34$ & & & 0.674 & 0.531 & & & & & & & \\
\hline Clérouin (OFMD) & $\mathrm{CH} 34$ & & & 1. & 0.63 & & & & & & & \\
\hline Haxhimali, Rudd & $\mathrm{CH} 34$ & & & 0.0932 & & & & & & & & \\
\hline Sjostrom (TFMD) & $\mathrm{CH} 34$ & & & & 0.9 & & & & & & & \\
\hline Ticknor & $\mathrm{CH} 34$ & & & & 0.57 & & & & & & & \\
\hline Hu (Spitzer-Lee-More) & $\mathrm{CH} 34$ & & $4.04 \mathrm{e} 10$ & & & & & & & & & \\
\hline Copeland [28] & $\mathrm{CH} 34$ & & & 1.79 & 0.339 & & & & & & & \\
\hline Copeland [30] & $\mathrm{CH} 34$ & & & 0.836 & 0.533 & & & & & & & \\
\hline Copeland [31] & $\mathrm{CH} 34$ & & & 1.03 & 0.623 & & & & & & & \\
\hline Clérouin (PIJ) & $\mathrm{CH} 35$ & $1.61 \mathrm{e} 6$ & $7.21 \mathrm{e} 12$ & 41.7 & 46.8 & & & & & & & \\
\hline Baalrud & $\mathrm{CH} 35$ & & & 32.8 & 43.6 & & & & & & & \\
\hline Clérouin (OFMD) & $\mathrm{CH} 35$ & & & 39.9 & 21.3 & & & & & & & \\
\hline Haxhimali, Rudd & $\mathrm{CH} 35$ & & & 3.93 & & & & & & & & \\
\hline Hu (Spitzer-Lee-More) & $\mathrm{CH} 35$ & & $6.42 \mathrm{e} 12$ & & & & & & & & & \\
\hline Copeland [28] & $\mathrm{CH} 35$ & & & 56.1 & 19.5 & & & & & & & \\
\hline Copeland [30] & $\mathrm{CH} 35$ & & & 43.6 & 31.9 & & & & & & & \\
\hline Copeland [31] & $\mathrm{CH} 35$ & & & 39.6 & 29.6 & & & & & & & \\
\hline Clérouin (PIJ) & $\mathrm{CH} 41$ & $2.14 \mathrm{e} 5$ & $1.21 \mathrm{e} 8$ & & & & & & & & & \\
\hline Haxhimali, Rudd & $\mathrm{CH} 41$ & & & $2.53 \mathrm{e} 4$ & & & & & & & & \\
\hline Copeland [28] & $\mathrm{CH} 41$ & & & 155. & 1.92 & & & & & & & \\
\hline Copeland [30] & $\mathrm{CH} 41$ & & & $1.82 \mathrm{e}-5$ & $1.58 \mathrm{e}-6$ & & & & & & & \\
\hline Copeland [31] & $\mathrm{CH} 41$ & & & 0.00292 & $9.11 \mathrm{e}-5$ & & & & & & & \\
\hline Clérouin (PIJ) & $\mathrm{CH} 42$ & $2.14 \mathrm{e} 5$ & $1.21 \mathrm{e} 9$ & & & & & & & & & \\
\hline Haxhimali, Rudd & $\mathrm{CH} 42$ & & & 0.815 & & & & & & & & \\
\hline Ticknor & $\mathrm{CH} 15$ & & & & $2.39 \mathrm{e}-4$ & & & & & & & \\
\hline Copeland [28] & $\mathrm{CH} 42$ & & & 49. & 0.608 & & & & & & & \\
\hline Copeland [30] & $\mathrm{CH} 42$ & & & 0.00325 & $3.02 \mathrm{e}-4$ & & & & & & & \\
\hline Copeland [31] & $\mathrm{CH} 42$ & & & 0.0191 & $6.62 \mathrm{e}-4$ & & & & & & & \\
\hline Clérouin (PIJ) & $\mathrm{CH} 43$ & $1.94 \mathrm{e} 5$ & $1.1 \mathrm{e} 10$ & 0.339 & 0.00699 & & & & & & & \\
\hline Baalrud & $\mathrm{CH} 43$ & & & 0.146 & 0.00614 & & & & & & & \\
\hline Clérouin (OFMD) & $\mathrm{CH} 43$ & & & 0.35 & 0.0055 & & & & & & & \\
\hline
\end{tabular}


Table A.3 - continued from previous page

\begin{tabular}{|c|c|c|c|c|c|c|c|c|c|c|c|c|}
\hline \multirow[t]{2}{*}{ Submitter } & \multirow[t]{2}{*}{ Case } & \multirow{2}{*}{$\begin{array}{c}\sigma \\
1 /(\Omega \mathrm{cm})\end{array}$} & \multirow{2}{*}{$\begin{array}{c}\kappa \\
\mathrm{erg} /(\mathrm{s} \mathrm{cm} \mathrm{K})\end{array}$} & \multirow{2}{*}{$\begin{array}{c}\eta \\
\mathrm{g} /(\mathrm{s} \mathrm{cm})\end{array}$} & \multirow{2}{*}{$\begin{array}{c}D \\
\mathrm{~cm}^{2} / \mathrm{s}\end{array}$} & \multicolumn{7}{|c|}{$d E / d x(\mathrm{eV} / \mathrm{cm})$} \\
\hline & & & & & & $1 \mathrm{keV}$ & $10 \mathrm{keV}$ & $100 \mathrm{keV}$ & $1 \mathrm{MeV}$ & $10 \mathrm{MeV}$ & $100 \mathrm{MeV}$ & $1 \mathrm{GeV}$ \\
\hline Daligault & $\mathrm{CH} 43$ & & & 0.393 & 0.00587 & & & & & & & \\
\hline Haxhimali, Rudd & $\mathrm{CH} 43$ & & & 0.355 & & & & & & & & \\
\hline Ticknor & $\mathrm{CH} 25$ & & & & 0.006 & & & & & & & \\
\hline Copeland [28] & $\mathrm{CH} 43$ & & & 15.6 & 0.193 & & & & & & & \\
\hline Copeland [30] & $\mathrm{CH} 43$ & & & 0.0869 & 0.0039 & & & & & & & \\
\hline Copeland [31] & $\mathrm{CH} 43$ & & & 0.177 & 0.00745 & & & & & & & \\
\hline Clérouin (PIJ) & $\mathrm{CH} 44$ & $1.8 \mathrm{e} 5$ & $9.09 \mathrm{e} 10$ & 1.78 & 0.123 & & & & & & & \\
\hline Baalrud & $\mathrm{CH} 44$ & & & 1.78 & 0.117 & & & & & & & \\
\hline Clérouin (OFMD) & $\mathrm{CH} 44$ & & & 19.5 & 0.107 & & & & & & & \\
\hline Haxhimali, Rudd & $\mathrm{CH} 44$ & & & 2.53 & & & & & & & & \\
\hline Ticknor & $\mathrm{CH} 35$ & & & & 0.129 & & & & & & & \\
\hline Copeland [28] & $\mathrm{CH} 44$ & & & 8.57 & 0.11 & & & & & & & \\
\hline Copeland [30] & $\mathrm{CH} 44$ & & & 1.74 & 0.103 & & & & & & & \\
\hline Copeland [31] & $\mathrm{CH} 44$ & & & 2.62 & 0.149 & & & & & & & \\
\hline Clérouin (PIJ) & $\mathrm{CH} 45$ & $2.24 \mathrm{e} 6$ & $1.01 \mathrm{e} 13$ & 60.4 & 5.96 & & & & & & & \\
\hline Baalrud & $\mathrm{CH} 45$ & & & 47.1 & 5.49 & & & & & & & \\
\hline Clérouin (OFMD) & $\mathrm{CH} 45$ & & & 71.1 & 6.9 & & & & & & & \\
\hline Haxhimali, Rudd & $\mathrm{CH} 45$ & & & 61.9 & & & & & & & & \\
\hline Ticknor & $\mathrm{CH} 45$ & & & 70. & 6.7 & & & & & & & \\
\hline Copeland [28] & $\mathrm{CH} 45$ & & & 86.2 & 2.78 & & & & & & & \\
\hline Copeland [30] & $\mathrm{CH} 45$ & & & 69.4 & 4.99 & & & & & & & \\
\hline Copeland [31] & $\mathrm{CH} 45$ & & & 62.8 & 4.57 & & & & & & & \\
\hline
\end{tabular}




\section{References}

[1] H. G. Rinderknecht, P. A. Amendt, S. C. Wilks, G. Collins, Kinetic physics in icf: Present understanding and future directions, Plasma Physics and Controlled Fusion 60 (2018) 064001. doi:https://doi.org/10.1088/1361-6587/aab79f.

URL https://iopscience.iop.org/article/10.1088/ 1361-6587/aab79f/meta

[2] J. A. Gaffney, S. X. Hu, P. Arnault, A. Becker, L. X. Benedict, T. R. Boehly, P. M. Celliers, D. M. Ceperley, O. Čertík, J. Clérouin, G. W. Collins, L. A. Collins, J.-F. Danel, N. Desbiens, M. W. C. Dharmawardana, Y. H. Ding, A. F.-P. nella, M. C. Gregor, P. E. Grabowski, S. Hamel, S. B. Hansen, L. Harbour, X. T. He, D. D. Johnson, W. Kang, V. V. Karasiev, L. Kazandjian, M. D. Knudson, T. Ogitsu, C. Pierleoni, R. Piron, R. Redmer, G. Robert, D. Saumon, A. Shamp, T. Sjostrom, A. V. Smirnov, C. E. Starrett, P. A. Sterne, A. Wardlow, H. D. Whitley, B. Wilson, P. Zhang, E. Zurek, A review of equation-of-state models for inertial confinement fusion materials, High Energy Density Physics 28 (2018) 7-24. doi : https ://doi.org/10.1016/j.hedp. 2018.08. 001.

URL http://www.sciencedirect.com/science/article/pii/ S1574181818300508

[3] R. W. Lee, J. K. Nash, Y. Ralchenko, Review of the nlte kinetics code workshop, Journal of Quantitative Spectroscopy and Radiative Transfer 58 (4) (1997) 737 - 742, radiative Properties of Hot Dense Matter III. doi:https://doi.org/10.1016/S0022-4073(97)00079-4.

URL http://www.sciencedirect.com/science/article/pii/ S0022407397000794

[4] C. Bowen, A. Decoster, C. J. Fontes, K. B. Fournier, O. Peyrusse, Y. V. Ralchenko, Review of the nlte emissivities code comparison virtual workshop, Journal of Quantitative Spectroscopy and Radiative Transfer 81 (1) (2003) $71-84$, radiative Properties of Hot Dense Matter. doi:https://doi.org/10.1016/S0022-4073(03)00061-X.

URL http://www.sciencedirect.com/science/article/pii/ S002240730300061X

[5] C. Bowen, R. W. Lee, Y. Ralchenko, Comparing plasma population kinetics codes: Review of the nlte-3 kinetics workshop, Journal of Quantitative Spectroscopy and Radiative Transfer 99 (1) (2006) 102 - 119, radiative Properties of Hot Dense Matter. doi:https://doi.org/10. 1016/j.jqsrt.2005.05.008.

URL http://www.sciencedirect.com/science/article/pii/ S0022407305001378

[6] J. G. Rubiano, R. Florido, C. Bowen, R. W. Lee, Y. Ralchenko, Review of the 4th nlte code comparison workshop, High Energy Density Physics 3 (1) (2007) 225 - 232, radiative Properties of Hot Dense Matter. doi:https://doi.org/10.1016/j.hedp.2007.02.027. URL http://www.sciencedirect.com/science/article/pii/ S1574181807000341

[7] C. J. Fontes, J. Abdallah, C. Bowen, R. W. Lee, Y. Ralchenko, Review of the nlte-5 kinetics workshop, High Energy Density Physics 5 (1) (2009) 15 - 22. doi : https://doi .org/10.1016/j.hedp.2009.02.004. URL http://www.sciencedirect.com/science/article/pii/ S1574181809000056

[8] Nlte-6 workshop, unpublished (December 2009). URL https://nlte.nist.gov/NLTE6/

[9] H.-K. Chung, C. Bowen, C. J. Fontes, S. B. Hansen, Y. Ralchenko, Comparison and analysis of collisional-radiative models at the nlte7 workshop, High Energy Density Physics 9 (4) (2013) 645 - 652. doi:https://doi.org/10.1016/j.hedp.2013.06.001. URL http://www.sciencedirect.com/science/article/pii/ S157418181300147X

[10] R. Piron, F. Gilleron, Y. Aglitskiy, H.-K. Chung, C. J. Fontes, S. B. Hansen, O. Marchuk, H. A. Scott, E. Stambulchik, Y. Ralchenko, Review of the 9th nlte code comparison workshop, High Energy Density Physics 23 (2017) 38 - 47. doi:https://doi.org/10.1016/ j.hedp. 2017.02 .009$.

URL http://www.sciencedirect.com/science/article/pii/ S1574181817300162

[11] S. B. Hansen, H.-K. Chung, C. J. Fontes, Y. Ralchenko, H. A. Scott, E. Stambulchik, Review of the 10th non-lte code comparison workshop, High Energy Density Physics 35 (2020) 100693. doi:https: //doi.org/10.1016/j.hedp.2019.06.001.
URL http://www.sciencedirect.com/science/article/pii/ S1574181819300357

[12] S. J. Rose, A review of opacity workshops, Journal of Quantitative Spectroscopy and Radiative Transfer 51 (1) (1994) 317 - 318, special Issue Radiative Properties of Hot Dense Matter. doi:https: //doi.org/10.1016/0022-4073(94)90093-0.

URL http://www.sciencedirect.com/science/article/pii/ 0022407394900930

[13] A. Rickert, Review of the third international opacity workshop and code comparison study, Journal of Quantitative Spectroscopy and Radiative Transfer 54 (1) (1995) 325 - 332, radiative Properties of Hot Dense Matter II. doi : https://doi .org/10.1016/0022-4073(95)00067-U. URL http://www.sciencedirect.com/science/article/pii/ $002240739500067 \mathrm{U}$

[14] F. J. D. Serduke, E. Minguez, S. J. Davidson, C. A. Iglesias, Workopiv summary: lessons from iron opacities, Journal of Quantitative Spectroscopy and Radiative Transfer 65 (1) (2000) 527 - 541. doi : https : //doi.org/10.1016/S0022-4073(99)00094-1.

URL http://www.sciencedirect.com/science/article/pii/ S0022407399000941

[15] J. A. Frenje, P. E. Grabowski, C. K. Li, F. H. Séguin, A. B. Zylstra, M. Gatu Johnson, R. D. Petrasso, V. Y. Glebov, T. C. Sangster, Measurements of ion stopping around the bragg peak in high-energydensity plasmas, Phys. Rev. Lett. 115 (2015) 205001. doi :10.1103/ PhysRevLett.115.205001.

URL https://link.aps.org/doi/10.1103/PhysRevLett.115. 205001

[16] J. A. Frenje, R. Florido, R. Mancini, T. Nagayama, P. E. Grabowski, H. Rinderknecht, H. Sio, A. Zylstra, M. Gatu Johnson, C. K. Li, F. H. Séguin, R. D. Petrasso, V. Y. Glebov, S. P. Regan, Experimental validation of low- $z$ ion-stopping formalisms around the bragg peak in high-energy-density plasmas, Phys. Rev. Lett. 122 (2019) 015002. doi:10.1103/PhysRevLett.122.015002.

URL https://link.aps.org/doi/10.1103/PhysRevLett.122. 015002

[17] A. B. Zylstra, J. A. Frenje, P. E. Grabowski, C. K. Li, G. W. Collins, P. Fitzsimmons, S. Glenzer, F. Graziani, S. B. Hansen, S. X. Hu, M. G. Johnson, P. Keiter, H. Reynolds, J. R. Rygg, F. H. Séguin, R. D. Petrasso, Measurement of charged-particle stopping in warm dense plasma, Phys. Rev. Lett. 114 (2015) 215002. doi:10.1103/PhysRevLett.114. 215002.

URL https://link.aps.org/doi/10.1103/PhysRevLett.114. 215002

[18] A. B. Zylstra, J. A. Frenje, P. E. Grabowski, C. K. Li, G. W. Collins, P. Fitzsimmons, S. Glenzer, F. Graziani, S. B. Hansen, S. X. Hu, M. G. Johnson, P. Keiter, H. Reynolds, J. R. Rygg, F. H. Séguin, R. D. Petrasso, Development of a wdm platform for charged-particle stopping experiments, Journal of Physics: Conference Series 717 (1) (2016) 012118. URL http: //stacks . iop.org/1742-6596/717/i=1/a=012118

[19] Y. Ping, A. Fernandez-Panella, H. Sio, A. Correa, R. Shepherd, O. Landen, R. A. London, P. A. Sterne, H. D. Whitley, D. Fratanduono, T. R. Boehly, G. W. Collins, Differential heating: A versatile method for thermal conductivity measurements in high-energy-density matter, Physics of Plasmas 22 (9) (2015) 092701. doi : 10.1063/1.4929797. URL https : //doi.org/10.1063/1.4929797

[20] A. McKelvey, G. E. Kemp, P. A. Sterne, A. Fernandez-Panella, R. Shepherd, M. Marinak, A. Link, G. W. Collins, H. Sio, J. King, R. R. Freeman, R. Hua, C. McGuffey, J. Kim, F. N. Beg, Y. Ping, Thermal conductivity measurements of proton-heated warm dense aluminum, Scientific Reports 7 (2017) 7015. doi : 10.1038/s41598-017-07173-0. URL https : //doi .org/10.1038/s41598-017-07173-0

[21] S. D. Baalrud, J. Daligault, Effective potential theory for transport coefficients across coupling regimes, Phys. Rev. Lett. 110 (2013) 235001. doi:10.1103/PhysRevLett.110.235001.

URL https://link.aps.org/doi/10.1103/PhysRevLett.110. 235001

[22] J. Daligault, S. D. Baalrud, C. E. Starrett, D. Saumon, T. Sjostrom, Ionic transport coefficients of dense plasmas without molecular dynamics, Phys. Rev. Lett. 116 (2016) 075002. doi:10.1103/PhysRevLett. 116.075002 .

URL https://link.aps.org/doi/10.1103/PhysRevLett.116. 
075002

[23] R. J. Magyar, L. Shulenburger, A. D. Baczewski, Stopping of deuterium in warm dense deuterium from ehrenfest time-dependent density functional theory, Contributions to Plasma Physics 56 (5) (2016) 459-466. doi:10.1002/ctpp. 201500143.

URL http: //dx.doi.org/10.1002/ctpp. 201500143

[24] A. D. Baczewski, L. Shulenburger, M. P. Desjarlais, S. B. Hansen, R. J. Magyar, X-ray thomson scattering in warm dense matter without the chihara decomposition, Phys. Rev. Lett. 116 (2016) 115004. doi:10.1103/PhysRevLett.116.115004.

URL http://link.aps.org/doi/10.1103/PhysRevLett.116. 115004

[25] P. Arnault, Modeling viscosity and diffusion of plasma for pure elements and multicomponent mixtures from weakly to strongly coupled regimes, High Energy Density Physics 9 (4) (2013) 711 - 721. doi:http://dx.doi.org/10.1016/j.hedp.2013.08.001. URL http://www.sciencedirect.com/science/article/pii/ S1574181813001651

[26] F. Lambert, J. Clérouin, S. Mazevet, D. Gilles, Properties of hot dense plasmas by orbital-free molecular dynamics, Contributions to Plasma Physics 47 (2007) 272-280, dOI: 10.1002/ctpp.200710037.

[27] F. Lambert, J. Clérouin, J.-F. Danel, L. Kazandjian, S. Mazevet, Properties of Hot and Dense Matter by Orbital-Free Molecular Dynamics, Vol. 6 of Recent Advances in Computational Chemistry, World Scientific, Singapore, 2013. doi : 978-981-4436-72-4.

[28] S. Chapman, T. Cowling, The Mathematical Theory of Non-uniform Gases: An Account of the Kinetic Theory of Viscosity, Thermal Conduction, Ad Diffusion in Gases, The University Press, 1939. URL https : //books . google.com/books?id=d8PQAAAAMAAJ

[29] Y. T. Lee, R. M. More, An electron conductivity model for dense plasmas, The Physics of Fluids 27 (5) (1984) 1273-1286. doi: $10.1063 / 1.864744$

URL https://aip.scitation.org/doi/abs/10.1063/1. 864744

[30] C. Paquette, C. Pelletier, G. Fontaine, G. Michaud, Diffusion in white dwarfs - New results and comparative study, The Astrophysical Journal Supplement Series 61 (1986) 197-217. doi:10.1086/191112.

[31] L. G. Stanton, M. S. Murillo, Ionic transport in high-energydensity matter, Phys. Rev. E 93 (2016) 043203. doi: 10.1103/PhysRevE.93.043203.

URL https://link.aps.org/doi/10.1103/PhysRevE.93. 043203

[32] M. P. Desjarlais, C. R. Scullard, L. X. Benedict, H. D. Whitley, R. Redmer, Density-functional calculations of transport properties in the nondegenerate limit and the role of electron-electron scattering, Phys. Rev. E 95 (2017) 033203. doi : 10.1103/PhysRevE.95.033203.

URL https://link.aps.org/doi/10.1103/PhysRevE.95. 033203

[33] F. Perrot, Ion-ion interaction and equation of state of a dense plasma: Application to beryllium, Phys. Rev. E 47 (1993) 570-582. doi: 10. 1103/PhysRevE.47.570.

URL http://link.aps.org/doi/10.1103/PhysRevE.47.570

[34] F. Perrot, M. W. C. Dharma-wardana, Equation of state and transport properties of an interacting multispecies plasma: Application to a multiply ionized al plasma, Phys. Rev. E 52 (1995) 5352-5367. doi: 10.1103/PhysRevE.52.5352.

URL http://link.aps.org/doi/10.1103/PhysRevE.52.5352

[35] F. Perrot, M. W. C. Dharma-wardana, Theoretical issues in the calculation of the electrical resistivity of plasmas, International Journal of Thermophysics 20 (4) (1999) 1299-1311. doi:10.1023/A : 1022639928248. URL https : //doi .org/10.1023/A : 1022639928248

[36] C. Blancard, G. Faussurier, Equation of state and transport coefficients for dense plasmas, Phys. Rev. E 69 (2004) 016409. doi:10.1103/PhysRevE.69.016409.

URL http://link.aps.org/doi/10.1103/PhysRevE.69. 016409

[37] G. Faussurier, C. Blancard, P. Cossé, P. Renaudin, Equation of state, transport coefficients, and stopping power of dense plasmas from the average-atom model self-consistent approach for astrophysical and laboratory plasmas, Physics of Plasmas 17 (5) (2010) 052707. doi:
$10.1063 / 1.3420276$

URL http://dx.doi.org/10.1063/1.3420276

[38] T. Haxhimali, R. E. Rudd, W. H. Cabot, F. R. Graziani, Shear viscosity for dense plasmas by equilibrium molecular dynamics in asymmetric yukawa ionic mixtures, Phys. Rev. E 92 (2015) 053110. doi:10.1103/PhysRevE.92.053110.

URL http://link.aps.org/doi/10.1103/PhysRevE.92. 053110

[39] L. S. Brown, D. L. Preston, R. L. Singleton, Jr, Charged particle motion in a highly ionized plasma, Physics Reports 410 (4) (2005) $237-333$. doi:https://doi.org/10.1016/j.physrep.2005.01.001. URL http://www.sciencedirect.com/science/article/pii/ S0370157305000037

[40] Y. Hou, R. Bredow, J. Yuan, R. Redmer, Average-atom model combined with the hypernetted chain approximation applied to warm dense matter, Phys. Rev. E 91 (2015) 033114. doi:10.1103/PhysRevE.91.033114.

URL https://link.aps.org/doi/10.1103/PhysRevE.91. 033114

[41] S. X. Hu, L. A. Collins, T. R. Boehly, J. D. Kress, V. N. Goncharov, S. Skupsky, First-principles thermal conductivity of warm-dense deuterium plasmas for inertial confinement fusion applications, Phys. Rev. E 89 (2014) 043105. doi : 10.1103/PhysRevE. 89.043105.

URL https://link.aps.org/doi/10.1103/PhysRevE.89. 043105

[42] S. X. Hu, L. A. Collins, V. N. Goncharov, J. D. Kress, R. L. McCrory, S. Skupsky, First-principles investigations on ionization and thermal conductivity of polystyrene for inertial confinement fusion applications, Physics of Plasmas 23 (4) (2016) 042704. doi : 10.1063/1.4945753. URL http: //dx.doi.org/10.1063/1.4945753

[43] Y. H. Ding, A. J. White, S. X. Hu, O. Certik, L. A. Collins, Ab initio studies on the stopping power of warm dense matter with timedependent orbital-free density functional theory, Phys. Rev. Lett. 121 (2018) 145001. doi:10.1103/PhysRevLett.121.145001.

URL https://link.aps.org/doi/10.1103/PhysRevLett.121. 145001

[44] A. J. White, O. Certik, Y. H. Ding, S. X. Hu, L. A. Collins, Time-dependent orbital-free density functional theory for electronic stopping power: Comparison to the mermin-kohn-sham theory at high temperatures, Phys. Rev. B 98 (2018) 144302. doi:10.1103/PhysRevB.98.144302.

URL https://link.aps.org/doi/10.1103/PhysRevB.98. 144302

[45] D. Kang, J. Dai, Dynamic electron-ion collisions and nuclear quantum effects in quantum simulation of warm dense matter, Journal of Physics: Condensed Matter 30 (7) (2018) 073002

URL http: //stacks.iop.org/0953-8984/30/i=7/a=073002

[46] Q. Ma, D. Kang, Z. Zhao, J. Dai, Directly calculated electrical conductivity of hot dense hydrogen from molecular dynamics simulation beyond kubo-greenwood formula, Physics of Plasmas 25 (1) (2018) 012707. doi:10.1063/1.5013631.

URL https : //doi.org/10.1063/1.5013631

[47] Q. Ma, J. Dai, D. Kang, M. S. Murillo, Y. Hou, Z. Zhao, J. Yuan, Extremely low electron-ion temperature relaxation rates in warm dense hydrogen: Interplay between quantum electrons and coupled ions, Phys. Rev. Lett. 122 (2019) 015001. doi:10.1103/PhysRevLett.122. 015001.

URL https://link.aps.org/doi/10.1103/PhysRevLett.122. 015001

[48] T. Sjostrom, J. Daligault, Ionic and electronic transport properties in dense plasmas by orbital-free density functional theory, Phys. Rev. E 92 (2015) 063304. doi:10.1103/PhysRevE.92.063304.

URL http://link.aps.org/doi/10.1103/PhysRevE.92. 063304

[49] C. E. Starrett, J. Daligault, D. Saumon, Pseudoatom molecular dynamics, Phys. Rev. E 91 (2015) 013104.

[50] C. E. Starrett, D. Saumon, Equation of state of dense plasmas with pseudoatom molecular dynamics, Phys. Rev. E 93 (2016) 063206. doi:10.1103/PhysRevE.93.063206.

URL http://link.aps.org/doi/10.1103/PhysRevE.93. 063206 
[51] C. Starrett, Kubo-greenwood approach to conductivity in dense plasmas with average atom models, High Energy Density Physics 19 (2016) 58 64. doi:http://dx.doi.org/10.1016/j.hedp.2016.04.001. URL http://www.sciencedirect.com/science/article/pii/ S1574181816300398

[52] C. E. Starrett, Potential of mean force for electrical conductivity of dense plasmas, High Energy Density Physics 25 (2017) 8 - 14. doi:https: //doi.org/10.1016/j.hedp.2017.09.003.

URL http://www.sciencedirect.com/science/article/pii/ S1574181817300769

[53] F. Lambert, J. Clérouin, G. Zérah, Very-high-temperature molecular dynamics, Phys. Rev. E 73 (2006) 016403. doi: 10.1103/PhysRevE.73.016403.

URL https://link.aps.org/doi/10.1103/PhysRevE.73. 016403

[54] F. Lambert, V. Recoules, Plastic ablator and hydrodynamic instabilities: A first-principles set of microscopic coefficients, Phys. Rev. E 86 (2012) 026405. doi:10.1103/PhysRevE.86.026405.

URL https://link.aps.org/doi/10.1103/PhysRevE.86. 026405

[55] E. R. Meyer, J. D. Kress, L. A. Collins, C. Ticknor, Effect of correlation on viscosity and diffusion in molecular-dynamics simulations, Phys. Rev. E 90 (2014) 043101. doi:10.1103/PhysRevE.90.043101.

URL https://link.aps.org/doi/10.1103/PhysRevE.90. 043101

[56] C. Ticknor, J. D. Kress, L. A. Collins, J. Clérouin, P. Arnault, A. Decoster, Transport properties of an asymmetric mixture in the dense plasma regime, Phys. Rev. E 93 (2016) 063208. doi:10.1103/PhysRevE.93.063208.

URL https://link.aps.org/doi/10.1103/PhysRevE.93. 063208

[57] R. M. More, Atomic physics in inertial confinement fusion part 1, Tech. rep., Lawrence Livermore National Laboratory, uCRL-84991 (1981).

[58] M. S. Murillo, J. Weisheit, S. B. Hansen, M. W. C. Dharma-wardana, Partial ionization in dense plasmas: Comparisons among averageatom density functional models, Phys. Rev. E 87 (2013) 063113 doi: 10.1103/PhysRevE.87.063113.

URL https://link.aps.org/doi/10.1103/PhysRevE.87. 063113

[59] P. Arnault, J. Clérouin, G. Robert, C. Ticknor, J. D. Kress, L. A Collins, Thomas-Fermi Z-scaling laws and coupling stabilization for plasmas, Phys. Rev. E 88 (2013) 063106. doi:10.1103/PhysRevE. 88.063106.

[60] J. Clérouin, P. Arnault, G. Robert, C. Ticknor, J. D. Kress, L. A. Collins, Self-organization in dense plasmas: The gammaplateau, Contributions to Plasma Physics 55 (2015) 159-163. doi:10.1002/ctpp. 201400064.

URL https://onlinelibrary.wiley.com/doi/abs/10.1002/ ctpp. 201400064

[61] L. D. Landau, Kinetic equation for the coulomb effect, Phys. Z. Sowjetunion 10 (1936) 154.

[62] L. D. Landau, Kinetic equation for the coulomb effect, Zh. Eksp. Teor. Fiz. 7 (1937) 203.

[63] L. Spitzer, Jr., Physics of Fully Ionized Gases, 2nd ed., Interscience, 1962.

[64] D. O. Gericke, M. S. Murillo, M. Schlanges, Dense plasma temperature equilibration in the binary collision approximation, Phys. Rev. E 65 (2002) 036418. doi : 10.1103/PhysRevE.65.036418.

URL https://link.aps.org/doi/10.1103/PhysRevE.65. 036418

[65] S. Chapman, T. G. Cowling, D. Burnett, C. Cercignani, The Mathematical Theory of Non-uniform Gases: An Account of the Kinetic Theory of Viscosity, Thermal Conduction and Diffusion in Gases, Cambridge Mathematical Library, Cambridge University Press, 1990. URL https : //books . google. com/books?id=Cbp5JP20TrwC

[66] L. Landau, E. Lifshitz, Fluid Mechanics, no. v. 6, Elsevier Science, 2013.

URL https : //books . google.com/books?id=CeBbAwAAQBAJ

[67] D. Pfefferlé, E. Hirvijoki, M. Lingam, Exact collisional moments for plasma fluid theories, Physics of Plasmas 24 (4) (2017) 042118. arXiv:https://doi.org/10.1063/1.4979992, doi:10.1063/1.
4979992.

URL https : //doi.org/10.1063/1.4979992

[68] R. L. Liboff, Kinetic Theory: Classical, Quantum, and Relativistic Descriptions, Graduate Texts in Contemporary Physics, Springer New York, 2006.

URL https ://books .google.com/books?id=iqASBwAAQBAJ

[69] M. Bonitz, Quantum Kinetic Theory, Springer International Publishing, 2015.

URL https://books.google.com/books?id=wW7_CgAAQBAJ

[70] S. Ichimaru, Strongly coupled plasmas: high-density classical plasmas and degenerate electron liquids, Rev. Mod. Phys. 54 (1982) 1017-1059. doi : 10.1103/RevModPhys.54.1017.

URL http://link.aps.org/doi/10.1103/RevModPhys.54. 1017

[71] S. Ichimaru, H. Iyetomi, S. Tanaka, Statistical physics of dense plasmas: Thermodynamics, transport coefficients and dynamic correlations, Physics Reports 149 (2) (1987) 91 -205. doi : https : //doi .org/10. 1016/0370-1573(87)90125-6.

URL http://www.sciencedirect.com/science/article/pii/ 0370157387901256

[72] S. Ichimaru, Statistical Physics of Dense Plasmas: Elementary Processes and Phase Transitions, Frontiers in Physics, CRC Press, 2019. URL https : //books .google.com/books?id=mLeCDwAAQBAJ

[73] A. Pribram-Jones, D. A. Gross, K. Burke, Dft: A theory full of holes?, Annual Review of Physical Chemistry 66 (1) (2015) 283-304, pMID: 25830374. doi : 10.1146/annurev-physchem-040214-121420. URL https : //doi .org/10.1146/annurev-physchem-040214-121420

[74] A. Pribram-Jones, P. E. Grabowski, K. Burke, Thermal density functional theory: Time-dependent linear response and approximate functionals from the fluctuation-dissipation theorem, Phys. Rev. Lett. 116 (2016) 233001. doi : 10.1103/PhysRevLett.116.233001. URL https://link.aps.org/doi/10.1103/PhysRevLett.116. 233001

[75] T. Dornheim, S. Groth, M. Bonitz, The uniform electron gas at warm dense matter conditions, Physics Reports 744 (2018) 1 - 86. doi: https://doi.org/10.1016/j.physrep.2018.04.001.

URL http://www.sciencedirect.com/science/article/pii/ S0370157318300516

[76] S. Ichimaru, S. Mitake, S. Tanaka, X.-Z. Yan, Theory of interparticle correlations in dense, high-temperature plasmas. i. general formalism, Phys. Rev. A 32 (1985) 1768-1774. doi:10.1103/PhysRevA.32. 1768.

URL https : //link.aps.org/doi/10.1103/PhysRevA.32.1768

[77] F. R. Graziani, V. S. Batista, L. X. Benedict, J. I. Castor, H. Chen, S. N. Chen, C. A. Fichtl, J. N. Glosli, P. E. Grabowski, A. T. Graf, S. P. HauRiege, A. U. Hazi, S. A. Khairallah, L. Krauss, A. B. Langdon, R. A. London, A. Markmann, M. S. Murillo, D. F. Richards, H. A. Scott, R. Shepherd, L. G. Stanton, F. H. Streitz, M. P. Surh, J. C. Weisheit, H. D. Whitley, Large-scale molecular dynamics simulations of dense plasmas: The cimarron project, High Energy Density Physics 8 (1) (2012) 105 - 131. doi: https://doi.org/10.1016/j.hedp. 2011. 06.010.

URL http://www.sciencedirect.com/science/article/pii/ S1574181811000826

[78] M. S. Murillo, J. C. Weisheit, Dense plasmas, screened interactions, and atomic ionization, Physics Reports 302 (1) (1998) 1 - 65. doi : https : //doi .org/10.1016/S0370-1573(98)00017-9.

URL http://www.sciencedirect.com/science/article/pii/ S0370157398000179

[79] J. Weisheit, M. Murillo, Atoms in Dense Plasmas, Springer New York, New York, NY, 2006, pp. 1303-1318. doi:10.1007/ 978-0-387-26308-3_86. URL https : //doi.org/10.1007/978-0-387-26308-3_86

[80] P. E. Grabowski, A. Markmann, I. V. Morozov, I. A. Valuev, C. A. Fichtl, D. F. Richards, V. S. Batista, F. R. Graziani, M. S. Murillo, Wave packet spreading and localization in electron-nuclear scattering, Phys. Rev. E 87 (2013) 063104. doi:10.1103/PhysRevE.87.063104. URL https://link.aps.org/doi/10.1103/PhysRevE.87. 063104

[81] P. E. Grabowski, A review of wave packet molecular dynamics, in: F. Graziani, M. P. Desjarlais, R. Redmer, S. B. Trickey (Eds.), Frontiers 
and Challenges in Warm Dense Matter, Springer International Publishing, Cham, 2014, pp. 265-282.

[82] J. Daligault, Diffusion in ionic mixtures across coupling regimes, Phys Rev. Lett. 108 (2012) 225004. doi:10.1103/PhysRevLett.108. 225004.

URL https://link.aps.org/doi/10.1103/PhysRevLett.108. 225004

[83] T. Haxhimali, R. E. Rudd, Diffusivity of mixtures in warm dense matter regime, in: F. Graziani, M. P. Desjarlais, R. Redmer, S. B. Trickey (Eds.), Frontiers and Challenges in Warm Dense Matter, Vol. 96 of Lecture Notes in Computational Science and Engineering, Springer International Publishing, 2014, pp. 235-263. doi:10.1007/ 978-3-319-04912-0_9.

URL http: //dx.doi .org/10.1007/978-3-319-04912-0_9

[84] T. Haxhimali, R. E. Rudd, W. H. Cabot, F. R. Graziani, Diffusivity in asymmetric yukawa ionic mixtures in dense plasmas, Phys. Rev. E 90 (2014) 023104. doi:10.1103/PhysRevE.90.023104.

URL http://link.aps.org/doi/10.1103/PhysRevE.90. 023104

[85] H. Ohta, S. Hamaguchi, Molecular dynamics evaluation of self-diffusion in yukawa systems, Physics of Plasmas 7 (2000) 4506-4514. URL http: //dx .doi .org/10.1063/1.1316084

[86] S. Tanaka, S. Ichimaru, Theory of interparticle correlations in dense, high-temperature plasmas. viii. shear viscosity, Phys. Rev. A 34 (1986) 4163-4170. doi:10.1103/PhysRevA.34.4163. URL https : //link.aps.org/doi/10.1103/PhysRevA.34.4163

[87] M. S. Murillo, Viscosity estimates of liquid metals and warm dense matter using the yukawa reference system, High Energy Density Physics 4 (1) (2008) 49 - 57. doi:https://doi.org/10.1016/j.hedp. 2007.11 .001$.

URL http://www.sciencedirect.com/science/article/pii/ S1574181807000857

[88] V. E. Fortov, V. B. Mintsev, Quantum bound of the shear viscosity of a strongly coupled plasma, Phys. Rev. Lett. 111 (2013) 125004. doi:10.1103/PhysRevLett.111.125004.

URL https://link.aps.org/doi/10.1103/PhysRevLett.111. 125004

[89] S. Ichimaru, S. Tanaka, Theory of interparticle correlations in dense, high-temperature plasmas. v. electric and thermal conductivities, Phys. Rev. A 32 (1985) 1790-1798. doi:10.1103/PhysRevA.32.1790. URL https : //link.aps.org/doi/10.1103/PhysRevA.32.1790

[90] G. Röpke, Quantum-statistical approach to the electrical conductivity of dense, high-temperature plasmas, Phys. Rev. A 38 (1988) 3001-3016. doi:10.1103/PhysRevA.38.3001.

URL https://link.aps.org/doi/10.1103/PhysRevA.38.3001

[91] H. Kitamura, S. Ichimaru, Electric and thermal resistivities in dense high-z plasmas, Phys. Rev. E 51 (1995) 6004-6009. doi:10.1103/ PhysRevE.51.6004.

URL https://link.aps.org/doi/10.1103/PhysRevE.51.6004

[92] E. M. Apfelbaum, Calculation of electronic transport coefficients of ag and au plasma, Phys. Rev. E 84 (2011) 066403. doi: 10.1103/PhysRevE.84.066403.

URL https://link.aps.org/doi/10.1103/PhysRevE.84. 066403

[93] D. V. Knyazev, P. R. Levashov, Transport and optical properties of warm dense aluminum in the two-temperature regime: $\mathrm{Ab}$ initio calculation and semiempirical approximation, Physics of Plasmas 21 (7) (2014) 073302. arXiv:https://doi.org/10.1063/1.4891341, doi:10. $1063 / 1.4891341$ URL https : //doi.org/10.1063/1.4891341

[94] N. R. Shaffer, C. E. Starrett, Model of electron transport in dense plasmas spanning temperature regimes, Phys. Rev. E 101 (2020) 053204. doi:10.1103/PhysRevE.101.053204.

URL https://link.aps.org/doi/10.1103/PhysRevE.101. 053204

[95] X.-Z. Yan, S. Tanaka, S. Mitake, S. Ichimaru, Theory of interparticle correlations in dense, high-temperature plasmas. iv. stopping power, Phys. Rev. A 32 (1985) 1785-1789. doi:10.1103/PhysRevA.32. 1785.

URL https : //link.aps.org/doi/10.1103/PhysRevA.32.1785

[96] T. Peter, J. Meyer-ter Vehn, Energy loss of heavy ions in dense plasma. i. linear and nonlinear vlasov theory for the stopping power, Phys. Rev. A 43 (1991) 1998-2014. doi:10.1103/PhysRevA.43.1998.

URL https : //link.aps .org/doi/10.1103/PhysRevA.43.1998

[97] T. Peter, J. Meyer-ter Vehn, Energy loss of heavy ions in dense plasma. ii. nonequilibrium charge states and stopping powers, Phys. Rev. A 43 (1991) 2015-2030. doi:10.1103/PhysRevA.43.2015. URL https://link.aps.org/doi/10.1103/PhysRevA.43.2015

[98] P. Wang, T. M. Mehlhorn, J. J. MacFarlane, A unified self-consistent model for calculating ion stopping power in icf plasma, Physics of Plasmas 5 (8) (1998) 2977-2987. arXiv:https://doi.org/10.1063/ 1.873022, doi:10.1063/1.873022. URL https : //doi.org/10.1063/1.873022

[99] D. O. Gericke, M. Schlanges, Beam-plasma coupling effects on the stopping power of dense plasmas, Phys. Rev. E 60 (1999) 904-910. doi:10.1103/PhysRevE.60.904. URL https ://link.aps.org/doi/10.1103/PhysRevE.60.904

[100] D. O. Gericke, M. Schlanges, W. D. Kraeft, Stopping power of a quantum plasma ? t-matrix approximation and dynamical screening, Physics Letters A 222 (4) (1996) 241 - 245. doi:https://doi.org/10. 1016/0375-9601 (96)00654-8.

URL http://www.sciencedirect.com/science/article/pii/ 0375960196006548

[101] G. Zwicknagel, C. Toepffer, P.-G. Reinhard, Stopping of heavy ions in plasmas at strong coupling, Physics Reports 309 (3) (1999) 117 - 208. doi:https://doi.org/10.1016/S0370-1573(98)00056-8. URL http://www.sciencedirect.com/science/article/pii/ S0370157398000568

[102] D. O. Gericke, Stopping power for strong beam-plasma coupling, Laser and Particle Beams 20 (3) (2002) 471-474, cited By 30. doi : 10.1017/S0263034602203225.

URL https://www.scopus.com/inward/record.uri?eid= 2 -s2.0-0036954893\&doi=10.1017\%2fS0263034602203225\& partnerID $=40 \& m d 5=c d 63 d 26 e 4351 \mathrm{f} 0 \mathrm{db} 6941276 \mathrm{~b} 7 \mathrm{ca} 81242$

[103] D. O. Gericke, M. Schlanges, Energy deposition of heavy ions in the regime of strong beam-plasma correlations, Physical Review E - Statistical, Nonlinear, and Soft Matter Physics 67 (3 2) (2003) 037401/1-037401/4, cited By 12.

URL https://www.scopus.com/inward/record. uri?eid=2-s2.0-42749103687\&partner ID=40\&md5= 5ea21115773aa5b32df8d7f81cc7ac4f

[104] P. E. Grabowski, M. P. Surh, D. F. Richards, F. R. Graziani, M. S. Murillo, Molecular dynamics simulations of classical stopping power, Phys. Rev. Lett. 111 (2013) 215002. doi:10.1103/PhysRevLett. 111.215002.

URL https://link.aps.org/doi/10.1103/PhysRevLett.111. 215002

[105] J. Ziegler, J. Biersack, M. Ziegler, SRIM, the Stopping and Range of Ions in Matter, SRIM Company, 2008.

URL https://books .google.com/books?id=JSN63qxPG5MC

[106] D. B. Boercker, E. Pollock, Interdiffusion in binary ionic mixtures, Physical Review A 36 (4) (1987) 1779.

[107] R. Zwanzig, Time-correlation functions and transport coefficients in statistical mechanics, Annual Review of Physical Chemistry 16 (1) (1965) 67-102.

[108] D. McQuarrie, Statistical Mechanics, University Science Books, 2000 URL https : //books . google.com/books?id=itcpPnDnJMOC

[109] L. Kadanoff, G. Baym, Quantum Statistical Mechanics: Green's Function Methods in Equilibrium and Nonequilibrium Problems, Frontiers in Physics. A Lecture Note and Reprint Series, Benjamin, 1962. URL https : //books . google.com/books?id=njT2xQEACAAJ

[110] P. L. Rossiter, The Electrical Resistivity of Metals and Alloys, Cambridge Solid State Science Series, Cambridge University Press, 1987. doi : 10.1017/CB09780511600289.

[111] M. Pozzo, M. P. Desjarlais, D. Alfè, Electrical and thermal conductivity of liquid sodium from first-principles calculations, Phys. Rev. B 84 (2011) 054203. doi:10.1103/PhysRevB.84.054203.

URL https://link.aps.org/doi/10.1103/PhysRevB.84. 054203

[112] J. M. Ziman, The method of neutral pseudo-atoms in the theory of metals, Advances in Physics 13 (49) (1964) 89-138. arXiv: https://doi.org/10.1080/00018736400101011, doi:10.1080/ 
00018736400101011

URL https : //doi .org/10.1080/00018736400101011

[113] J. Matteucci, W. Fox, A. Bhattacharjee, D. Schaeffer, C. Moissard, K. Germaschewski, G. Fiksel, S. Hu, Biermann-battery-mediated magnetic reconnection in $3 \mathrm{~d}$ colliding plasmas, Physical Review Letters 121 (9) (2018) 095001

[114] V. Y. Bychenkov, W. Rozmus, V. Tikhonchuk, A. Brantov, Nonlocal electron transport in a plasma, Physical Review Letters 75 (24) (1995) 4405 .

[115] Z. Gribnikov, K. Hess, G. Kosinovsky, Nonlocal and nonlinear transport in semiconductors: Real-space transfer effects, Journal of applied physics 77 (4) (1995) 1337-1373.

[116] J. D. Callen, M. W. Kissick, Evidence and concepts for non-local transport, Plasma Physics and Controlled Fusion 39 (12B) (1997) B173B188. doi:10.1088/0741-3335/39/12b/014.

[117] M. W. C. Dharma-wardana, D. D. Klug, L. Harbour, L. J. Lewis, Isochoric, isobaric, and ultrafast conductivities of aluminum, lithium, and carbon in the warm dense matter regime, Phys. Rev. E 96 (2017) 053206. doi:10.1103/PhysRevE.96.053206.

URL https://link.aps.org/doi/10.1103/PhysRevE.96. 053206

[118] M. S. Green, Markoff random processes and the statistical mechanics of time-dependent phenomena. ii. irreversible processes in fluids, The Journal of Chemical Physics 22 (3) (1954) 398-413. doi : 10.1063/1. 1740082 .

URL https://doi.org/10.1063/1.1740082

[119] R. Kubo, Statistical-mechanical theory of irreversible processes. i. general theory and simple applications to magnetic and conduction problems, Journal of the Physical Society of Japan 12 (6) (1957) 570-586. doi : 10.1143/JPSJ.12.570.

URL https : //doi.org/10.1143/JPSJ .12.570

[120] X. Andrade, S. Hamel, A. A. Correa, Negative differential conductivity in liquid aluminum from real-time quantum simulations, The European Physical Journal B 91 (10) (2018) 229. doi:10.1140/epjb/ e2018-90291-5.

URL https ://doi.org/10.1140/epjb/e2018-90291-5

[121] J. T. Su, W. A. Goddard, Excited electron dynamics modeling of warm dense matter, Phys. Rev. Lett. 99 (2007) 185003. doi:10.1103/PhysRevLett.99.185003.

URL https://link.aps.org/doi/10.1103/PhysRevLett.99. 185003

[122] J. T. Su, W. A. Goddard, The dynamics of highly excited electronic systems: Applications of the electron force field, The Journal of Chemical Physics 131 (24) (2009) 244501. doi:10.1063/1.3272671. URL https ://doi.org/10.1063/1.3272671

[123] J. Dai, Y. Hou, J. Yuan, Quantum langevin molecular dynamic determination of the solar-interior equation of state, The Astrophysical Journal 721 (2) (2010) 1158

URL http: //stacks. iop.org/0004-637X/721/i=2/a=1158

[124] J. Chihara, Integral Equations for Neutral and Charged Quantum Fluids Including Extension of the Percus-Yevick Equation, Progress of Theoretical Physics 50 (4) (1973) 1156-1181. arXiv:https://academic.oup.com/ptp/article-pdf/50/4/ 1156/5156674/50-4-1156.pdf, doi:10.1143/PTP.50.1156. URL https : //doi.org/10.1143/PTP.50.1156

[125] J. Chihara, Derivation of quantul hyper-netted chain equation from the kohn-sham theory, Progress of Theoretical Physics 59 (1) (1978) 76

[126] M. W. C. Dharma-wardana, F. Perrot, Density-functional theory of hydrogen plasmas, Phys. Rev. A 26 (1982) 2096-2104. doi:10.1103/ PhysRevA.26.2096.

URL https ://link.aps .org/doi/10.1103/PhysRevA . 26.2096

[127] L. H. Thomas, The calculation of atomic fields, Mathematical Proceedings of the Cambridge Philosophical Society 23 (5) (1927) 542-548. doi : $10.1017 /$ S0305004100011683.

[128] E. Fermi, Un metodo statistico per la deter-minazione di alcune priorieta dell'atome, Rend. Acc. Naz. Lincei 6 (1927) 602-607.

[129] T. Sjostrom, J. Daligault, Gradient corrections to the exchangecorrelation free energy, Phys. Rev. B 90 (2014) 155109. doi:10.1103/PhysRevB.90.155109.

URL https://link.aps.org/doi/10.1103/PhysRevB.90. 155109
[130] W. Kohn, L. J. Sham, Self-consistent equations including exchange and correlation effects, Phys. Rev. 140 (1965) A1133-A1138. doi:10.1103/PhysRev.140.A1133.

URL https://link.aps.org/doi/10.1103/PhysRev.140. A1133

[131] J. M. Ziman, A theory of the electrical properties of liquid metals. i: The monovalent metals, The Philosophical Magazine: A Journal of Theoretical Experimental and Applied Physics 6 (68) (1961) 1013-1034. doi : $10.1080 / 14786436108243361$ URL https : //doi .org/10.1080/14786436108243361

[132] R. Evans, B. L. Gyorfey, N. Szabo, J. M. Ziman, The Properties of Liquid Metals, Taylor and Francis, London, 1973, Ch. On the resistivity of liquid transition metals

[133] F. Perrot, M. W. C. Dharma-wardana, Electrical resistivity of hot dense plasmas, Phys. Rev. A 36 (1987) 238-246. doi:10.1103/PhysRevA. 36.238

URL https://link.aps.org/doi/10.1103/PhysRevA.36.238

[134] M. W. C. Dharma-wardana, Static and dynamic conductivity of warm dense matter within a density-functional approach: Application to aluminum and gold, Phys. Rev. E 73 (2006) 036401. doi: 10.1103/PhysRevE.73.036401.

URL https://link.aps.org/doi/10.1103/PhysRevE.73. 036401

[135] P. A. Sterne, S. B. Hansen, B. G. Wilson, W. A. Isaacs, Equation of state, occupation probabilities and conductivities in the average atom purgatorio code, High Energy Density Physics 3 (1) (2007) 278 - 282, radiative Properties of Hot Dense Matter. doi:https://doi.org/10.1016/ j.hedp. 2007.02.037.

URL http://www.sciencedirect.com/science/article/pii/ S1574181807000420

[136] B. F. Rozsnyai, Electron scattering in hot/warm plasmas, High Energy Density Physics 4 (1) (2008) 64 - 72. doi : https://doi.org/10. 1016/j.hedp.2008.01.002

URL http://www.sciencedirect.com/science/article/pii/ S1574181808000049

[137] J. C. Pain, G. Dejonghe, Electrical resistivity in warm dense plasmas beyond the average-atom model, Contributions to Plasma Physics 50 (1) (2010) 39-45. doi:10.1002/ctpp. 201010010.

URL https://onlinelibrary.wiley.com/doi/abs/10.1002/ ctpp. 201010010

[138] G. Faussurier, C. Blancard, Resistivity saturation in warm dense matter, Phys. Rev. E 91 (2015) 013105. doi:10.1103/PhysRevE.91. 013105.

URL https://link.aps.org/doi/10.1103/PhysRevE.91. 013105

[139] D. Burrill, D. Feinblum, M. Charest, C. Starrett, Comparison of electron transport calculations in warm dense matter using the ziman formula, High Energy Density Physics 19 (2016) 1 - 10. doi:https: //doi.org/10.1016/j.hedp.2016.01.004.

URL http://www.sciencedirect.com/science/article/pii/ S1574181816300015

[140] D. A. Greenwood, The boltzmann equation in the theory of electrical conduction in metals, Proceedings of the Physical Society 71 (4) (1958) 585 . URL http: //stacks. iop.org/0370-1328/71/i=4/a=306

[141] W. R. Johnson, C. Guet, G. F. Bertsch, Optical properties of plasmas based on an average-atom model, Journal of Quantitative Spectroscopy and Radiative Transfer 99 (1) (2006) 327 - 340, radiative Properties of Hot Dense Matter. doi:https://doi.org/10.1016/j.jqsrt. 2005.05 .026

URL http://www.sciencedirect.com/science/article/pii/ S0022407305001573

[142] M. Y. Kuchiev, W. R. Johnson, Low-frequency plasma conductivity in the average-atom approximation, Phys. Rev. E 78 (2008) 026401. doi:10.1103/PhysRevE.78.026401.

URL https://link.aps.org/doi/10.1103/PhysRevE.78. 026401

[143] W. R. Johnson, Low-frequency conductivity in the average-atom approximation, High Energy Density Physics 5 (1) (2009) 61 - 67. doi : https://doi.org/10.1016/j.hedp.2009.03.007. URL http://www.sciencedirect.com/science/article/pii/ 
S157418180900007X

[144] C. E. Starrett, J. Clérouin, V. Recoules, J. D. Kress, L. A. Collins, D. E. Hanson, Average atom transport properties for pure and mixed species in the hot and warm dense matter regimes, Physics of Plasmas 19 (10) (2012) 102709. doi:10.1063/1.4764937. URL https : //doi.org/10.1063/1.4764937

[145] M. P. Desjarlais, J. D. Kress, L. A. Collins, Electrical conductivity for warm, dense aluminum plasmas and liquids, Phys. Rev. E 66 (2002) 025401. doi:10.1103/PhysRevE.66.025401.

URL https://link.aps.org/doi/10.1103/PhysRevE.66. 025401

[146] D. E. Hanson, L. A. Collins, J. D. Kress, M. P. Desjarlais, Calculations of the thermal conductivity of national ignition facility target materials at temperatures near $10 \mathrm{ev}$ and densities near $10 \mathrm{~g} / \mathrm{cc}$ using finitetemperature quantum molecular dynamics, Physics of Plasmas 18 (8) (2011) 082704. doi : 10.1063/1.3619811. URL https ://doi.org/10.1063/1.3619811

[147] B. Holst, M. French, R. Redmer, Electronic transport coefficients from $\mathrm{ab}$ initio simulations and application to dense liquid hydrogen, Phys. Rev. B 83 (2011) 235120. doi : 10.1103/PhysRevB.83.235120. URL https://link.aps.org/doi/10.1103/PhysRevB.83. 235120

[148] M. French, A. Becker, W. Lorenzen, N. Nettelmann, M. Bethkenhagen, J. Wicht, R. Redmer, AB INITIO SIMULATIONS FOR MATERIAL PROPERTIES ALONG THE JUPITER ADIABAT, The Astrophysical Journal Supplement Series 202 (1) (2012) 5. doi:10.1088/ 0067-0049/202/1/5 URL https : //doi .org/10.1088\%2F0067-0049\%2F $202 \% 2 \mathrm{~F} 1 \% 2 \mathrm{~F} 5$

[149] A. Becker, M. Bethkenhagen, C. Kellermann, J. Wicht, R. Redmer, Material properties for the interiors of massive giant planets and brown dwarfs, The Astronomical Journal 156 (4) (2018) 149. doi:10.3847/ 1538-3881/aad735. URL https : //doi .org/10.3847\%2F1538-3881\%2Faad735

[150] A. Sarasola, J. D. Fuhr, V. H. Ponce, A. Arnau, Study of the validity of the local density approximation in calculating stopping power and related quantities, Nuclear Instruments and Methods in Physics Research Section B: Beam Interactions with Materials and Atoms 182 (1) (2001) 67 -72. doi :https://doi.org/10.1016/S0168-583X (01) 00656-5.

URL http://www.sciencedirect.com/science/article/pii/ S0168583X01006565

[151] A. A. Correa, Calculating electronic stopping power in materials from first principles, Computational Materials Science 150 (2018) 291 - 303. doi:https://doi.org/10.1016/j.commatsci.2018.03.064.

URL http://www.sciencedirect.com/science/article/pii/ S0927025618302234

[152] C. Kittel, P. McEuen, J. W. . Sons, Introduction to Solid State Physics, John Wiley \& Sons, Limited, 2018. URL https : //books . google.com/books?id=S3gAugEACAAJ

[153] J.-P. Hansen, I. R. McDonald, Chapter 8 - hydrodynamics and transport coefficients, in: J.-P. Hansen, I. R. McDonald (Eds.), Theory of Simple Liquids (Third Edition), third edition Edition, Academic Press, Burlington, 2006, pp. 219 - 254. doi: https ://doi.org/10.1016/ B978-012370535-8/50010-0.

URL http://www.sciencedirect.com/science/article/pii/ B9780123705358500100

[154] T. Saigo, S. Hamaguchi, Shear viscosity of strongly coupled yukawa systems, Physics of Plasmas 9 (4) (2002) 1210-1216. doi:10.1063/ 1.1459708

URL https : //doi.org/10.1063/1.1459708

[155] Z. Donkó, P. Hartmann, Shear viscosity of strongly coupled yukawa liquids, Phys. Rev. E 78 (2008) 026408. doi: 10.1103/PhysRevE.78.026408.

URL https://link.aps.org/doi/10.1103/PhysRevE.78. 026408

[156] J. Daligault, K. O. Rasmussen, S. D. Baalrud, Determination of the shear viscosity of the one-component plasma, Phys. Rev. E 90 (2014) 033105. doi:10.1103/PhysRevE.90.033105.

URL https://link.aps.org/doi/10.1103/PhysRevE.90. 033105

[157] M. J. Rosenberg, F. H. Séguin, P. A. Amendt, S. Atzeni, H. G.
Rinderknecht, N. M. Hoffman, A. B. Zylstra, C. K. Li, H. Sio, M. Gatu Johnson, J. A. Frenje, R. D. Petrasso, V. Y. Glebov, C. Stoeckl, W. Seka, F. J. Marshall, J. A. Delettrez, T. C. Sangster, R. Betti, S. C. Wilks, J. Pino, G. Kagan, K. Molvig, A. Nikroo, Assessment of ion kinetic effects in shock-driven inertial confinement fusion implosions using fusion burn imaging, Physics of Plasmas 22 (6) (2015) 062702. doi: $10.1063 / 1.4921935$.

URL https : //doi.org/10.1063/1.4921935

[158] J. P. Hansen, I. R. McDonald, E. L. Pollock, Statistical mechanics of dense ionized matter. iii. dynamical properties of the classical onecomponent plasma, Phys. Rev. A 11 (1975) 1025-1039. doi:10.1103/ PhysRevA.11.1025.

URL https : //link.aps.org/doi/10.1103/PhysRevA.11.1025

[159] H. Ohta, S. Hamaguchi, Molecular dynamics evaluation of self-diffusion in yukawa systems, Physics of Plasmas 7 (11) (2000) 4506-4514. doi : 10.1063/1.1316084.

URL https://doi.org/10.1063/1.1316084

[160] A. B. Zylstra, O. A. Hurricane, On alpha-particle transport in inertial fusion, Physics of Plasmas 26 (6) (2019) 062701. arXiv:https:// doi.org/10.1063/1.5101074, doi:10.1063/1.5101074. URL https : //doi.org/10.1063/1.5101074

[161] J. Kim, B. Qiao, C. McGuffey, M. S. Wei, P. E. Grabowski, F. N. Beg, Self-consistent simulation of transport and energy deposition of intense laser-accelerated proton beams in solid-density matter, Phys. Rev. Lett. 115 (2015) 054801. doi : 10.1103/PhysRevLett.115.054801. URL https://link.aps.org/doi/10.1103/PhysRevLett.115. 054801

[162] W. Bang, B. J. Albright, P. A. Bradley, E. L. Vold, J. C. Boettger, J. C. Fernández, Uniform heating of materials into the warm dense matter regime with laser-driven quasimonoenergetic ion beams, Phys. Rev. E 92 (2015) 063101. doi : 10.1103/PhysRevE.92.063101.

URL https://link.aps.org/doi/10.1103/PhysRevE.92. 063101

[163] J. Jacoby, D. H. H. Hoffmann, W. Laux, R. W. Müller, H. Wahl, K. Weyrich, E. Boggasch, B. Heimrich, C. Stöckl, H. Wetzler, S. Miyamoto, Stopping of heavy ions in a hydrogen plasma, Phys. Rev. Lett. 74 (1995) 1550-1553. doi:10.1103/PhysRevLett.74.1550. URL https://link.aps.org/doi/10.1103/PhysRevLett.74. 1550

[164] D. H. H. Hoffmann, K. Weyrich, H. Wahl, D. Gardés, R. Bimbot, C. Fleurier, Energy loss of heavy ions in a plasma target, Phys. Rev. A 42 (1990) 2313-2321. doi:10.1103/PhysRevA .42.2313. URL https : //link.aps.org/doi/10.1103/PhysRevA.42.2313

[165] M. Roth, C. Stöckl, W. Süß, O. Iwase, D. O. Gericke, R. Bock, D. H. H. Hoffmann, M. Geissel, W. Seelig, Energy loss of heavy ions in laserproduced plasmas, Europhysics Letters (EPL) 50 (1) (2000) 28-34. doi : 10.1209/epl/i2000-00230-6. URL https : //doi .org/10.1209\%2Fepl\%2Fi2000-00230-6

[166] A. Frank, A. Blažević, V. Bagnoud, M. M. Basko, M. Börner, W. Cayzac, D. Kraus, T. Heßling, D. H. H. Hoffmann, A. Ortner, A. Otten, A. Pelka, D. Pepler, D. Schumacher, A. Tauschwitz, M. Roth, Energy loss and charge transfer of argon in a laser-generated carbon plasma, Phys. Rev. Lett. 110 (2013) 115001. doi:10.1103/ PhysRevLett.110.115001.

URL https://link.aps.org/doi/10.1103/PhysRevLett.110. 115001

[167] W. Cayzac, A. Frank, A. Ortner, V. Bagnoud, M. M. Basko, S. Bedacht, C. Bläser, A. Blažević, S. Busold, O. Deppert, J. Ding, M. Ehret, P. Fiala, S. Frydrych, D. O. Gericke, L. Hallo, J. Helfrich, D. Jahn, E. Kjartansson, A. Knetsch, D. Kraus, G. Malka, N. W. Neumann, K. Pépitone, D. Pepler, S. Sander, G. Schaumann, T. Schlegel, N. Schroeter, D. Schumacher, M. Seibert, A. Tauschwitz, J. Vorberger, F. Wagner, S. Weih, Y. Zobus, M. Roth, Experimental discrimination of ion stopping models near the bragg peak in highly ionized matter, Nature Communications 8 (2017) 15693. doi:https://doi.org/10.1038/ncomms 15693. URL https : //www. nature.com/articles/ncomms 15693

[168] D. G. Hicks, C. K. Li, F. H. Séguin, A. K. Ram, J. A. Frenje, R. D. Petrasso, J. M. Soures, V. Y. Glebov, D. D. Meyerhofer, S. Roberts, C. Sorce, C. Stöckl, T. C. Sangster, T. W. Phillips, Charged-particle acceleration and energy loss in laser-produced plasmas, Physics of Plasmas 7 (12) (2000) 5106-5117. arXiv:https ://doi.org/10.1063/ 
1.1320467, doi:10.1063/1.1320467

URL https : //doi.org/10.1063/1.1320467

[169] S. N. Chen, S. Atzeni, T. Gangolf, M. Gauthier, D. P. Higginson, R. Hua, J. Kim, F. Mangia, C. McGuffey, J.-R. Marqués, R. Riquier, H. Pépin, R. Shepherd, O. Willi, F. N. Beg, C. Deutsch, J. Fuchs, Experimental evidence for the enhanced and reduced stopping regimes for protons propagating through hot plasmas, Scientific Reports 8 (2018) 14586. doi:https://doi.org/10.1038/s41598-018-32726-2.

URL https://www.nature.com/articles/ s41598-018-32726-2

[170] D. B. Sayre, C. J. Cerjan, S. M. Sepke, D. O. Gericke, J. A. Caggiano, L. Divol, M. J. Eckart, F. R. Graziani, G. P. Grim, S. B. Hansen, E. P Hartouni, R. Hatarik, S. P. Hatchett, A. K. Hayes, L. F. B. Hopkins, M. G. Johnson, S. F. Khan, J. P. Knauer, S. Le Pape, A. J. MacKinnon, J. M. McNaney, N. B. Meezan, H. G. Rinderknecht, D. A. Shaughnessy, W. Stoeffl, C. B. Yeamans, A. B. Zylstra, D. H. Schneider, Neutron time-of-flight measurements of charged-particle energy loss in inertial confinement fusion plasmas, Phys. Rev. Lett. 123 (2019) 165001 doi:10.1103/PhysRevLett.123.165001.

URL https://link.aps.org/doi/10.1103/PhysRevLett.123. 165001

[171] A. C. Hayes, G. Jungman, A. E. Schulz, M. Boswell, M. M. Fowler, G. Grim, A. Klein, R. S. Rundberg, J. B. Wilhelmy, D. Wilson, C. Cerjan, D. Schneider, S. M. Sepke, A. Tonchev, C. Yeamans, Reactionin-flight neutrons as a test of stopping power in degenerate plasmas, Physics of Plasmas 22 (8) (2015) 082703. arXiv: https://doi.org/ 10.1063/1.4928104, doi:10.1063/1.4928104 URL https ://doi.org/10.1063/1.4928104

[172] C.-K. Li, R. D. Petrasso, Charged-particle stopping powers in inertial confinement fusion plasmas, Phys. Rev. Lett. 70 (1993) 3059-3062. doi:10.1103/PhysRevLett.70.3059.

URL https://link.aps.org/doi/10.1103/PhysRevLett.70. 3059

[173] C.-K. Li, R. D. Petrasso, Erratum: Charged-particle stopping powers in inertial confinement fusion plasmas [phys. rev. lett. 70, 3059 (1993)], Phys. Rev. Lett. 114 (2015) 199901. doi:10.1103/PhysRevLett. 114.199901.

URL https://link.aps.org/doi/10.1103/PhysRevLett.114. 199901

[174] Maynard, G., Deutsch, C., Born random phase approximation for ion stopping in an arbitrarily degenerate electron fluid, J. Phys. France 46 (7) (1985) 1113-1122. doi:10.1051/jphys:019850046070111300. URL https : //doi.org/10.1051/jphys: 019850046070111300

[175] G. B. Zimmerman, Recent developments in monte carlo techniques, Tech. Rep. Internal Report No. UCRL-JC-105616, Lawrence Livermore National Laboratory (1990).

[176] H. A. Gould, H. E. DeWitt, Convergent kinetic equation for a classical plasma, Phys. Rev. 155 (1967) 68-74. doi : 10.1103/PhysRev. 155. 68.

URL https : //link.aps.org/doi/10.1103/PhysRev.155.68

[177] D. A. Liberman, Inferno: A better model of atoms in dense plasmas, Journal of Quantitative Spectroscopy and Radiative Transfer 27 (3) (1982) 335 - 339. doi:https://doi.org/10.1016/ 0022-4073 (82) $90125-\mathrm{X}$.

URL http://www.sciencedirect.com/science/article/pii/ $002240738290125 X$

[178] B. Wilson, V. Sonnad, P. Sterne, W. Isaacs, Purgatorio: a new implementation of the inferno algorithm, Journal of Quantitative Spectroscopy and Radiative Transfer 99 (1) (2006) 658 - 679, radiative Properties of Hot Dense Matter. doi:https://doi.org/10.1016/j.jqsrt. 2005.05 .053

URL http://www.sciencedirect.com/science/article/pii/ S0022407305001846 